\title{
LONG-RANGE TRANSPORT OF OZONE AND ITS PRECURSORS ACROSS US-CANADA BORDER
}

A thesis submitted to the Faculty of Graduate and Postdoctoral Affairs in partial fulfillment of the requirements for the degree of

Master of Science

in

Environmental Engineering

by

Maryam Mirzajani

Department of Civil and Environmental Engineering

Carleton University

Ottawa-Carleton Institute of Civil and Environmental Engineering January 2011

(C) 2011, Maryam Mirzajani 
Library and Archives
Canada

Published Heritage

Branch

395 Wellington Street

Ottawa ON K1A ON4

Canada
Bibliothèque et

Archives Canada

Direction du

Patrimoine de l'édition

395, rue Wellington

Ottawa ON K1A ON4

Canada
Your file Votre reférence

ISBN: 978-0-494-79540-8

Our file Notre reférence

ISBN: 978-0-494-79540-8
NOTICE:

The author has granted a nonexclusive license allowing Library and Archives Canada to reproduce, publish, archive, preserve, conserve, communicate to the public by telecommunication or on the Internet, loan, distribute and sell theses worldwide, for commercial or noncommercial purposes, in microform, paper, electronic and/or any other formats.

The author retains copyright ownership and moral rights in this thesis. Neither the thesis nor substantial extracts from it may be printed or otherwise reproduced without the author's permission.
AVIS:

L'auteur a accordé une licence non exclusive permettant à la Bibliothèque et Archives Canada de reproduire, publier, archiver, sauvegarder, conserver, transmettre au public par télécommunication ou par l'Internet, prêter, distribuer et vendre des thèses partout dans le monde, à des fins commerciales ou autres, sur support microforme, papier, électronique et/ou autres formats.

L'auteur conserve la propriété du droit d'auteur et des droits moraux qui protège cette thèse. $\mathrm{Ni}$ la thèse ni des extraits substantiels de celle-ci ne doivent être imprimés ou autrement reproduits sans son autorisation.
In compliance with the Canadian Privacy Act some supporting forms may have been removed from this thesis.

While these forms may be included in the document page count, their removal does not represent any loss of content from the thesis.
Conformément à la loi canadienne sur la protection de la vie privée, quelques formulaires secondaires ont été enlevés de cette thèse.

Bien que ces formulaires aient inclus dans la pagination, il n'y aura aucun contenu manquant. 


\begin{abstract}
Long-range transport of ozone across geopolitical borders is a growing concern for attainment of ozone standards in North America and the world over. Accurate knowledge of the extent of long-range transport plays an important role in design of successful air pollution control strategies. This work is focused on quantification of transport of ozone and its precursors across the US-Canada border and establishment of source-receptor relationships for this region during the Summer of 2007. Different analytical methods implemented in a widely used air quality model allow comprehensive evaluation of contribution from various sources, local or regional, to the ozone metrics over the US-Canada border. Various sensitivity analyses are particularly useful for quantification of source-receptor impact matrices. It was consistently found in this study that during the summer 2007 American emissions had a significantly larger contribution to the surface ozone air pollution in Canadian border area than Canadian emissions to the US border area. We concluded that for certain areas of Canada contributions from American emissions were as high (peaking at $72 \mathrm{ppb}$ at southern Ontario) as those from domestic sources, whereas Canadian emissions had smaller impact on the US ozone pollution (peaking at $42 \mathrm{ppb}$ in northeast). Southern Ontario and northeast US were areas the most affected by crossborder transport in Canada and the US during the episode, respectively. Urban centers particularly close to the border in each country had the largest contribution to the average ozone in US-Canada border area. And finally great deal of temporal variations was found in mass export of pollution in the border area during the episode.
\end{abstract}




\section{ACKNOWLEDGEMENT}

This work would not have been possible without support and encouragement of many people. I would like to express my deep and sincere gratitude to my supervisor, Professor Amir Hakami, for his guidance, support, and constructive comments throughout this work. I would specially like to thank him for his advices and motivations at crucial times.

I am also grateful to Dr. Yongtao $\mathrm{Hu}$ (Georgia Institute of Technology) for his collaboration in data generation of this research. I warmly thank Dr. Shunliu Zhao, for his help. I would like to thank Susan Logie from linguistic department and Audrey Murray for their help in editing of this thesis. I would also like to acknowledge my colleagues, in our research team, Matthew Russell, Morteza Mesbah, and Farid Amid who have been tremendously helpful in various aspects of this work.

I wish to extend my warmest thanks to all my friends at Civil and Environmental department for their help and to my family for their wonderful support along the way. And, of course, it would have been impossible for me to finish this work without their encouragements at my difficult moments. Finally, this research was financially supported by the Canadian Foundation for Climate and Atmospheric Science (CFCAS) and the National Science and Engineering Research Council (NSERC) of Canada. 


\section{TABLE OF CONTENT}

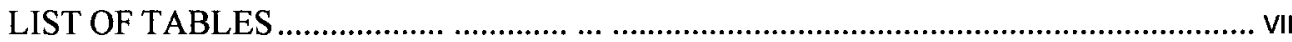

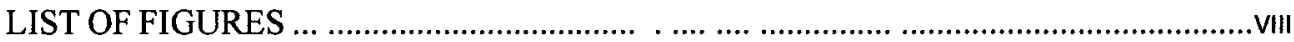

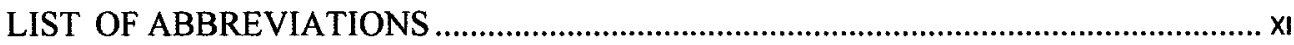

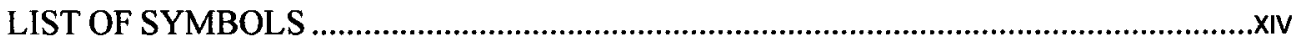

CHAPTER1: INTRODUCTION

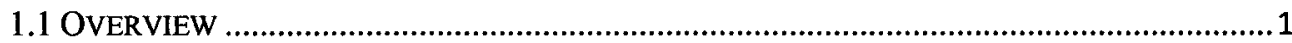

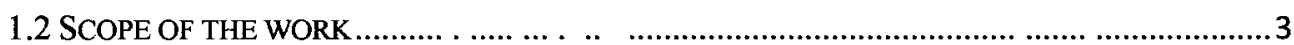

CHAPTER 2: OZONE AND ITS LONG-RANGE TRANSPORT ............................................. 6

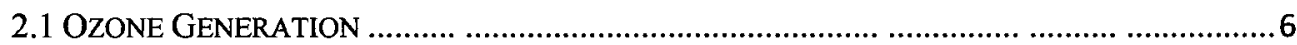

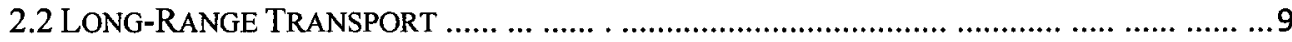

2.3 LITERATURE REVIEW OF INTERCONTINENTAL TRANSPORT (ICT) . . ...............11

2.3.1 INTERCONTINENTAL TRANSPORT FROM ASIA TO NORTH AMERICA ....................12

2.3.2 INTERCONTINENTAL TRANSPORT FROM NORTH AMERICA TO EUROPE ...............14

2.3.3 INTERCONTINENTAL TRANSPORT FROM EUROPE TO ASIA ..................................15

2.4 REGIONAL LONG-RANGE TRANSPORT OF OZONE ........................................................17

2.5 INTERNATIONAL CONVENTIONS ON LONG-RANGE TRANSPORT OF OZONE...................21

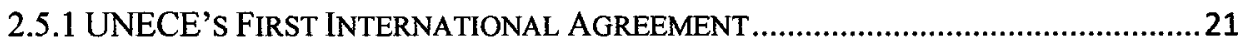

2.5.2 CANADA-UNITED STATES AIR QUALITY AGREEMENT .....................................24

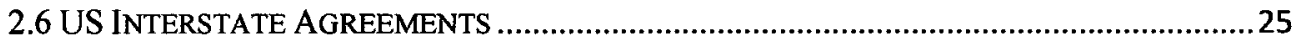

2.6.1 CLEAN AIR INTERSTATE RULE (CAIR) ............................................................26

CHAPTER 3: QUANTIFICATION OF SOURCE-RECEPTOR RELATIONSHIPS............... 28

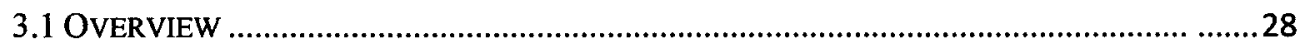

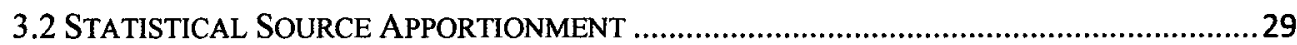




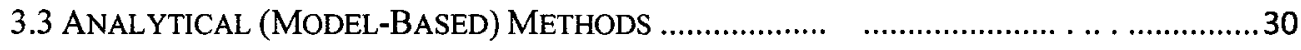

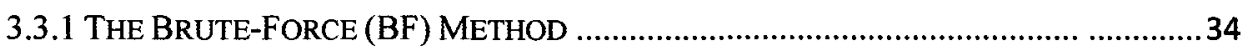

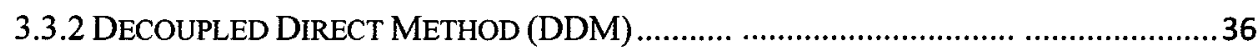

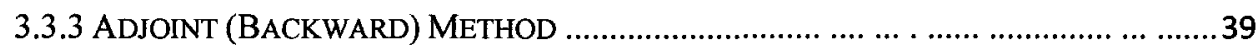

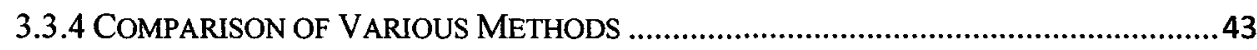

CHAPTER 4: MODELING SIMULATION AND METHODS .......................................... 45

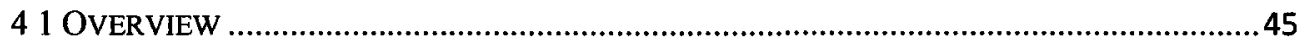

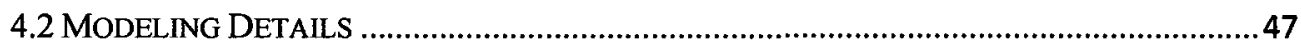

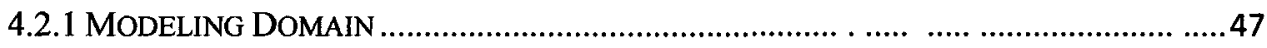

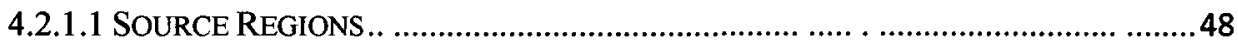

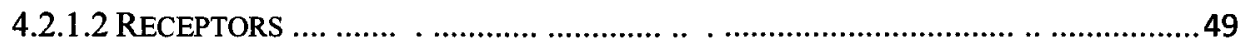

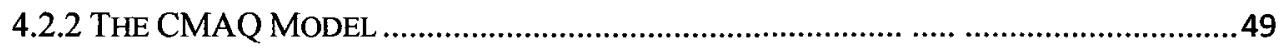

4.2.3 CMAQ INPUT GENERATION.............................................................53

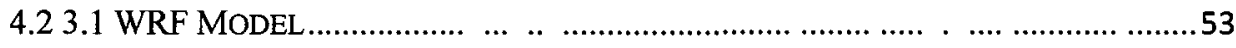

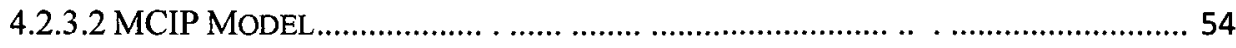

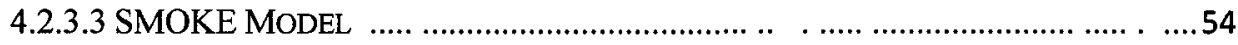

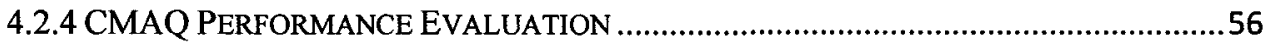

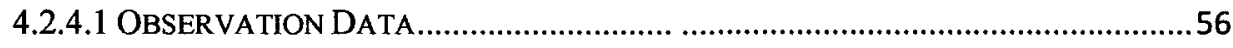

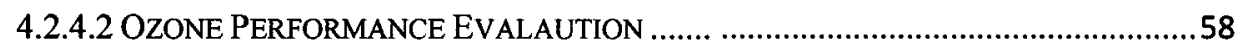

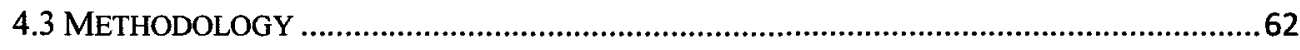

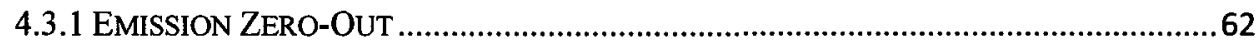

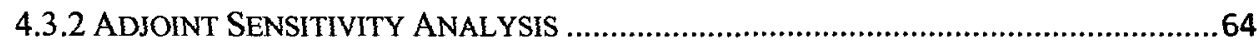

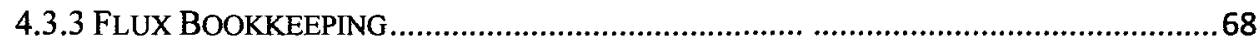

CHAPTER 5: RESULTS AND DISCUSSION ..................................................................... 70

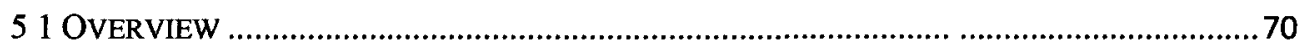


5.2.1 IMPACT OF ANTHROPOGENIC EMISSIONS ZERO-OUT ON MAXIMUM 8H-AVERAGE

OZONE

5.2.2 IMPACTS OF ELIMINATION OF $\mathrm{NO}_{\mathrm{x}}$ EMISSIONS (FOREIGN VS. DOMESTIC) ON

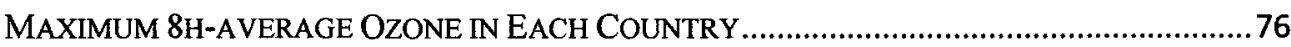

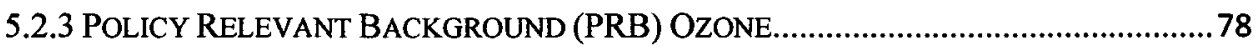

5.2.4 CROSS-BORDER IMPACT ON DAILY AVERAGE OZONE ........................................81

5.2.5 DISCUSSION OF EMISSIONS ZERO-OUT RESULTS .................................................8

5.3 MARGINAL EMISSION REDUCTION AND CROSS-BORDER TRANSPORT .........................99

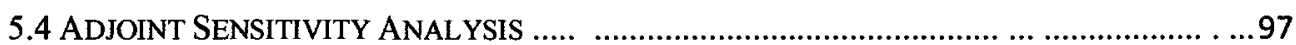

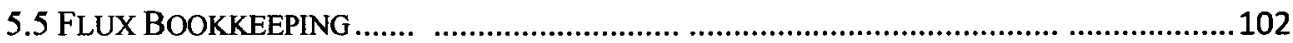

5 5.1 LONGITUDINAL AND LATITUDINAL EXPORT OF POLLUTION FLUX IN THE

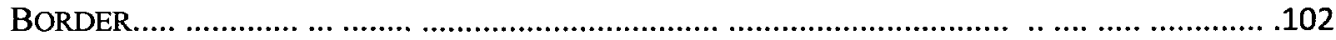

CHAPTER 6: CONCLUSIONS AND FUTURE WORK .......................................................120

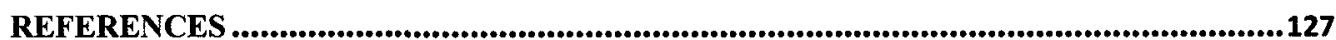

APPENDIX A: A SIMPIFIED EXAMPLE OF APPLYING ADJOINT METHOD ..........135

APPENDIX B: TERRAIN FOLLOWING HYDROSTATIC-PRESSURE VERTIVCALCOORDINATE IN METEOROLOGICAL MODEL ..............................138 


\section{LIST OF TABLES}

Table 4.1 CMAQ.4.5.1 Specifications...................................52

Table 4.2 Model performance evaluation statistics............................57

Table 4.3 Ozone performance statistics for the duration of episode in Canada and

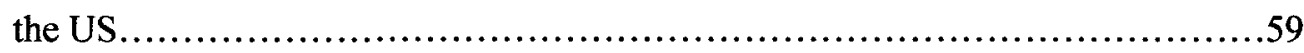

Table 5.1 Means and standard deviations for probability distribution of ozone concentration in Canada when different scenarios were applied......................85

Table 5.2 Means and standard deviations for probability distribution of ozone concentration in the US when different scenarios were applied..................86 


\section{LIST OF FIGURES}

Figure 2.1Typical ozone isopleths used in EPA's EKMA.........................

Figure 2. 2 Fifty-one countries that are party to the convention....................22

Figure 2.3 Pollutant Emission Management Area in Canada and in the US..........24

Figure 2.4 The area in the US, which is covered by CAIR..........................26

Figure 3.1 Schematic of Brute-Force Method and DDM sensitivity coefficient......38

Figure 4.1 Simulation domain with a $36 \mathrm{~km}$ horizontal resolution. .48

Figure 4.2 (a) Canadian emission region and (b) US source region for zero-out scenarios 48

Figure 4.3 Receptor areas in (a) Canada and (b) the US .........................................49

Figure 4.4 CMAQ and CMAQ-ADJ components, CCTM and preprocessors.........51

Figure 4.5 Time series of observed (red line) and simulated (blue) maximum $8 \mathrm{~h}$ average ozone at three observation sites in the US.

Figure 4.6 Time series of observed (red) and simulated (blue) maximum 8h-average ozone at three observation sites in Canada......................................662

Figure 4.7 Schematic of Jacobian and adjoint matrices and their relationship........66 Figure 4.8 Latitudinal and longitudinal transport of pollution across the Canada-US border.

Figure 4.9 The mass export/import calculation schematic in the border area, between Canada and US in both south-north and west-east directions

Figure 5.1 Maximum $8 \mathrm{~h}$-averge ozone in the receptor area of Canada, a) in base-case scenario $b$ ) in the absence of American anthropogenic emissions.

Figure 5.2. Reduction in maximum $8 \mathrm{~h}$-average ozone in the receptor area of Canada due to the removal of American emissions....................................73

Figure 5.3 Maximum 8h-average ozone in the receptor area of the US a) base-case b) in the absence of Canadian anthropogenic emissions.

Figure 5.4 Reduction in maximum 8h-average ozone in the US receptor area due to the removal of Canadian emissions.

Figure 5.5 Reductin in maximum 8h-average ozone in a) Canada and b) United States due to elimination of domestic emissions................................76

Figure 5.6 Reduction in maximum 8h-average ozone in Canada due to elimination of American $\mathrm{NO}_{\mathrm{x}}$ emisisons.................................................77

Figure 5.7 Reduction in maximum 8h-average ozone in the US due to removal of Canadian $\mathrm{NO}_{\mathrm{x}}$ emissions.....................................................78 
Figure 5.8 Maximum 8h-average ozone in a) Canada b) the United States in the absence of North American anthropogenic emissions (PRB)

Figure 5.9 Reduction in maximum 8 h-average ozone in a) Canada b) the United States due to elimination of North American anthropogenic emissions .80

Figure 5.10 Reduction in daily average ozone in the receptor areas of Canada due to the absence of American emissions.

Figure 5.11 Reduction in daily average ozone in receptor areas of the US due to the absence of Canadian emissions

Figure 5.12 Reduction in daily average ozone in a) the receptor area of Canada b) in the receptor area of US due to the elimination of domestic emissions .83

Figure 5.13 Probability distribution of hourly ozone concentration in all grid cells in the receptor area of Canada, when different scenarios were applied.................85

Figure 5.14 Probability distribution of hourly ozone concentration in all grid cells in the receptor area of the US, when different scenarios were applied.................86

Figure 5.15 Cumulative Distribution Function (CDF) of zero-out impact of American and Canadian emissions on hourly ozone concentration in Canada .87

Figure 5.16 Cumulative Distribution Function of zero-out impact of Canada (in red) and zero-out impact of US (in blue) on hourly ozone concentration in the US .........88

Figure 5.17 Changes in maximum $8 \mathrm{~h}$-average ozone in the receptor area of Canada resulting from $100 \%$ reduction of American emissions plotted as a function of maximum 8h-average ozone

Figure 5.18 Changes in maximum $8 \mathrm{~h}$-average ozone concentration in the US resulting from $100 \%$ reduction of Canadian emissions (zero-out) plotted as a function of maximum 8 h-average ozoneconcentration.

Figure 5.19 Response of maximum 8h-average ozone in Canada due to reduction of American emissions (10\% and 100\% perturbations), spatial plots..................93

Figure 5.20 Response of maximum 8h-average ozone in Canada due to reduction of American emissions ( $10 \%$ and $100 \%$ perturbations), spatial plots............... 94

Figure 5.21 Responses of maximum 8h-average ozone in the receptor area of Canada to perturbations in American emissions (10\%, and 100\%), scatter plot..............95

Figure 5.22 Response of maximum 8h-average ozone in the receptor area of the US to perturbations in Canadian emissions (10\% and 100\%),scatter plot...............96

Figure 5.23 Sensitivities of average ozone (integrated in receptor area of Canada) with respect to $\mathrm{NO}_{\mathrm{x}}$ emissions in each grid cell in the Continental US..............98

Figure 5.24 Sensitivities of average ozone (integrated in the receptor area of the US) with respect to the $\mathrm{NO}_{\mathrm{x}}$ emissions in each grid cell in Canada

Figure 5.25 Latitudinal mass export (tonnes) of different pollutants in the troposphere during the summer 2007.

Figure 5.26 Longitudinal mass export (tonnes) of different pollutants in the troposphere during the summer 2007.

Figure 5.27 Summer time series of mass of a) Ozone b) $\mathrm{NO}_{x}$ c) VOCs exported across the border in longitudinal and latitudinal directions 
Figure 5.28 Latitudinal export of different pollutants in the layer and in the free

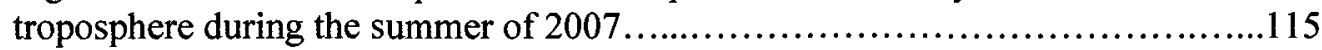

Figure 5.29 Longitudinal export of different pollutants in boundary layer and in the

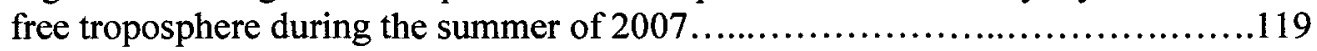

Figure B.1Terrain following ( $\eta$-coordinate) vertical layers in the meteorological model.......................................................................... 138 


\section{LIST OF ABBREVIATIONS}

\begin{tabular}{|c|c|}
\hline ADE & Atmospheric Diffusion Equation \\
\hline $\mathrm{AQM}$ & Air Quality Model \\
\hline AQS & Air Quality System \\
\hline BAT & Best Available Technique \\
\hline BCON & Boundary Condition PreProcessor \\
\hline $\mathrm{BF}$ & Brute-Force \\
\hline CAA & Clean Air Act \\
\hline CAIR & Clean Air Interstate Rule \\
\hline CCTM & CMAQ Chemical Transport Model \\
\hline CLTRAP & Convention on Long-range Trans-boundary Air Pollution \\
\hline CMAQ & Community Multiscale Air Quality model \\
\hline $\mathrm{CMB}$ & Chemical Mass Balance \\
\hline CPU & Central Processing Unit \\
\hline CTM & Chemical Transport Model \\
\hline CWS & Canada-Wide Standards \\
\hline DDM-3D & Decoupled Direct Method in Three Dimensions \\
\hline DLR & Deutsches Zentrumfür Luft- und Raumfahrt \\
\hline EKMA & Empirical Kinetic Modeling Approach \\
\hline GCM & General Circulation Model \\
\hline GRIB & Gridded Binary \\
\hline
\end{tabular}


HDDM

ICARTT

ICON

ICT

ITCT

MCIP

MFB

MFE

MNB

MNE

MPI

MPICH

NAAQS

NAPS

$\mathrm{NH}$

OTC

PBL

PEACE-B

PEMA

PRB

SAPRC

SIP

SMOKE

TF HTAP
High-order Decoupled Direct Method

International Consortium for Atmospheric Research on Transport and Transformation

Initial Condition PreProcessor

Intercontinental Transport

Intercontinental Transport and Chemical

Transformation

Meteorology Chemistry Interface Processor

Mean Fractional Bias

Mean Fractional Error

Mean Normalized Bias

Mean Normalized Error

Message Passing Interface

Message Passing Interface Chameleon

National Ambient Air Quality Standards

National Air Pollution Surveillance

Northern Hemisphere

Ozone Transport Commission

Planetary Boundary Layer

Pacific Exploration of Asian Continental Emission--B

Pollutant Emission Management Area

Policy Relevant Background

Statewide Air Pollution Research Center

State Implementation Plan

Sparse Matrix Operator and Kernel Emissions

Task Force on Hemispheric Transport of Air pollution 
TLM

UNECE

US EPA

VMT

VOC

NMVOC

WCB
Tangent Linear Model

United Nation Economic Commission for Europe

United States Environmental Protection Agency

Vehicle Miles Travelled

Volatile Organic Compound

Non Methane Volatile Organic Carbon

Warm Conveyor Belt 


\section{LIST OF SYMBOLS}

$C_{l}$

$m_{l}$

$u$

K

$R$

E

$P_{J}$

$\varepsilon_{J}$

$S_{1 \mathrm{j}}$

$E_{1}^{\prime}$

$\varphi_{1}$

$\lambda$

$N$

N

$N^{*}$

$\xi$

$\phi$

$\Delta t$

$\Delta x$

$\Delta y$

$\delta$

$G^{\prime}$ concentration of species $l$

observed concentration of species $i$

three-dimensional wind field

turbulent diffusivity tensor

chemical reaction rate of species $i$

emission rate of species $i$

model parameter or input

scaling factor

semi-normalized sensitivity of species i with respect to the emissions of species $\mathbf{j}$

unperturbed emission rate

adjoint forcing term

vector of the adjoint variables

numerical operator

tangent linear operator

transpose of tangent linear operator

solution operator for transport

chemistry operator

time interval used in numerical operation

length of the grid cells

width of the grid cells

perturbations, small changes

Jacobian matrix 


$\begin{array}{ll}G^{*} & \text { transpose of Jacobian matrix } \\ G_{1}^{\mathrm{T}} & \text { the } i^{\text {th }} \text { row vector in the Jacobian matrix } \\ O & \text { the } \mathrm{i}^{\text {th }} \text { row of transpose of Jacobian matrix } \\ I & \text { output vector } \\ g & \text { input vector } \\ J & \text { local function of concentration } \\ Z F & \text { cost function, scalar function of concentration } \\ Z H & \text { height of middle of vertical layers } \\ U_{x} & \text { height of top of vertical layers } \\ U_{y} & \text { longitudinal component of the wind } \\ M_{1} & \text { latitudinal component of the wind } \\ \rho & \text { molecular weight of species } \\ w & \text { density of the air } \\ & \text { specific spatial coordinate }\end{array}$




\section{Chapter1: Introduction}

\subsection{Overview}

Adverse health effects of ground-level ozone have been proven by several exposure and epidemiological studies. Short-term exposures to high concentrations of ozone is correlated with adverse health effects including aggravated asthma symptoms, and increased emergency room visits and hospitalizations [Bell et al, 2000; Levy et al., 2005]. Long-term exposure to low concentrations of ozone also can reduce lung functions. Ground-level ozone is also harmful to the environment. It is damaging to vegetation and reduces the crops production yields [WHO, 2008].

In order to protect public health and the environment, air quality policy makers and managers are tasked with promulgating and maintaining ozone air quality standards. Air quality standards state maximum allowable levels for ambient ozone concentrations. For example, the Canada-Wide Standards (CWS) stipulate the maximum allowable level as $65 \mathrm{ppb}$ (8h-average) in Canada [Environment Canada, 2000]. Similarly, National Ambient Air Quality Standards (NAAQS) are set by the United States Environmental Protection Agency (US EPA) as maximum allowable 
ground-level ozone concentrations across the US [US EPA, 2008]. In 1997, the NAAQS were set to $80 \mathrm{ppb}$ ( $8 \mathrm{~h}$-average), in 2008 these standards became more stringent at $75 \mathrm{ppb}$, and more recently, NAAQS have been changed to a value (to be determined) in the range of $60-70 \mathrm{ppb}$ [CRS, 2010].

As the ozone standards have become more stringent, design of effective control strategies to achieve and maintain those standards have become more difficult. Historically, ozone has been addressed as a local pollutant. This local approach to the smog (ozone) problem is still followed to some extent, but in the last two decades, regulators have begun to look at ozone as a regional pollutant. Today, long-range transport of ozone and its precursors across geopolitical boundaries has become a growing concern for ozone standard attainment. The long-range transport of ozone and its precursors far from their origins contributes to violations of ozone standards in downwind regions and creates more challenges for these regions to meet their air quality targets.

In North America, new and stricter air quality standards have shifted the focus to long-range transport of ozone and its precursors across the US-Canada border. The US-Canada border area is highly industrialized and densely populated. The air quality of the border areas in each country can be significantly affected by cross-border pollution exported from the neighboring country. Therefore, large populations can be exposed to poor air quality over which the local policies have no control or jurisdiction. Accordingly, it is essential to quantify the magnitude and the spatial extent of this non-local pollution. 
In May 2000, to address the cross-border transport of ozone, the governments of Canada and the United Sates entered into an agreement, which commits both countries to reducing their emissions [Environment Canada, 2010]. To design and implement effective emission reductions strategies in this area, quantitative analyses of ozone responses to the reduction of precursor emissions from local and upwind sources are required. For a secondary pollutant such as ozone, calculation of responses to emission reduction (ozone sensitivity coefficients) is not easily achieved. Chemical Transport Models (CTMs) equipped with sensitivity analyses extensions are the most potent tools for such quantifications and examination of the efficiency of emission reduction strategies. Over the past two decades, several studies have used chemical transport models to calculate the long-range transport of ozone and its precursors on a hemispheric and intercontinental scale. However, few studies have paid attention to intra-continental and regional transport of ozone between countries or among states/provinces. Recently, the near-field (cross-border) international influences on surface ozone concentrations in the Unites States have been investigated [Wang et al, 2009]. Given the outcomes of this US-oriented investigation, the incentive for this research is to compare the impact of cross-border emissions on surface ozone concentrations in the border area of both Canada and the US. This work will also attempt to address the issue of cross-border transport from various perspectives using complementary approaches.

\subsection{Scope of the work}

The aim of this work is to quantitatively evaluate transport of ozone and its precursors across US-Canada border. This quantification includes employing several methods 
that provide different perspectives to answer the overall question of cross-border transport. This comprehensive analysis is intended to result in establishment of more robust regional source-receptor relationships that are currently available. The sourcereceptor relationship matrices indicate the contributions of local and regional emission sources to the surface ozone air quality of the border area in each country. The modelbased approaches used in this study are divided into three main categories: sourcebased sensitivity analysis, receptor-based sensitivity analysis, and geographical flux bookkeeping. Each method is a distinct approach, and provides a unique perspective in quantification of long-range transport. The magnitude and spatial extent of surface ozone enhancement in the border area of each country are calculated using sourcebased sensitivity analyses. Contributions of individual sources to the surface ozone concentrations in the border area of each country are quantified using receptor-based (backward or adjoint) sensitivity analysis. The geographical flux bookkeeping is used to maintain the budget of export and import of pollution flux across the border. The results of various approaches are not compared with each other because each method answers the overall question differently. A widely used and thoroughly evaluated regional scale chemical transport model (the US EPA's Community Multiscale Air Quality, CMAQ), with a finer spatial gridding than that allowed in global models, is used in this study.

The thesis consists of 6 chapters including this short introduction. In the literature review, ozone and the nonlinear chemistry governing it and its precursors will be introduced and available literature on long-range transport of ozone on intercontinental and regional scales will be reviewed. The chapter also discusses the international and interstate agreements on long-range transport of ozone. In Chapter 3, 
the widely used analytical (model-based) methods in long-range transport studies over the last decade, and their strength and weaknesses will be reviewed. In Chapter 4, various methodologies used in this thesis, including the sensitivity analyses (forward and backward) and the geographical flux bookkeeping approach will be described. The perspectives, approaches, advantages and disadvantages of each method will also be reviewed. In Chapter 5, the results will be presented. Finally, a summary of main findings in this research and suggestions for future research will be given in the last chapter. 


\section{Chapter 2: Ozone and its Long-Range Transport}

\subsection{Ozone Generation}

Tropospheric ozone is a secondary pollutant, i.e., it is generated through a set of complex photochemical reactions occurring simultaneously in the atmosphere involving $\mathrm{NO}_{\mathrm{x}}$ and VOCs [NRC, 1991]. Ozone concentration shows strong nonlinear response with respect to reduction of its precursor emissions, particularly $\mathrm{NO}_{\mathrm{x}}$. This nonlinear response is best illustrated in the form of ozone isopleths (contour lines of constant values) (Figure 2.1). The location of a point on a particular isopleth is defined by the ratio of the VOC and $\mathrm{NO}_{\mathrm{x}}$ coordinates of the point, referred to as the $\mathrm{VOC} / \mathrm{NO}_{\mathrm{x}}$ ratio. The $\mathrm{VOC} / \mathrm{NO}_{\mathrm{x}}$ ratio is important in the behavior of the $\mathrm{VOC}-\mathrm{NO}_{\mathrm{x}}-\mathrm{O}_{3}$ system and affects ozone responses to the reduction of $\mathrm{NO}_{\mathrm{x}}$ and VOC emissions [NRC, 1991]. A diagonal area from the lower left to the upper right corner of the graph (with a nearly constant $\mathrm{VOC} / \mathrm{NO}_{\mathrm{x}}$, typically between 4 and 15 depending on the VOC mixture and environmental conditions) is referred to as the ozone ridge where the maximum ozone generation can be expected. 


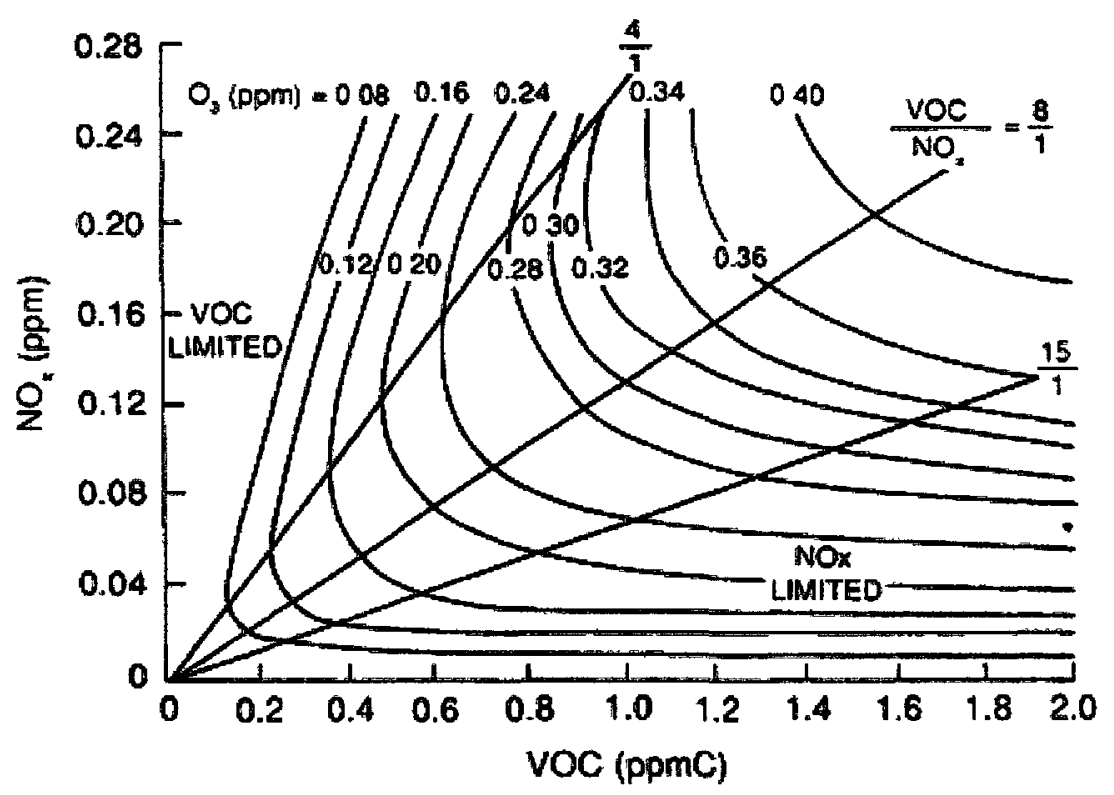

Figure 2.1 Typical ozone isopleths used in EPA's Empirical Kinetic Modeling Approach (EKMA). The $\mathrm{NO}_{\mathrm{x}}$-limited region is typical of rural areas, whereas the VOClimited region is typical of highly polluted urban areas [Dodge. M. C., 1977]

The VOC/NO $\mathrm{x}_{\mathrm{x}}$ ratio to the right of the ridge line, referred to as $\mathrm{NO}_{\mathrm{x}}$-limited regime, has typical characteristics of rural areas. In rural areas, $\mathrm{VOC} / \mathrm{NO}_{\mathrm{x}}$ ratio is high, as those are often located far away from $\mathrm{NO}_{\mathrm{x}}$ emission sources and also saturated by natural VOCs emissions from trees and vegetation (biogenic emissions). Reducing the $\mathrm{NO}_{\mathrm{x}}$ concentration in these areas either at constant VOC concentrations or with decreasing VOCs contributes to the lower peak ozone concentrations. In other words, in $\mathrm{NO}_{\mathrm{x}}$-limited areas, ozone concentrations have a positive sensitivity to $\mathrm{NO}_{\mathrm{x}}$ emissions. The low VOC/NO $\mathrm{N}_{\mathrm{x}}$ ratio to the left of the ridge line is typical of urban areas and city centers. This region is called VOC-limited, $\mathrm{NO}_{\mathbf{x}}$-inhibited, or radicallimited. In urban areas, the VOC/NO ${ }_{x}$ ratio is low due to the high $\mathrm{NO}_{\mathrm{x}}$ emissions from stationary and mobile sources. In $\mathrm{NO}_{\mathrm{x}}$-inhibited areas, lowering $\mathrm{NO}_{\mathrm{x}}$ emissions/concentrations contributes to increased peak ozone concentrations until a shift to the ridge region is made. This negative sensitivity of ozone to $\mathrm{NO}_{\mathrm{x}}$ emissions results from complex chemistry involved in the generation of ozone from $\mathrm{NO}_{\mathrm{x}}$ and 
VOCs. Some of the important reactions that affect the ozone generation are as follows:

$\mathrm{NO}_{2}+\mathrm{O}_{2} \stackrel{h v}{\longrightarrow} \mathrm{NO}+\mathrm{O}_{3}$

$\mathrm{O}_{3}+\mathrm{NO} \longrightarrow \mathrm{NO}_{2}+\mathrm{O}_{2}$

$\mathrm{O}_{3} \stackrel{h v}{\longrightarrow} \mathrm{O}\left({ }^{1} \mathrm{D}\right)+\mathrm{O}_{2}$

$\mathrm{O}\left({ }^{1} \mathrm{D}\right)+\mathrm{H}_{2} \mathrm{O} \longrightarrow 2 \mathrm{OH}$

$\mathrm{OH}+\mathrm{RH}+\mathrm{O}_{2} \longrightarrow \mathrm{RO}_{2}+\mathrm{H}_{2} \mathrm{O}$

$\mathrm{RO}_{2}+\mathrm{NO} \longrightarrow \mathrm{NO}_{2}+\mathrm{RO}$

$\mathrm{OH}+\mathrm{NO}_{2} \longrightarrow \mathrm{HNO}_{3}$

The main tropospheric source of ozone during the day is reaction (2-6) where NO is converted to $\mathrm{NO}_{2}$ without loss of ozone (unlike reaction 2-2). Ozone also titrates NO in reaction (2-2) which happens at night while during the day $\mathrm{NO}_{2}$ is photolyzed back to NO (2-1). For effective production of ozone, availability of radicals $\left(\mathrm{OH}, \mathrm{HO}_{2}\right.$, $\mathrm{RO}_{2}$ ) is essential. However, $\mathrm{NO}_{\mathrm{x}}$ and VOCs (or $\mathrm{RH}$ above) compete for reaction with radicals (reactions $2-5$ and 2-7). While VOC reaction with radicals propagates ozone production through $\mathrm{NO}$ to $\mathrm{NO}_{2}$ conversion, reaction of $\mathrm{NO}_{\mathrm{x}}$ with radicals removes them from the atmosphere in the form of nitric acid. In $\mathrm{NO}_{\mathrm{x}}$-limited areas, reaction 2 5 is more important. In $\mathrm{NO}_{\mathrm{x}}$-inhibited areas, relatively high concentrations of $\mathrm{NO}_{\mathrm{x}}$ scavenge the $\mathrm{OH}$ radicals as reaction (2-7) becomes more important in competition for $\mathrm{OH}$. Therefore, in the $\mathrm{NO}_{\mathrm{x}}$-inhibited regime, when $\mathrm{NO}_{\mathrm{x}}$ is decreased, more $\mathrm{OH}$ radicals will be available for $\mathrm{RO}_{2}$ production and $\mathrm{NO}-\mathrm{to}-\mathrm{NO}_{2}$ conversion, hence higher ozone generation. More detailed discussion about atmospheric chemistry is beyond the scope of this work and can be found elsewhere [NRC, 1991]. 
Ozone isopleths provide quantitative information about the relationship between ozone concentrations and VOCs and $\mathrm{NO}_{\mathrm{x}}$ emissions. These isopleths, however, are specific to each location and time. Therefore calculation of a location and timespecific ozone isopleth is usually a very difficult task [Hakami et al, 2004]. For ozone abatement in a particular region, precursor emission sources should be clearly identified and the relationship between ozone and its precursors should be quantitatively evaluated. The first-order ozone sensitivity coefficients, i.e. derivative of ozone concentration with respect to the variations of $\mathrm{NO}_{\mathbf{x}}\left(\partial\left[O_{3}\right] / \partial E_{N O x}\right)$ or VOC $\left(\partial\left[O_{3}\right] / \partial E_{V O C S}\right)$ emissions, are usually used to examine the response of ozone concentration to the reduction in its precursors [Yang et al, 1997; Hakamı et al, 2003; Hakamı et al , 2004; Cohan et al, 2005, Jin et al , 2008]. In Chapter 3, various analytical methods for quantification of ozone sensitivity coefficients with respect to precursor emissions will be discussed.

\subsection{Long-Range Transport}

Resistance to decomposition and physical removal, or atmospheric lifetime, is a determining factor in long-range transport of pollutants. Ozone has a shorter lifetime in the lower layer of troposphere (boundary layer), whereas it remains for a long time in the upper layer of troposphere (free troposphere). Long-range transport of ozone might be due to transport of ozone precursors ( $\mathrm{NO}_{\mathrm{x}}$ and VOCs) or generated ozone in the source region. However, the long-range transport of ozone's precursors does not occur as significantly as ozone itself. $\mathrm{NO}_{\mathbf{x}}$ (particularly $\mathrm{NO}_{2}$ ), which is a major precursor of ozone, has a short lifetime (few hours to 1-2 days depending on altitude). Having a short lifetime, only a small percentage of $\mathrm{NO}_{\mathrm{x}}$ is lifted into the free troposphere, (where it has a longer lifetime), and, therefore, long-range transport of 
$\mathrm{NO}_{\mathrm{x}}$ mainly occurs in the boundary layer and in short ranges (between countries or states/provinces).

The planetary boundary layer $(\mathrm{PBL})$ is the lowest layer of the troposphere $(2-3 \mathrm{Km}$ from the ground), and its behavior is dictated by the planetary surface. In the PBL, vertical mixing and turbulence are high due to friction from the earth's surface and convective heating of air close to the surface resulting from the daytime sunlight [TF HTAP, 2007]. Pollutants are removed in the PBL by chemical transformation, scavenging, and wet and dry deposition. Ozone has a short lifetime (few days) in the boundary layer which allows it to be transported only on a regional scale (among countries or states/provinces) [Flore et al, 2002]. The regional long-range transport of ozone and its precursors mainly occurs in a residual layer of the PBL, which is normally formed during the transition between day and night. Formation of the residual layer is due to the variability in PBL's thickness during day and night or passage of cold and warm air masses. The height of the PBL reaches its maximum during the day and in warm days while it decreases to a minimum at night and in cold days. Long-range transport of pollutants in the residual layer occurs slowly, as the wind speed is low close to the surface [TF HTAP, 2007]. Ozone has a long lifetime (several weeks with the average 22 days) in the free troposphere which results in its intercontinental transport [Wang et al 1998; Fiore et al, 2002, West et al, 2009]. In the free troposphere, long-lived pollutants are transported rapidly by strong winds on a hemispheric scale. The typical continental transport time in the free troposphere is between 5 to 10 days [TF HTAP, 2007]. 
The mid-latitude region $\left(30^{\circ}-60^{\circ}\right.$ Northern Hemisphere) is well-known for experiencing substantial intercontinental transport. The dominant vertical circulation regimes in the mid-latitude region are deep convection during the summer and midlatitude cyclone for the rest of the year. The deep convective process and mid-latitude cyclones both lift the pollutants into the free troposphere. Deep convection winds are generated when there is a temperature gradient between the earth's surface and the air. This unstable condition results in upward movement of polluted air from the boundary layer to the upper troposphere empowered by adiabatic cooling and condensation of available moisture in the air [TF HTAP, 2007]. Mid-latitude cyclones consist of four main streams. The warm conveyor belt (WCB) is the most important for vertical transport of pollutants from the boundary layer into the free troposphere. Due to the coriolis force acting on moving masses of air, winds in the mid-latitude troposphere generally have a westerly component as they travel northward (in the northern hemisphere) from subtropical high pressure to sub-polar low pressure regions. These general wind patterns in mid-latitudes (i.e., the Ferrell cell) are referred to as geostrophic winds. Hemispheric transport of pollutants from Asia to North America occurs mainly in the mid-latitude region because of the location of Asia with respect to the mid-latitude cyclones and westerlies. These general transport patterns play a significant role in both intercontinental and regional transport of ozone and its precursors.

\subsection{Literature Review of Intercontinental Transport (ICT)}

The background ozone concentration is defined as an ozone concentration that would exist in a region, in the absence of local anthropogenic emissions. The natural component of background ozone results from natural precursors, $\mathrm{NO}_{\mathrm{x}}$ emission from soil and lightning, and biogenic emissions from vegetation. There is also an 
anthropogenic component of the background concentration which is due to the transport of emissions from upwind emission sources [Fiore et al, 2002]. Policy Relevant Background (PRB) ozone was defined by the US EPA in 2006 as a surface ozone concentration that would exist in the US in the absence of anthropogenic emissions from North America (the US, Canada, and Mexico) [US EPA, 2006]. Even though the PRB is defined by the US EPA, it is continental and lumps emissions from Canada, Mexico, and the United States. The PRB represents the portion of ozone which is not generated by anthropogenic emissions of domestic sources in North America. PRB ozone is important in regulatory policymaking as it shows the maximum jurisdictional ozone abatement potential, and the associated benefits resulting from reduction of North American anthropogenic emissions.

The long-range transport of ozone has been observed by surface, satellite, and aircraft measurements as well as model simulations [TF HTAP, 2007]. Several studies have investigated intercontinental transport of ozone. A review of these studies is given in the following subsections.

\subsubsection{Intercontinental Transport from Asia to North America}

Recently, it has been suggested that background ozone is enhanced over continental United Sates due to the rapid industrialization and increase in fossil fuel emissions in developing countries in Asia. Such an enhancement in the background ozone concentrations increases the challenge for air quality managers to achieve and maintain the ozone standards in Canada and in the US. It has been shown that ozone background concentrations have a contribution of $30-40 \mathrm{ppb}$ in $3 \%$ and $25 \mathrm{ppb}$ in $9 \%$

of ozone violation events in the US (above NAAQS) [Fiore et al, 2002]. Increase in background ozone concentration in the United States has been subject of many 
investigations [Liang et al, 1998, Jacob et al, 1999, Fiore et al, 2002; Hudman et $a l, 2004]$. Over the past two decades several studies have used global chemical transport models to calculate the contribution of various upwind emission sources to the background ozone concentration over the continental US. Liang et al. (1998) calculated the background ozone concentration over the United States, ranged from $20-40 \mathrm{ppb}$, due to upwind emissions transported to the continent. They quantified the ozone background concentration using a global-scale model, with horizontal resolution of $4^{\circ} \times 5^{\circ}$ and 9 vertical layers. Jacob et al. (1999) also quantified the impacts of increased anthropogenic emissions in Asia on ozone concentration across the United States. They employed sensitivity analysis in the Harvard-GISS global model with a horizontal resolution of $4^{\circ} \times 5^{\circ}$ and 9 vertical layers. They predicted a monthly mean ozone concentration increase of 2-6 ppbv in the western United States and 1-3 ppbv in the eastern United States as a result of a tripling of Asian anthropogenic emissions from 1985 to 2010 . Recently, Fiore et al., (2002) based on observation data, reported that a significant portion of the surface ozone over the United States, ranging from 20 to $45 \mathrm{ppb}$ in summer, is a background transported from outside the North American boundary layer. They have used the GEOS-Chem chemical transport model to interpret ozone observations in North America and demonstrated that background ozone produced outside of the North American boundary layer contributed an average $25-35 \mathrm{ppbv}$ to surface ozone concentrations in the western United States and 15-30 ppbv in the eastern United States during the summer of 1995.

In addition to simulation studies, there are also measurements (aircraft and surface level observations) to suggest the long-range transport of pollution from 
intercontinental sources into North America. For example, Hudman et al., (2004) found substantial evidence in surface and aircraft observations to suggest that pollution plumes transported from Asia have a sizable impact on background ozone concentrations in the US. The aircraft data were retrieved from the ITCT $2 \mathrm{~K} 2$ campaign (Intercontinental Transport and Chemical Transformation 2002, off the California coast) and the PEACE-B campaign (Pacific Exploration of Asian Continental Emission-B, over the northwest Pacific). They used the global-scale model, GEOS-Chem (horizontal resolution of $2^{\circ} \times 2.5^{\circ}$ ) to interpret the data and demonstrated the ozone generation efficiency of the Asian plume. They predicted a mean enhancement of $7 \mathrm{ppb}$ in California, when ozone concentration exceeded 80 $\mathrm{ppb}$, partly due to transport of Asian emissions. They concluded that Asian pollution could contribute significantly to the ozone nonattainment in the United States.

\subsubsection{Intercontinental Transport from North America to Europe}

The majority of investigations on ICT have focused on hemispheric transport of pollution from Asia to North America. In mid-latitudes, hemispheric transport of pollutants also occurs from North America to Europe and from Europe to Asia. The hemispheric transport of ozone from North America to Europe has been studied in several investigations [Stohl and Trickl, 1999; Lie et al, 2002, Stohl et al, 2003a, Hudman et al, 2009]. Stohl and Trickl (1999) studied ozone transport from the eastern North American boundary layer to Europe resulting from ozone being uplifted in a warm conveyor belt (WCB) over the Atlantic Ocean. They found that aircraft measurements of ozone and water vapor over Atlantic Ocean by MOZAIC program in May 1997 supported such transport. They also carried out two trajectory model simulations using the Lagrangian model FLEXTRA and the particle dispersion model FLEXPART. They predicted the transport of parcels of air with a high $\mathrm{O}_{3}$ mixing 
ratio from North America to the upper troposphere over Europe, with satisfactory consistency between model simulation and observation (ozone and water vapor). Li et al. (2002) predicted, using the global model GEOS-Chem, that the anthropogenic emissions from North America enhance ozone in continental Europe by $2-4$ ppbv and accounted for $20 \%$ of ozone violation events (European Community ozone standards violations) in Europe in Summer of 1997. Stohl et al., (2003) also described modeling efforts with a Lagrangian particle dispersion model, FLEXPART, to interpret aircraft measurement data during an aircraft measurement campaign over Europe. The North American plumes were measured on the 19 and 27 of November 2001 by DLR (Deutsches Zentrumfür Luft- und Raumfahrt) research aircraft Falcon for different tracer species (e.g., ozone). For both plumes, they reported that the majority of emission sources, contributing to the tracer concentration at the receptor, were located in North America. Recently, Hudman et al. (2009) used a global 3-D model (GEOSChem) to interpret the aircraft data from ICARTT (International Consortium for Atmospheric Research on Transport and Transformation) campaign over eastern North America in the summer of 2004. They calculated the influences of North American emission sources on global tropospheric ozone by conducting brute-force sensitivity analysis. They demonstrated that North American $\mathrm{NO}_{\mathrm{x}}$ emissions reported by ICARTT contributed to $12.4 \%(21.9 \mathrm{Tg})$ of the summertime northern hemispheric concentrations of tropospheric ozone during the summer of 2004.

\subsubsection{Intercontinental Transport from Europe to Asia}

Hemispheric transport from Europe to Asia has been the subject of few studies [Duncan and Bey, 2004, Pochanart et al, 2003]. Duncan and Bey (2004) conducted simulation studies with GEOS-Chem to investigate the pollution export pathways from Europe during 1987-1997. Pochanart et al., (2003) explored the impact of 
European pollution export to the remote atmosphere of Siberia using $\left(\mathrm{O}_{3}\right.$ and $\left.\mathrm{CO}\right)$ data from observation sites in Central Eastern Siberia followed by trajectory analysis for the 1997-1998. Their results demonstrated that continental background $\mathrm{O}_{3}$ and $\mathrm{CO}$ levels in Siberia are influenced by European Emissions. They found higher mixing ratios of $\mathrm{O}_{3}$ and $\mathrm{CO}$ in the air masses transported from Europe compared to those originated from Siberia.

Recently, intercontinental source-receptor relationships have been established between multiple continents in modeling studies. Fiore et al., (2009) calculated the intercontinental transport of ozone among North America, Asia and Europe using 21 global chemical transport models. The horizontal resolution of their study ranged from $5^{\circ} \times 5^{\circ}$ to $1^{\circ} \times 1^{\circ}$. The source-receptor pairs among four main regions (East Asia, Europe and northern Africa, North America, and south Asia) were established by perturbing the source region by $20 \%$ and quantifying the impacts on receptor region. Similarly, Wu et al., (2009) investigated the intercontinental transport of ozone between North America, Asia, and Europe. They found a strong contribution from North America to the ozone pollution of Europe. Their study also addressed the nonlinearity of ozone response to the reduction of emissions of its precursors. To investigate the chemical nonlinearity between global ozone concentration and the anthropogenic emissions of $\mathrm{NO}_{\mathrm{x}}$ and non methane volatile organic carbon (NMVOC), they quantified the ozone response to different perturbations of the source continent (20\% and $100 \%)$. They concluded that for any source-receptor pair, a response of ozone is strongly nonlinear to the magnitude of reduction of $\mathrm{NO}_{\mathrm{x}}$ emission. In other words, sensitivity results could not be readily extrapolated from $20 \%$ perturbation to $100 \%$ or vice versa. More recently, West et al. (2009) established comprehensive 
source-receptor relationships among 9 world regions in the ozone season and examined the impacts of long-range transport of ozone and its precursors in air quality of each of these 9 regions. They quantified the impacts of a $10 \%$ reduction in anthropogenic $\mathrm{NO}_{\mathrm{x}}$ emissions from each of the regions on the surface ozone air quality of that region and the others. They concluded that the strongest intercontinental transport among the 9 world regions occur from Europe to Russia, from East Asia to Southeast Asia, and from Europe to Africa. For all other regions the influences of upwind $\mathrm{NO}_{\mathrm{x}}$ emissions are insignificant compared to that of domestic emissions.

\subsection{Regional Long-Range Transport of Ozone}

As discussed earlier, long-range transport of ozone also occurs on a regional scale in the boundary layer and in the free troposphere. Regional transport of ozone and its precursors impact surface ozone air quality in downwind areas of neighboring countries, states or provinces, and results in more difficulty for downwind areas to meet their ozone standards. Effective regional policies control upwind emission sources (foreign sources) as well as local sources in the region. Fewer studies have paid attention to the regional, intra-continental, transport of ozone [Hakami et al., 2006, Bergin et al., 2007, Tong and Mauzerall, 2008, Wang et al , 2009].

Wang et al., (2009) studied the transport of pollution from Canada and Mexico and outside of North America to the United States using global model, GEOS-Chem, with a horizontal resolution of $1^{\circ} \times 1^{\circ}$. They estimated the magnitude and spatial extent of the near-field international influences on US surface ozone concentrations which has not been a focus of previous research. They compared the North American background (PRB) and US background ozone, defined as ozone concentration that 
would exist in the US in the absence of North American anthropogenic emissions vs. American emissions respectively [US EPA, 2006]. Their results indicate that the US background is 1-3 ppb higher than the North American background resulting from Canadian and Mexican enhancements. They also reported that ozone standard violation events in the US (above $75 \mathrm{ppb}$ ) are often associated with Canadian and Mexican pollution enhancement at levels higher $10 \mathrm{ppb}$. The Canadian enhancement averages $3 \pm 4 \mathrm{ppb}$ in the US and it is larger in the downwind regions (i.e., in New York has largest episode $33 \mathrm{ppb}$ and largest summer mean of $11 \mathrm{ppb}$ ). Wang et al. (2009) in their investigation confirmed US background ozone enhancement and surface ozone air quality impairment due to the transport of anthropogenic emissions from Canada. Given the outcome of their investigation, the question of interest is the impact of American emissions on Canada's background ozone in downwind areas. In our study, it has been attempted to partially follow the Wang et al. approach to quantify the impacts of American emissions on surface ozone air quality in Canada as well.

Global models encompass all emission sources and receptors worldwide in their domain. Global scale simulation enables straightforward quantification of the impact of an emission region in a continent on the surface ozone air quality of a receptor in another continent. Regional models are not able to cover the globe in their domain and the hemispheric transport of pollution and its impacts on background ozone are quantified by calculating the inlet flux entering in to the domain from boundaries. However, global models have a coarse resolution (finest resolution is $1^{\circ} \times 1^{\circ}$, i.e. $111 \mathrm{~km} \times 111 \mathrm{~km}$ ) which is not ideal for capturing the variations in emissions and concentration pattern within the polluted grids. In addition, due to the coarse grid 
spacing, the geopolitical border between countries cannot be clearly determined in the domain, causing uncertainties in the results. Therefore, for quantification of longrange transport of pollutants on a regional scale (between countries or states), regional models are a more suitable tools. Regional models have a finer horizontal resolution which allows more precise definition of border between countries.

A number of researchers have studied interstate transport in the US. Bergin et al., (2007) examined the interstate impacts of anthropogenic $\mathrm{NO}_{\mathrm{x}}$ emissions on the ozone air quality of the eastern United States. They applied URM-1ATM over a variable scale grid ranging from $192 \times 192$ to $24 \times 24 \mathrm{~km}$. They established the source-receptor pairs by calculating sensitivity of ozone concentrations at the receptor state with respect to the emission reductions from a source state. They concluded that a significant portion of the ozone concentration in each receptor state is due to out-ofstate emissions. In the same manner, emissions from each state contribute to the ozone pollution of other states. For most of the high ozone episodes, receptor states are impacted by interstate transport of pollutants and/or precursors over which they have no control. Therefore, federal policy makers have decided to design regional control strategies to control emissions from main contributing sources and achieve air quality targets across states. Detailed information about international and interstate conventions will be found in the following section of this chapter.

Hakami et al., (2006) also investigated the sensitivity of a US ozone NAAQS nonattainment metric with respect to surface, elevated $\mathrm{NO}_{\mathbf{x}}$, and VOCs emissions from various sources in North America. They applied a continental scale model, STEM, with a horizontal resolution of $60 \mathrm{~km}$. They quantified contributions of each 
state to a nationwide ozone nonattainment metric in order to calculate the influence of interstate transport of ozone and its precursors on air quality attainment of each state They demonstrated that some states are not significantly contributing to the nonattainment metric, although they are ranked as high $\mathrm{NO}_{\mathrm{x}}$ emitters in the US. This study will be discussed in more details in the next chapter.

More recently, Tong and Mauzerall (2008) also investigated the interstate transport of ozone and its precursors in the US and its associated consequences on the ozone standard attainment in each state. They carried out their simulations for the summer of 1996, using the CMAQ model with a horizontal resolution of $36 \mathrm{~km}$. They demonstrated that interstate $\mathrm{NO}_{\mathrm{x}}$ emissions impact state-level mean ozone concentrations by -1.4 to $15.1 \mathrm{ppbv}$ and monthly maximum $8 \mathrm{~h}$ ozone concentrations by 0.4 to $22 \mathrm{ppbv}$. For maximum $8 \mathrm{~h}$ ozone concentrations, they found 16 states in which ozone concentrations are more sensitive to at least one neighboring state's $\mathrm{NO}_{\mathrm{x}}$ emissions than its own $\mathrm{NO}_{\mathrm{x}}$ emissions. They also concluded that for the majority of the states ( $80 \%$ of states), emissions from other states are contributing more to the peak ozone concentrations than local emissions.

Several model-based and statistical studies on long-range transport of ozone from hemispheric to regional scale were discussed in this section. Regionally driven regulatory programs such as $\mathrm{NO}_{\mathrm{x}}$ State Implementation Plan (SIP) and the Clean Air Interstate Rule (CAIR) have been developed to address the regional component of ozone pollution, to meet federal goals, and to support international cooperative efforts in pollution mitigation [Bergin et al, 2007]. In the following section, some of the 
most important international/interstate agreements among countries/states will be presented.

\subsection{International Conventions on Long-Range Transport of Ozone}

Traditionally, each country has individually committed to establishment of independent regulations for ozone standards and to the reduction of ozone nonattainment. As studies have repeatedly found that ozone nonattainment typically has a sizeable contribution from upwind emission sources, air quality decision makers have endeavored to develop regional control policies alongside local measures for air quality standard attainment. For developing such multi-jurisdictional strategies that cross geopolitical borders, a scientific understanding of the long-range transport of ozone and the source-receptor relationship among countries or states/provinces is required [Fiore et al, 2009]. Therefore, the Task Force on Hemispheric Transport of Air Pollution (TF HTAP; www.htap.org) was established by United Nation Economic Commission for Europe (UNECE) to promote knowledge of long-range transport in the Northern Hemisphere and to coordinate a multi-model effort to quantify and assess uncertainties in different intercontinental ozone transport studies. Hundreds of scientists and experts are linked in a global information network to evaluate the longrange transport of ozone and its associated health and environmental problems and to develop regional solutions [TF HTAP, 2007].

\subsubsection{UNECE's First International Agreement}

The first International Convention on Long-range Trans-boundary Air Pollution (CLTRAP) was established in 1979 among European and North American countries 
under the authority of UNECE and entered into force in 1993. This convention is an international agreement among countries to recognize the environmental and human health impacts of pollution transport over political boundaries and to develop emission reduction strategies for regional air quality. Currently, fifty-one countries and the European Community are party to this convention covering entire regions in Europe and North America (Figure 2.2). The convention aims to design control strategies which reduce pollutant emissions from the parties through developing an international information network. The parties meet annually at sessions of the executive body to exchange information, report their annual emission, review their previous tasks and achievements, and make decision for oncoming year. The executive body is a meeting of the representatives of the parties to the convention. They are tasked to implement the fundamental principles of the convention. The implementation committee (consists of 9 parties including Canada), was established by the executive body to review compliance by parties with their obligations under the protocols to the Convention [UNECE, 2006]
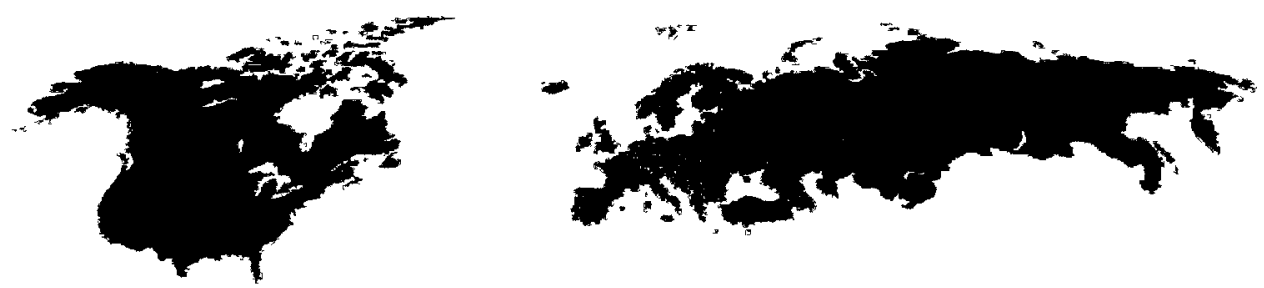

Figure 2.2 Fifty-one countries that are party to CLTRAP [UNECE, 2006]

The convention includes eight legally binding protocols to control different pollutant concentrations. The protocol to abate ground-level ozone (Gothenburg Protocol) was established in 1999 and entered into force in May 2005 with twenty-five signatures from the parties. The Gothenburg Protocol aims to reduce and control emissions of $\mathrm{NO}_{\mathbf{x}}$, VOCs, sulphur and ammonia and sets an emission ceiling to be achieved for 
these pollutants by 2010 . The protocol states that "parties whose emissions have a more severe environmental or health impact and whose emissions are relatively cheap to reduce will have to make the biggest cuts" [UNECE, 2006]. The protocol is source specific and sets tighter emission limit values for particular sources (e.g. power plants, and mobile sources) and requires the Best Available Technique (BAT) and Cap and Trade program to achieve these emissions reductions [US EPA, 2003]. Once the Protocol is fully implemented, European emissions of $\mathrm{SO}_{2}, \mathrm{NO}_{\mathbf{x}}, \mathrm{VOCs}$, and $\mathrm{NH}_{3}$ are expected to decrease by $63,40,40$, and 17 percent respectively, by 2010 compared to the 1990 levels. Canada is also expected to reduce its $\mathrm{NO}_{\mathrm{x}}$ and VOCs emissions in the Pollutant Emission Management Area (PEMA) by 34\% and 29\% from 1990 levels, respectively [UNECE, 2006]. The states and the provinces within the PEMA are areas whose emission reduction has the largest impact on trans-boundary ozone. The PEMA is determined for each country specifically; for example, in Canada the PEMA includes central and southern Ontario, southern Quebec, and in the United States, PEMA covers a number of northeastern States and District of Columbia (Figure 2.3) [Environment Canada, 2010]. It has been estimated that once the protocol is implemented the number of days with excessive ozone levels will be reduced by half, which will result in $2,300,000$ fewer life-years lost (premature deaths due to air pollution) due to chronic ozone exposure, and a $44 \%$ reduction in impacted vegetation areas in 2010 compared to 1999 [UNECE, 2006]. No information has been released yet about achievements and associated benefits of this agreement. 


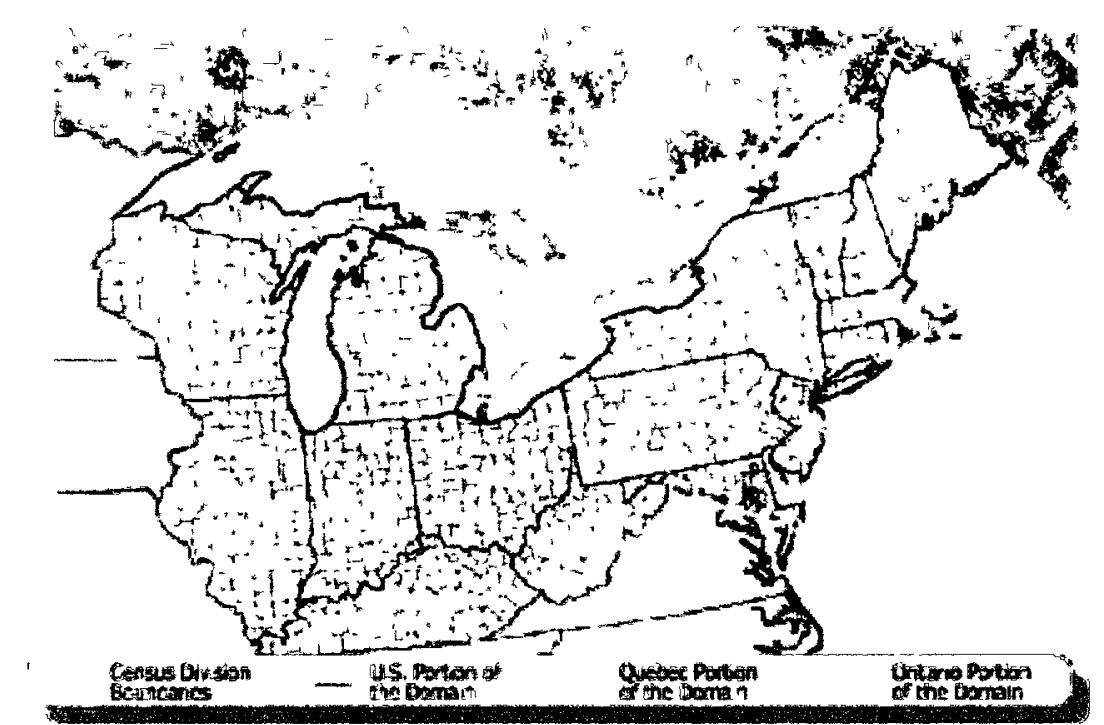

Figure 2.3 Pollutant Emission Management Area in Canada and the United States [Environment Canada, 2010]

\subsubsection{Canada-United States Air Quality Agreement}

Polluted air masses can be transported across states and provinces and between Canada and the US. The government of Canada and the government of the United State signed the Canada-United States air quality agreement in March of 1991 to address trans-boundary air pollution between Canada and the US. The agreement aims to keep the ozone concentration below the Canada Wide Standards (CWS) in Canada and below the NAAQS in the US. Annex-three (ground-level ozone) was added to the protocol in May 2000 to address the trans-boundary ground-level ozone and precursor emissions ( $\mathrm{NO}_{\mathrm{x}}$ and VOCs). Annex three commits both countries to the reduction of their emissions of $\mathrm{NO}_{\mathrm{x}}$ and VOCs in the PEMA. The regulations vary for different emission sources (e.g. stationary, mobile, etc) and are different for each state or province. For Canada the anticipated overall $\mathrm{NO}_{\mathrm{x}}$ and VOC emission reductions in PEMA are expected to be $44 \%$ and $20 \%$ from 1990 levels by 2010 . For the Unites States annual $\mathrm{NO}_{\mathrm{x}}$ and VOCs emissions reduction in the PEMA are expected to be $36 \%$ and 38\% from 1990 levels by 2010 [Environment Canada, 2010]. According to 
the protocol, "Each Party shall update its quantitative estimates referred by noted regulations, from time to time, and announce such estimates to the other Party and to the public" [Environment Canada, 2010]. Under this convention, both countries have begun regional air quality modeling to predict the impacts of ozone control strategies in a broad trans-boundary area. The results of air quality modeling indicate that joint emissions reduction strategies are associated with substantial trans-boundary regional benefits for both countries.

\subsection{US Interstate Agreements}

Historically, each state/province in North America has controlled individual emissions within its border. Recently, regulators have understood that emissions transported from upwind regions affect the abilities of downwind states/provinces to meet their ozone standards to the extent that some states/provinces may never achieve attainment by local controls. Regional regulatory programs are required to efficiently address the relationship between emissions and pollutant concentrations across North America. The regional reduction strategies in the United State address the interstate transport of pollution in a highly cost-effective manner (e.g. cap and trade program). From 1999 to 2003 a committee of 13 northeastern and Mid-Atlantic States established the Ozone Transport Commission (OTC) under the Clean Air Act (CAA) and started a multistate $\mathrm{NO}_{\mathrm{x}}$ cap and trade program called the OTC $\mathrm{NO}_{\mathrm{x}}$ budget program [US EPA, 2003]. The OTC program used a cap on the total $\mathrm{NO}_{\mathrm{x}}$ emissions from large combustion sources (power plants) and allowed the emitters to trade their emissions among themselves. The OTC program contributed to a $70 \%$ (from 1990 levels) reduction of $\mathrm{NO}_{\mathrm{x}}$ emissions from stationary sources by 2003 [Tong and Mauzerall, 2008]. 


\subsubsection{Clean Air Interstate Rule (CAIR)}

The Clean Air Interstate Rule (CAIR) was promulgated in March 2005 by the United States Environmental Protection Agency (US EPA) in order to help eastern states to attain ozone standards [US EPA, 2005]. CAIR provides a federal framework covering 28 eastern states and the District of Columbia for coordinated control of pollutants that contribute to nonattainment of 8 h-average ozone standards (Figure 2.4). The CAIR program is estimated to result in considerable human health benefits and environmental improvements [US EPA, 2005]. The US EPA claims that if states follow CAIR regulations and reduce their emissions, this program will achieve substantial $\mathrm{NO}_{\mathrm{x}}$ reductions across states within a decade. The US EPA modeling shows that, "in 2015 CAIR will reduce power plant $\mathrm{NO}_{\mathrm{x}}$ emissions by 2 million tons, achieving a regional emissions level of 1.3 million tons, a $61 \%$ reduction from 2003 levels" [US EPA, 2005]. CAIR aims to achieve these reductions through a federally sanctioned cap and trade program where main polluters in the electricity generation sector can trade emissions.

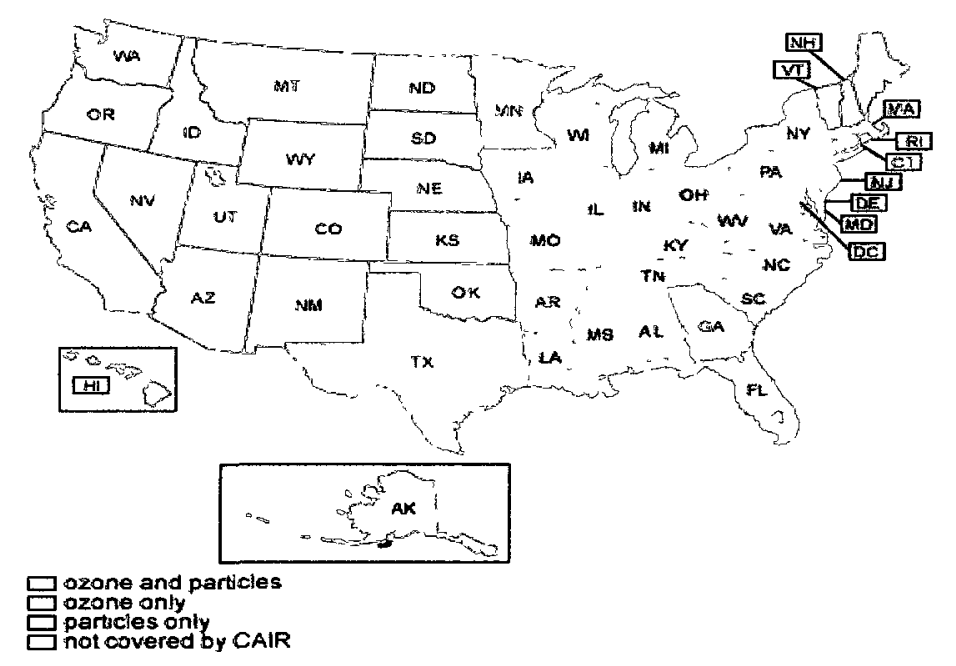

Figure 2.4 The areas covered by CAIR [US EPA, 2005] 
Much of the existing interstate regulations (OTC cap-and-trade program and CAIR) put more effort on $\mathrm{NO}_{\mathrm{x}}$ reduction from high emitters (i.e. power plants) without considering their geographical situations and meteorological conditions. Hakami et al. (2006) and Tong and Mauzerall (2008) in their studies demonstrated that meteorology, local biogenic VOC emissions, and population distributions impact the contribution seen from a particular emission source to the specific receptor. Hakami et al. showed that the emissions caps in the classic cap-and-trade programs are not necessarily true indicators of the influence of each state on the nationwide nonattainment metric. Developing regulatory programs requires an extensive knowledge and scientific quantification of interstate transport of ozone and precursor emissions in this region. Recently developed approaches (e.g., adjoint sensitivity analysis) equip air quality decision makers with suitable tools for developing more efficient regional policies. More details about implications of CAIR's cap and trade program can be found elsewhere [Hakami et al, 2007, Hakami et al, 2006]. 


\section{Chapter 3: Quantification of Source-Receptor Relationships}

\subsection{Overview}

Meeting ozone air quality standards over an extended region requires design of an effective emission reduction strategy. Such strategy should control regional emission sources (upwind sources) in addition to the local sources. To develop such a strategy, establishment of accurate source-receptor (S/R) relationship matrices is necessary. Source-receptor relationships demonstrate the impact of each source on each receptor in the region of interest. This relationship is defined as the sensitivity of the pollution observed at a receptor to the reduction of emissions of a particular source. By quantifying the source-receptor relationships, it is possible to evaluate the contribution from various emissions sources (from local to upwind) to the pollution observed in a certain location. First-order sensitivity coefficients (derivatives) are often used as a first-order approximation to such contributions, ignoring nonlinearities in presence of large perturbations [Cohan et al, 2005]. In that sense, sensitivity analysis can be regarded as an inherent source apportionment method. 
Existing approaches for establishing source-receptor matrices are categorized into two groups; statistical methods (e.g. traditional source apportionment techniques) and analytical methods that rely on calculation of sensitivity coefficients through formal or implicit sensitivity analyses approaches. The main focus of this chapter is on sensitivity analyses methods and their application in long-range transport studies.

\subsection{Statistical Source Apportionment}

Source apportionment method, also referred to as source attribution, is a statistical receptor-based analysis exercise, which attributes the observed concentration at a given receptor to the contributor sources based on the chemical characteristics of emission sources and the receptors [Lee et al, 2008]. In other words, a sample at the receptor is apportioned to a number of fractions by statistical interpretation of data. Each fraction is contribution of an individual source, and the summation of the fractions is equal to one. The relationship between sources and pollutant concentrations at the receptors are quantified through sets of mass balance equations. The most basic approach for source apportionment is Chemical Mass Balance (CMB). Eq (3-1) shows the general mass balance used in the CMB method [Hopke et al, 2003]:

$x_{\imath}=\sum_{k=1}^{N} g_{\imath k} f_{k j}+e_{\imath}$

$i=1, \ldots, \mathrm{m}, j=1, \ldots, \mathrm{n}, \quad k=1, \ldots, \mathrm{N}$,

where $x_{\mathrm{ij}}$ is the ambient concentration of species $j$ in sample $i, f_{\mathrm{kj}}$ is the mass fraction of species $j$ in source $k, g_{1 \mathrm{k}}$ is the source contribution of source $k$ in sample $l$, and $e_{1 \mathrm{j}}$ is the error. The source apportionment methods are mainly categorized in two groups depending on whether the method needs information about chemical characteristics of 
emissions sources (source profiles) or not [Hopke et al, 2003]. A review of source apportionment methods is beyond the scope of this study. However, they are mentioned here to emphasize that quantification of source-receptor relationships is, in fact, an exercise in apportionment of impacts among various sources. The main difference between statistical source apportionment methods and sensitivity-based analytical methods is that the former do not consider the atmospheric processes that affect transportation, transformation and removal of pollutants in a pathway from the source to the receptor. This limitation renders such methods of little practical use for a secondary pollutant such as ozone. Furthermore, statistical source apportionment methods are only used to apportion concentrations while sensitivity-based methods can be used to apportion any end-metric of interest such as concentration, pollution costs, mortality, etc.

\subsection{Analytical (Model-Based) Methods}

Source-receptor relationships can also be estimated using Eulerian Chemical Transport Models (CTMs). CTMs predict the temporal and spatial distribution of ambient concentration of pollutants in a three-dimensional fixed-coordinate array of horizontal and vertical grids [Russell and Dennis, 2000]. The governing equation in CTMs is the Atmospheric Diffusion Equation (ADE), Eq (3-2). The ADE includes all atmospheric processes that influence transportation and transformation of pollutants in the pathway from the source to the receptor (e.g. transport, emission, transformation, and removal processes, etc) [Seinfeld \& Pandis, 1998]. 


$$
\frac{\partial C_{t}}{\partial t}=-\nabla \cdot\left(\mathbf{u} C_{t}\right)+\nabla\left(\mathbf{K} \nabla C_{\imath}\right)+R_{\imath}+E_{\imath}
$$

where, $\mathrm{C}_{l}$ is grid average concentration of species $i, \mathbf{u}$ is the three-dimensional wind field, $\mathbf{K}$ is the turbulent diffusivity tensor, $R_{l}$ is chemical reaction rate of species $i$ and $E_{l}$ is emission of species $i$ [Seinfeld $\&$ Pandis, 1998]. The ADE is the basis for integrating evolution of concentrations in time but it (or its differentiated forms) can be used to calculate sensitivity coefficients of concentrations as well.

The ADE is usually integrated by operator splitting in a sequence of operators over multiple $(N)$ time steps $(\Delta t)$. In each time step the concentration is calculated by numerical approximation $C^{k}(x) \approx C\left(t^{k}, x\right)$ at $t^{k}=t^{0}+k \Delta t$ such that [Sandu et al, 2005]:

$$
C^{k+1}=N_{\left[t^{h}, t^{k+1}\right]} \circ C^{k}, \text { and } C^{N}=\prod_{K=0}^{N-1} N_{\left[t^{k}, t^{k+1}\right]} \circ C^{0}
$$

where, $C^{0}$ is initial concentration and $N$ is numerical operator, which acts on concentration in time step $k$ and produces concentration in one time step ahead $(k+l)$ and $\circ$ designates an operation performed by the operator $\mathrm{N}$ on an operand. $\mathrm{N}$ is derived using operator splitting while $\xi$ is the solution operator for transport (horizontal advection, vertical advection, and diffusion), and $\phi$ is the chemistry operator as follows [Sandu et al, 2005]:

$$
N_{[t, t+\Delta t]}=\xi_{X}^{\frac{\Delta t}{2}} \circ \xi_{Y}^{\frac{\Delta t}{2}} \circ \xi_{Z}^{\frac{\Delta t}{2}} \circ \phi^{\Delta t} \circ \xi_{Z}^{\frac{\Delta t}{2}} \circ \xi_{Y}^{\frac{\Delta t}{2}} \circ \xi_{X}^{\frac{\Delta t}{2}}
$$

Sensitivity analysis is a widely used approach in a variety of applications such as uncertainty analysis, quantification of source-receptor relationships, air quality forecasting, and design of control strategies. Sensitivity analyses are applied in 
chemical transport models to quantify the variations of model output with respect to each model input or parameter. The sensitivity coefficient is defined as the first-order derivative of a model output (e.g. concentration of species $i, C_{l}$ ) with respect to the model input or parameter, as shown in Eq (3-5) [Yang et al, 1997]:

$$
S_{\jmath \jmath}=\frac{\partial C_{r}}{\partial p_{J}}
$$

where $C_{1}$ is the concentration of species $i$ and $p_{J}$ is the model input (e.g., emission, initial condition) or parameters (e.g. rate constant, dry deposition velocities). The first-order sensitivity of $C_{t}$ represents the responses of concentration of pollutant $l$ with respect to perturbation in specific model input or parameter $\left(p_{J}\right)$ while other parameters are held constant. In other words, the first-order sensitivity is the slope of the response surface produced by the model in the direction of the parameter of concern. The model inputs might vary in a broad range causing significant variability in the magnitude of sensitivity coefficients. In order to avoid these fluctuations, a semi-normalized sensitivity coefficient is often used. The semi-normalized sensitivity coefficient is generated by normalizing the absolute coefficient to an unperturbed field $P_{J}$, where $p_{J}=\varepsilon_{J} P_{J}$ and $\varepsilon_{J}$ is a scaling variable. As a result, sensitivity coefficients have the same unit as the model output $C_{l}$ (concentration, ppb) and indicate change in the output that would result from $100 \%$ change in the parameter [Yang et al, 1997]:

$$
S_{J}=\frac{\partial C}{\partial p_{J}} \times P_{J}=\frac{\partial C}{\partial\left(P_{\jmath} \varepsilon_{\jmath}\right)} \times P_{\jmath}=\frac{\partial C}{\partial \varepsilon_{J}}
$$

Sensitivity analysis techniques can be divided into two general categories, forward and backward sensitivity analyses [Hakami et al, 2007]. In the forward method, the 
perturbation is made in a single model input or parameter and is propagated forward in time and space into the model output. The forward method results in the sensitivity of various model outputs with respect to the perturbation in a single input or parameter of the model. However, in the backward sensitivity analysis (also referred to as the adjoint method), the perturbation is made in a scalar function of the model output and the perturbation is propagated backward in time and space through a set of auxiliary equations (adjoint equations) resulting in the sensitivity coefficients of the scalar function with respect to all model inputs [Hakami et al, 2007].

Sensitivity analysis methods can also be categorized into two groups based on the manner in which calculations are carried out. In the Brute-Force (BF) method, model parameters of interest are perturbed one-at-a-time, and the finite difference sensitivity coefficient is calculated from corresponding change in the model output. BF method is easy to implement but can become prohibitively expensive and/or cumbersome when the number of parameters increase. Typically, the perturbation is chosen in the range of $5 \%$ to $20 \%$ to be big enough to impact the response and to be small enough such that the response adequately represents the slope of the response surface [Hakamı et al, 2003; Cohan et al, 2005]. However, sensitivity calculations using large, wholesome perturbations (such as the zero-out approach explained later) can also be categorized as a BF method. In the second group of sensitivity analysis methods, local sensitivity coefficients are directly calculated. The most widely used techniques in this group include the Decoupled Direct Method (DDM) and the adjoint method. DDM is a forward sensitivity approach while adjoint is a backward method. Obviously, for very small perturbations or linear response, BF and local sensitivity methods produce similar results. Brief discussions of these methods and their respective strengths and limitations follow. 


\subsubsection{The Brute-Force (BF) Method}

Sensitivity coefficients have traditionally been calculated using the BF Method. This method is based on finite difference estimation and calculates the sensitivity coefficient as a difference in the model outputs due to a perturbation in the base simulation. The BF Method is easy to implement but is not necessarily the best approach for sensitivity analysis due to the numerical noises that can occur for very small perturbations. Furthermore, it is a computationally expensive method as it has to simulate one-at-a-time perturbations which becomes difficult when the number of sensitivity parameters increases. The brute-force method has been widely used in air quality studies, particularly for source-receptor relationships quantification [Jacob et al, 1999, Fiore et al, 2009]. In these studies, the emission from a particular source is perturbed and the resulting change in the concentrations are translated into $\mathrm{BF}$ sensitivity coefficients of concentration with respect to that single source. Jacob et al., (1999) demonstrated the impacts of increase in Asian fossil fuel emissions on ozone concentration over North America. They applied the BF method to evaluate the impact of tripling Asian fossil fuel emissions from 1985 to 2010 on ozone concentrations across North America. Recently, Fiore et al., (2009) applied BF method to calculate the intercontinental source-receptor relationships among East Asia, Europe, North America, and South Asia. They used perturbations of $20 \%$ in emissions of each source region. In general, smaller perturbations (e.g., 10\% or less) produce results that are more consistent with local sensitivities but may not be extrapolated to wider range of change due to nonlinearities in response. Large 
perturbations account for nonlinearity over a wider range but cannot be interpolated back to marginal changes.

The zero-out method is a large-scale brute-force approach that is commonly used in source-receptor relationship establishment [Tong and Mauzerall, 2008, Wang et al, 2009, West et al, 2009]. As discussed, the BF method aims to make a small (typically in the order of $10 \%$ ) perturbation in a single source. However, the zero-out method eliminates the entire emission from a particular source and calculates the variations in pollutant concentration at different receptors. In so doing, the contribution of a particular source to the particular receptor is equal to the changes in pollutant concentration at the receptor due to the elimination of that specific source. The zeroout method has been used widely in air quality studies for quantification of background ozone concentration. As previously discussed, Wang et al., (2009) examined surface background ozone enhancement in the US due to the transport of pollution plumes from Canada and Mexico using the emission zero-out method. Tong and Mauzerall (2008) also quantified the summertime source-receptor matrices for 48 continental states using the emission zero-out method. They carried out one baseline simulation and 48 perturbed simulations. In each perturbed simulation, they removed $\mathrm{NO}_{\mathrm{x}}$ emissions (both anthropogenic and biogenic) from one state. The contribution of each state to the state-level surface ozone was calculated from the difference between the baseline and the perturbed simulations. The emission zero-out method enables researchers to calculate the impact of removing $100 \%$ of emissions from a region on the ozone concentration. This information is not readily available from local sensitivity approaches due to nonlinearity in the response. However, from a practical point of view, it is not feasible to entirely eliminate emissions from a country or a 
continent. Local sensitivity coefficients, on the other hand, provide information on more realistic emission control scenarios

At a practical level, air quality managers require local (marginal) sensitivity information. The nonlinearity of ozone with respect to changes in the precursors' emissions is discussed extensively in works of other investigators [Hakami et al, 2004, Cohan et al, 2005]. Cohan et al., (2005) showed that ozone response to a small reduction of $\mathrm{NO}_{\mathrm{x}}$ emissions might be overestimated if it is extrapolated from the response of ozone to the large reduction of $\mathrm{NO}_{\mathbf{x}}$ emissions. In other words, the zeroout method is not able to address the response of ozone concentrations to marginal changes in emissions. Accordingly, local sensitivity approaches are required for quantification of the response of ozone concentrations to marginal changes in emissions.

\subsubsection{Decoupled Direct Method (DDM)}

The Decoupled Direct Method (DDM), also referred to as the Tangent Linear Model (TLM), is a commonly used forward sensitivity analysis method. DDM is a sourceoriented sensitivity analysis technique that enables the calculation of the local sensitivities of pollutant concentrations with respect to specific emissions. DDM is an alternative approach to the BF method, as several different perturbations in model inputs can be integrated simultaneously [Yang et al, 1997]. In DDM, the perturbation of a single input (e.g., an emission source) is made and propagated forward in time to develop a sensitivity field of model outputs (e.g., concentration at the different receptors). The sensitivities of outputs with respect to the perturbation in the input are governed by a linearized version of the Atmospheric Diffusion Equation, which is referred to as tangent linear equation ( Eq (3-7)) [Yang et al, 1997]. 
$\frac{\partial S_{\imath \jmath}}{\partial t}=-\nabla \cdot\left(\mathbf{u} S_{\imath \jmath}\right)+\nabla \cdot\left(\mathbf{K} \nabla S_{\imath \jmath}\right)+G_{\imath} \mathbf{S}_{\imath}+E_{\imath}^{\prime}$

where $S_{l}$ is semi-normalized sensitivity of species $l$ with respect to the emissions of species $j, \mathbf{u}$ and $\mathbf{K}$ are the same as defined for $\operatorname{ADE}(\operatorname{Eq~} 3-2), G_{t}$ is the $i^{\text {th }}$ row vector in the Jacobian matrix, $G\left(\mathrm{G}_{\mathrm{lk}}=\partial \mathrm{R}_{\mathrm{l}} / \partial \mathrm{C}_{\mathrm{k}}\right)$, and $E_{\mathrm{r}}^{\prime}$ is the unperturbed emission rate. Subsequently, the tangent linear equation is integrated separately (decoupled) from $\mathrm{ADE}$. The sensitivity equation, $\mathrm{Eq}(3-7)$, is similar to the $\mathrm{ADE}$ and can be mostly integrated using numerical integration routines used for concentrations. Integration of Eq (3-7) results in a first-order local sensitivity of model output (concentration) with respect to model input (e.g., emission) [Hakami $A, 2003]$. The DDM and BF methods provide the same results for small perturbation and in linear cases. However, for nonlinear cases, the BF results in a sensitivity which is different from the real slope of the function that is developed by the DDM. Figure 3.1 shows a schematic of the BF and DDM sensitivity coefficients. The sensitivity coefficient $\left(\tan \left(a_{1}\right)\right)$ is approximated by $\left(O_{2}-O_{1}\right) /\left(I_{2}-I_{1}\right)$ in $\mathrm{BF}$ which is different from the real slope of the function which is derivative of output with respect to input ( $\partial O / \partial I)[$ Hakami $A$, 2003]. 


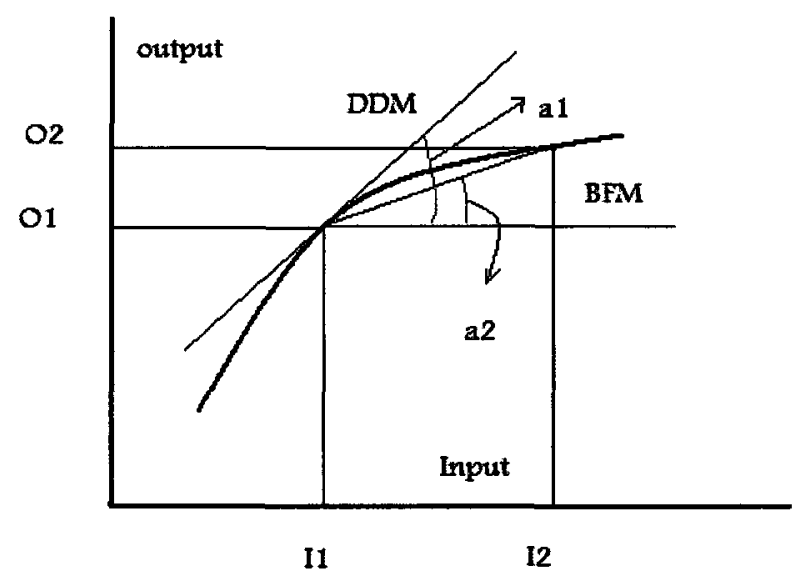

Figure 3.1 Schematic of BF and DDM sensitivity coefficients [Hakami. A., 2003]

DDM has been extended to High-order DDM (HDDM) for calculation of higher-order derivatives [Hakami et al, 2003]. Through calculation of higher-order derivatives HDDM can explain and predict nonlinearity in atmospheric response. HDDM has been applied in several studies over the last decade to evaluate the sensitivities of surface level ozone to precursor emissions [Cohan et al, 2005, Bergin et al, 2008, Jin et al, 2008, Kim et al, 2009]. Cohan et al. (2005) used CMAQ model equipped with HDDM-3D to develop first and second-order sensitivity coefficients for ozone. They quantified the nonlinear responses of ozone to the $\mathrm{NO}_{\mathrm{x}}$ and VOCs. Recently, Jin et al. (2008) also used the HDDM implementation in CMAQ to investigate the spatial and temporal variation of ozone sensitivities to the precursors' emissions. They attempted to examine the effectiveness of various control strategies $\left(\mathrm{NO}_{\mathrm{x}}\right.$ vs. VOCs reduction) in central California. Control strategies were evaluated by calculation of first-order sensitivity coefficients for maximum 8 h-average ozone concentration with respect to the domain wide emission of $\mathrm{NO}_{\mathrm{x}}$ and VOCs. Their study showed that VOC reduction strategy is efficient where maximum $1 \mathrm{~h}$ ozone exceeds standards (urban centers, $\mathrm{NO}_{\mathrm{x}}$ saturated), whereas, $\mathrm{NO}_{\mathrm{x}}$ reduction strategy is more effective for maximum $8 \mathrm{~h}$ ozone standard achievement particularly in rural areas. They also 
quantitatively compared the contribution of local vs. upwind emissions to the ozone concentration in central California. More recently, Kim et al. (2009) applied CMAQ equipped with HDDM to calculate the contributions of local and regional emission sources of $\mathrm{NO}_{\mathbf{x}}$ and VOCs to the ozone concentration in a certain region of Texas. They demonstrated that ozone concentration in that region is sensitive to upwind sources (outside the region and main neighbor states) as much as local sources. Their results indicated the capability of HDDM for capturing ozone variation with respect to the changes in $\mathrm{NO}_{\mathrm{x}}$ emissions up to $100 \%$ reduction (emission zero-out).

\subsubsection{Adjoint (Backward) Method}

While the forward sensitivity analysis is well suited for calculating the sensitivity coefficient with respect to few parameters, the adjoint method is an efficient tool for calculation of the sensitivity of a small number of target (cost) functions to a large number of model parameters or inputs [Sandu et al, 2005]. The adjoint (backward) method is a receptor-oriented approach and as such it is more suitable for policy applications. In the adjoint approach, the perturbation in the concentration or concentration-based metric at the receptor is propagated backward in time and space [Hakami et al, 2007]. The adjoint method results in sensitivities of a concentrationbased metric (e.g. average concentration all over the domain) with respect to spatiotemporal distribution of emission sources [Zhang et al, 2009]. This capability of the adjoint method makes it a computationally efficient tool in receptor-based analysis. The equation governing backward sensitivities is given in Eq (3-8). The adjoint equation is similar in structure to the tangent linear equation. One difference is that first-order derivatives change sign in the adjoint which results in backward integration in time and reversal of wind field [Hakami et al, 2007]: 
$-\frac{\partial \lambda_{t}}{\partial t}=\mathbf{u} \cdot\left(\nabla \lambda_{t}\right)+\nabla \cdot\left(\mathbf{K} \nabla \lambda_{t}\right)+\left(G^{T} \lambda\right)_{t}+\varphi_{t}$

where $G_{i}^{T}$ is the transpose of $i^{\text {th }}$ column of the original Jacobian for chemical reaction rate, $\mathrm{G},\left(G_{\imath}=\partial R_{t} / \partial C_{J}\right), \rho$ is the density of the air, $\varphi_{1}$ is the adjoint forcing term and $\lambda$ is the vector of the adjoint variables for each species at certain time and location such that $\lambda_{1}=\partial J / \partial C_{1}$, and $J$ is the scalar receptor-based cost function for adjoint analysis. The adjoint equation is driven by the forcing term $\varphi_{1}$. The adjoint forcing term functions in a fashion analogous to emissions in the ADE. The forcing term will therefore be defined as perturbations in the local cost function $(g)$ injected into the domain at any location and time at which the cost function is affected by concentrations $\left(\varphi_{1}=\partial g / \partial C_{1}\right)$. The overall cost function $J$ is computed by the model as an integration of the local cost function $(g)$ over time and space $J=\int_{t^{0}}^{T} \int_{w} g(c(c, t, w)) d w d t$, where $w$ is a specific spatial coordinate [Hakamı et al, 2007]. Cost functions can be defined and calculated in the model, based on the purpose of each specific study. Integration of adjoint equation results in the sensitivities of the cost function with respect to concentration at any given location and time. The gradients of the cost function with respect to emissions can be calculated from the adjoint variables during backward integrations [Hakami et al, 2007].

$\frac{\partial J}{\partial E^{n}}=\left(\frac{\partial C^{n+1}}{\partial E^{n}}\right)^{T} \times \frac{\partial J}{\partial C^{n+1}}$

where $E$ is emission vector at the $n^{\text {th }}$ time-step, $C$ is the concentration vector (state) at the final time step of forward simulation, and $\partial J / \partial C^{n+1}$ is adjoint variable at the first time step of backward simulation. This gradient calculates the contributions of each 
individual emission source (emission in each grid cell) across the domain to the cost function. More information about deriving the gradient of the metric with respect to the model input will be found in a simplified example in Appendix A.

Two different approaches exist for integration of the adjoint equation, continuous and discrete. In the continuous method the adjoint equation, Eq (3-8), is discretized and solved numerically (in a manner largely similar to ADE), whereas the discrete adjoint models are developed directly from dicretized forward model. Continuous and discrete approaches provide different results and the consistency between these two approaches is a subject of continued debate [Gou et al, 2009]. In discrete adjoint, a similar operator splitting scheme that is used for integration of concentrations, is also employed for backward integration of adjoint variables which results in Eq (3-10) [Sandu et al , 2005]:

$$
\lambda^{k}=N_{\left[t^{k}, t^{k+1}\right]}^{*} \circ \lambda^{k+1}+\varphi^{k}, \quad \lambda^{N}[\jmath]=\lambda^{F}\left(x_{\jmath}\right)
$$

$K=N-1, N-2, \ldots 2,1,0$

where $\varphi^{k}$ is the forcing term as was discussed, the $\lambda^{N}$ is the initial value and $N^{* *}$ is corresponding adjoint to the numerical operator $N(\mathrm{Eq} \mathrm{3-4)} \mathrm{and} \mathrm{is} \mathrm{equal} \mathrm{to:}$

$$
N^{\prime^{*}}{ }_{[t, t+\Delta t]}=\xi^{* \frac{\Delta t}{2}} \circ \xi_{Y}^{* \frac{\Delta t}{2}} \circ \xi_{Z}^{* \frac{\Delta t}{2}} \circ \phi^{\prime * \Delta t} \circ \xi_{Z}^{* \frac{\Delta t}{2}} \circ \xi_{Y}^{*}{ }^{* \frac{\Delta t}{2}} \circ \xi_{X}^{*}{ }_{X}^{* \frac{\Delta t}{2}}
$$

More information about derivation and integration of adjoint equation is found elsewhere [Sandu et al, 2005, Elbern et al, 2000, Hakami et al, 2005]. Adjoint of CMAQ (4.5.1 gas-phase) model was developed using hybrid approach in which the discrete adjoint was used for all processes except the horizontal advection [Hakami et al, 2007]. 
The adjoint method has appeared in chemical transport models in the last few years for various applications including sensitivity analysis, emission inverse modeling and data assimilation. In atmospheric modeling, the adjoint method was first used in the Lagrangian stratospheric model of Fisher and Lary (1995), and in the Lagrangian tropospheric model of Elbern et al. (1997) For the first time Elbern and Schmidt (1999) developed the adjoint of the Eulerian chemical transport model, including chemistry, (European Air Pollution Dispersion Model, EURAD-CTM2) for a 4dimensional data assimilation. Vukicevic and Hess (2000), conducted sensitivity analysis of an inert gas-phase tracer over the Pacific Ocean with respect to various parameters using the adjoint method in the tracer model HANK. Recently, Henze et al. (2007) developed the adjoint of global CTM model GOES-Chem [Henze et al, 2007]. Hakami et al. (2007) developed an adjoint for gas-phase processes in the CMAQ model. The adjoint version of some other regional models have also been developed; STEM [Sandu et al, 2005], CHIMERE [Vautard et al, 2000, Menut et al , 2000; Schmidt and Martin, 2003], and DRAIS [Nester and Panitz, 2006].

Adjoint sensitivity analysis has only been applied in a few air quality studies since there is limited number of CTMs for which the adjoint version is available [Zhang et al , 2009; Hakami et al , 2006; Hakami et al, 2005, Henze et al, 2009]. Hakami et al. (2005) applied an adjoint version of STEM for inverse modeling of the black carbon to explore the spatial distribution of black carbon in Asia for April of 2001. Hakami et al. (2006) also applied an adjoint version of STEM for sensitivity analysis of NAAQS nonattainment ozone metric in the continental US. They quantified the interstate transport of ozone and its impacts on air quality impairment in some states in the continental US. Their study introduced adjoint (backward) sensitivity analysis as a 
flexible tool in quantification of regional pollution transport. More recently, Zhang et al. (2009) applied adjoint of GEOS-Chem to quantify contributions to ozone concentrations over two receptor sites in the west coast of the US. Henze et al. (2009) also applied adjoint of GEOS-Chem for inverse modeling of $\mathrm{PM}_{25}$ precursors emissions in the US.

\subsubsection{Comparison of Various Methods}

The earlier sections discussed analytical and statistical methods used in previous investigations of long-range transport of ozone. Analytical source apportionment (zero-out) methods enable the calculation of the total contribution of each source to the ambient concentration of pollutants, whereas the local gradient methods (adjoint and DDM) quantify the response of pollutant concentration to incremental perturbations (local sensitivities). For long-lived primary pollutants (directly emitted to the atmosphere) a linear relationship can be assumed between emission sources and pollutant concentrations. However, secondary pollutants (e.g., ozone) are generated in the atmosphere from precursors and generally in a nonlinear fashion [Cohan et al, 2005]. In linear cases, the impact of control strategies and source contribution can both be scaled directly (extrapolated) from local sensitivities. Therefore, for primary pollutants, it is possible to calculate the source contributions to the pollution at the receptor from local sensitivities. However, local gradient methods cannot quantify an accurate source contribution for secondary pollutants (e.g., ozone), i.e., the extrapolation of the total contribution from local sensitivities would not be accurate for secondary pollutants [Yarwood et al, 2007]. Zero-out and brute-force methods on the other hand quantify the total (and actual, within the model's accuracy) 
contribution of each source to the receptor, whereas they are unable to quantify the response of the receptor to more marginal but realistic changes in emissions. Accordingly, each of these methods is applied depending on the purpose of investigation. Previous studies have applied various methods to quantify the longrange transport of ozone on an intercontinental or regional scale. Each of the studies investigated this phenomenon from a particular perspective. For instance, Bergin et al. (2007) and Hakami et al. (2006) investigated interstate transport using local sensitivities but their approach could not evaluate total contributions from each state. Tong and Mauzerall (2008) calculated the total contribution of each state to the air pollution of other states applying zero-out method, while they could not address the sensitivity of ozone concentration with respect to the small reduction of emissions in each state. 


\section{Chapter 4: Simulations and Methods}

\subsection{Overview}

As discussed in previous chapters, the long-range transport of ozone is a growing concern in ozone attainment for North America. Design of optimal control strategies requires quantitative understanding of long-range transport of ozone in this region. The aim of this work is to quantitatively evaluate the cross-border transport of ozone and its precursors in North America, specifically between Canada and the US. This objective will be achieved through establishment of scientifically robust sourcereceptor relationships in North America. The required source-receptor matrices are developed using sensitivity analyses that are implemented in a widely used Eulerian chemical transport model. The approaches in this study are mainly divided into three categories: a) source-based sensitivity analysis, b) receptor-based sensitivity analysis, c) geographical flux bookkeeping. In brief:

1. The emission zero-out method is used to calculate the contribution of each country to the surface ozone pollution in the other. This method is a commonly used source-oriented analysis in the quantification of long-range transport of ozone. The impact of elimination of foreign emissions on surface 
ozone air quality of each country is quantified by zeroing out the anthropogenic emissions in the source country. The marginal zero-out method (brute-force), a source-oriented method is also applied to quantify the response of surface ozone concentration in each country to the marginal changes $(10 \%)$ of foreign emissions. This method will test whether the changes in ozone concentration resulting from $10 \%$ reduction in emission can be linearly extrapolated from ozone response to $100 \%$ reduction.

2. Adjoint sensitivity analysis is a receptor-oriented approach that enables calculation of the impact of each individual source on a receptor-based cost function (i.e., scalar metric of pollutant concentration). The adjoint method is applied in this work to calculate the sensitivities of concentration-based cost functions (e.g average ozone) at the receptor areas of each country with respect to emission sources across the domain.

3. Geographical border flux bookkeeping is employed to quantify the crossborder export/import of individual pollutants to/from each country. The method enables budgeting of the transport of ozone and its precursors across the border but does not provide any information on emission sources.

The goal of this study is to explore available methodologies that can provide different perspectives to the question of cross-border transport. Each method is a distinct approach, and provides a unique perspective in quantification of long-range transport. These methods are not compared with each other because each one addresses the overall question from different angle. The aim is to acquire a more encompassing understanding about the topic than that offered by a single approach. In this chapter, the modeling effort will be described. Additionally, each analysis method and its 
perceived strength and/or weakness will be discussed at the end. Note that the focus of this work is on the impact of anthropogenic emissions. Therefore, throughout this section and the rest of the document use of the word "emissions" implies anthropogenic emissions unless otherwise noted.

\subsection{Modeling Details}

The US EPA's CMAQ model (4.5.1 version, gas-phase) [Byun and Ching, 1999], was set up to simulate the Summer 2007 (three months, July to September) episode using a 36-km horizontal resolution domain covering North America. The dynamics of the atmosphere and emissions for the duration of episode were simulated separately using other models. The Weather Research and Forecast (WRF, version 3.1) model [NCAR, 2010] was employed for simulating the meteorological fields for the episode. The Sparse Matrix Operator Kernel for Emissions (SMOKE, version 2.4) model [CEP, 2000 was used to generate gridded and speciated emission files from annual emission inventories. The outputs of these models were used as inputs for CMAQ. The CMAQADJ, adjoint version of gas-phase CMAQ, [Hakami et al, 2007], was also used for receptor-based sensitivity analysis.

\subsubsection{Modeling Domain}

The modeling domain is a Lambert conformal projection of North America. It includes 148 columns and 112 rows with horizontal grid spacing of $36 \mathrm{~km}$ (Figure 4.1). The vertical extension of the domain includes 13 vertical layers with the terrainfollowing hydrostatic pressure vertical coordinate (See Appendix B) [NCAR, 2010]. Parts of Northern Canada are not included in this domain, as the anthropogenic emission contributions from those parts are assumed to be insignificant. Even though 
parts of Mexico are included in the modeling domain, the focus is on transport across the US-Canada border.

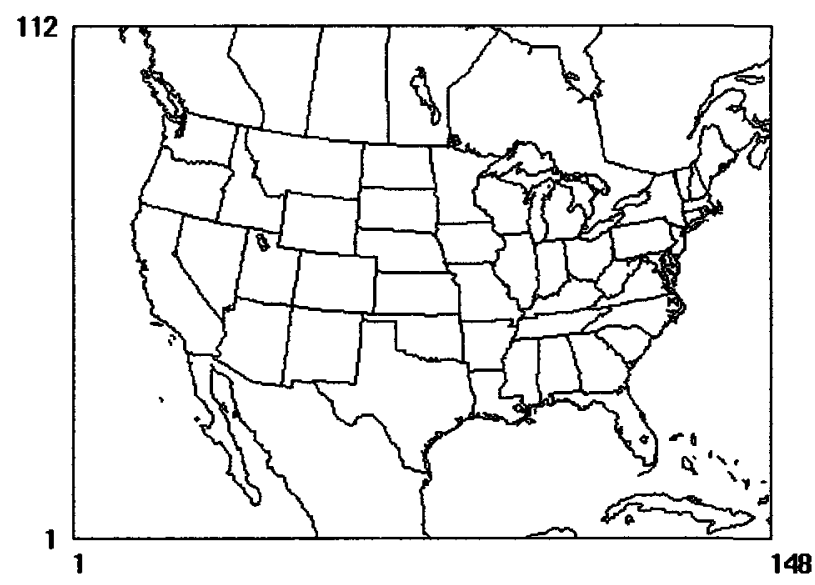

Figure 4.1 Simulation domain with a $36 \mathrm{~km}$ horizontal resolution.

\subsubsection{Source Regions}

In the zero-out approach, sources are defined differently for each simulation scenario.

For instance, for prediction of the contribution of Canada to ozone concentrations in the US, the source region in the simulation is defined as Canada. Similarly, for quantification of impact of American emissions on ozone concentrations in Canada, all emission sources in the US are considered as a source region (Figure 4.2).

a)

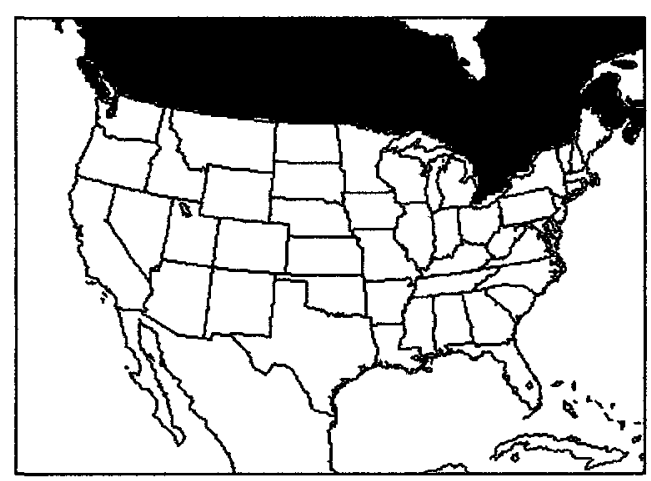

b)

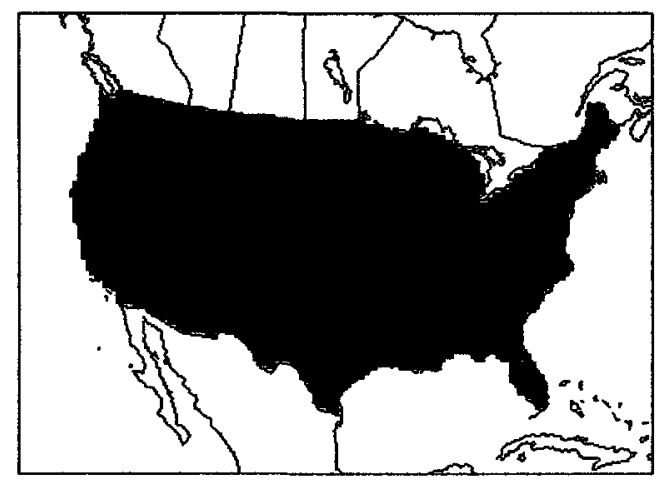

Figure 4.2 (a) Canadian emission region and (b) US source region for zero-out scenarios 


\subsubsection{Receptors}

In adjoint sensitivity analysis, the sensitivity of an ozone cost function (e.g., daily average ozone metric) is quantified in the receptor areas of each country. Therefore, the receptor areas, over which the cost function is integrated, must be determined. The domain covers the continental US while parts of Canada are excluded. Therefore, for consistency in quantification and comparison, receptor areas are selected as bands (15 grid cells above or below the border line) in the vicinity of the border in each country (Figure $4.3 \mathrm{a} \& \mathrm{~b}$ ). In so doing, the ozone cost function, required for the adjoint method, is calculated over the same number of grid cells in each country. Border areas in each country are more likely to be affected by the cross-border transport. Thus, the receptor areas are defined similarly in zero-out simulations, to capture the highest impact of cross-border emissions on ozone concentrations.

a)

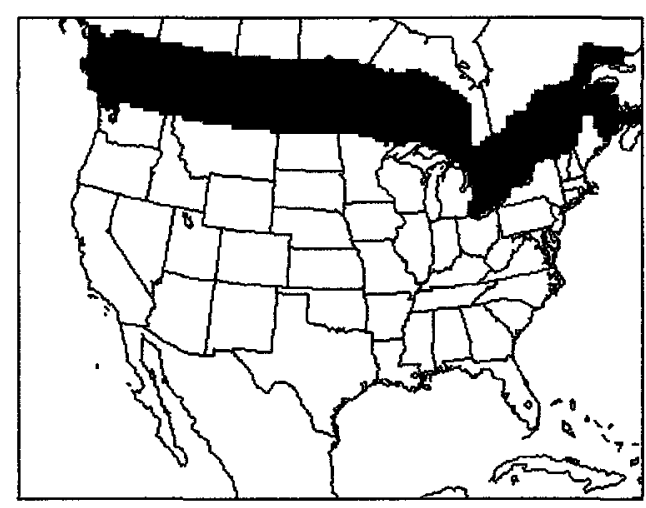

b)

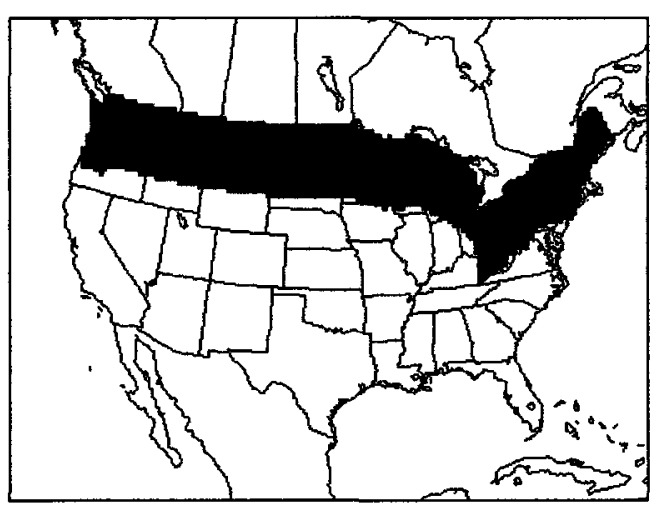

Figure 4.3 Receptor areas in (a) Canada and (b) the US

\subsubsection{The CMAQ Model}

Three-dimensional Chemical Transport Models are the most widely applicable used models in prediction of ambient concentration of pollutants and examination of the influences of pollution reduction strategies. CTMs are able to calculate the time evolution of pollutants by considering transportation and transformation processes in 
the pathway from the source to the receptor. Unlike General Circulation Models (GCMs), CTMs do not calculate the dynamics of the atmosphere (i.e., winds and atmospheric circulations). Atmospheric dynamics are simulated separately in meteorological models with consistent model assumptions. The CMAQ model (version 4.5.1, gas-phase), a regional-scale Eulerian CTM, is used in this study to predict the pollutant concentrations across the domain and carry out sensitivity analyses. The CMAQ model is the most widely used regional air quality model in North America and across the world. The CMAQ model uses state-of-the-science techniques to model atmospheric processes that affect transportation, transformation, and deposition of pollutants and provides temporal and spatial distributions of concentrations of multiple air pollutants on various scales [Byun and Ching, 1999]. The CMAQ model is a set of Fortran programs developed to integrate the Atmospheric Diffusion Equation (ADE) shown in Eq (3-2).

The CMAQ Chemistry-Transport Model (CCTM) solves the ADE equation using numerical operator splitting in a three-dimensional gridded domain. Meteorological and emissions files for CMAQ are generated by meteorology and emission models, respectively. Spatial grid extents and temporal resolution of CMAQ outputs are specified by the user. However, the horizontal and vertical grid extent and resolution should be consistent with meteorological data. CMAQ also requires other inputs including initial and boundary conditions. The lateral (horizontal) boundary condition is required to initiate advection into the domain. The boundary conditions are estimated in CMAQ using the boundary conditions preprocessor (BCON). For initial conditions, the first time step of simulation is predicted in CMAQ using an initial conditions preprocessor ICON. The initial concentration generated by ICON is taken 
either from pollution climatology (average concentrations) or from simulations over a larger area. CMAQ also requires clear sky photolysis reaction rates to simulate the chemical system governing in the atmosphere. The clear sky photolysis rates are produced by the Photolysis Rate Preprocessor, JPROC, for various latitudes and times of the day. The amount of solar radiation is dependent on the sun angle (time of day), season and latitude [Byun and Ching, 1999]. CMAQ uses the outputs of all preprocessors and the meteorology and emission models for model simulations (Figure 4.4).

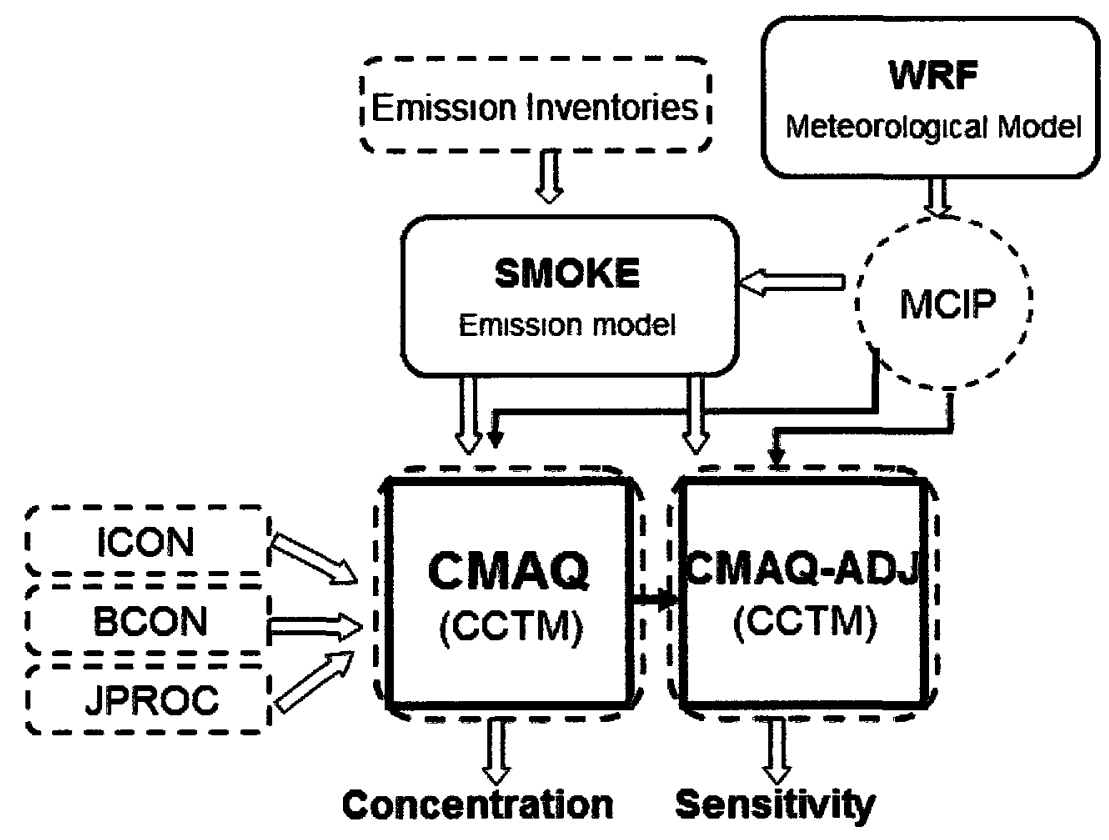

Figure 4.4 CMAQ and CMAQ-ADJ components, CCTM and preprocessors.

The gas phase chemistry is simulated in CMAQ with the Statewide Air Pollution Research Center, Version 1999 (SAPRC99) photochemical mechanisms [Carter, 2000], or the Carbon Bond mechanism (CB05) [Yarwood et al, 2005] which is an update on Carbon Bond IV (CB-IV). CMAQ uses chemistry solvers to compute pollutant concentrations and their rate of formation or depletion (chemical kinetics). 
The chemical solver used in this model (CMAQ v.4.5.1) is the Kinetic PreProcessor (KPP) package of Rosenbrock solvers (version 2.2) to facilitate the implementation of forward and adjoint sensitivity analysis [Damian et al, 2002]. The main transport processes that contribute to the dispersion of pollutants in the atmosphere are: advection, defined as a transport of pollutants by bulk motion of the wind, and diffusion, defined as dilution and dispersion of pollutants due to the random fluctuation in the wind [Tesch $T W, 1983$ ]. The advection process is simulated separately in vertical and horizontal directions in the CMAQ. The reason is that the domain is spaced regularly (in equal increments) in the horizontal direction, whereas it is irregularly spaced in vertical direction (grids are expanding with altitude, See Appendix B). The horizontal advection in CMAQ is simulated using the Piecewise Parabolic Method (PPM) [Colella and Woodward, 1984] (Table 4.1). CMAQ is also able to simulate other processes including cloud formation, particular matter and plume-in-grid model which are not in used in gas-phase version of CMAQ but are discussed elsewhere [Byun and Ching, 1999]

\begin{tabular}{cl}
\hline \multicolumn{2}{c}{ Table 4.1 CMAQ.4.5.1 Specifications } \\
\hline chemistry & SAPRC-99 \\
number of species & 94 \\
number of chemical reactions & 235 \\
number of photolytic reactions & 30 \\
chemical solver & KPP \\
horizontal advection & Finite difference scheme \\
advection scheme & PPM \\
\hline
\end{tabular}

CMAQ was set up in parallel mode for this simulation using MPICH message passing interface (MPI) [Gropp and Lusk, 1996] to control communication between processors in a multiprocessor computing environment. Thus, in the parallel mode, the simulation domain is divided into subsections processed separately by individual CPUs. 


\subsubsection{CMAQ Input Generation}

Meteorological inputs for Summer 2007 were generated by the Weather Research and Forecasting (WRF, version 3.1) model [NCAR, 2010]. The outputs of WRF model were converted by Meteorology-Chemistry Interface Processor (MCIP, version 3.4.1) to a model-ready format for CMAQ and emission model [Byun et al, 1999a]. The emissions inputs for CMAQ were generated by the Sparse Matrix Operator Kernel for Emissions (SMOKE, version 2.4) model [CEP, 2006].

\subsubsection{WRF Model}

The WRF model (version 3.0) is a mesoscale numerical weather prediction system designed to provide a platform for atmospheric research and weather forecasting. The WRF model is a compressible, non-hydrostatic meteorological model with the terrainfollowing hydrostatic pressure vertical coordinate (Appendix B). The hydrostatic assumption works well for large scale domains, as it assumes a balance between vertical pressure and gravitational forces with no net vertical acceleration in the atmosphere. However, the compressible non-hydrostatic assumption is a better match for resolving the atmospheric dynamics of finer resolutions (regional or urban scale) [NCAR, 2010]. The WRF model is used in this study to generate the meteorological fields required for the simulations. The WRF model uses North American Mesoscale (NAM) datasets [NCEP, 2005] that are in GRIB format and model products from National Center for Environmental Prediction [NCEP, 2005]. The WRF prepares the meteorological fields, suited for the emission model (SMOKE) and CMAQ, which are temporal and gridded. The modeling domain of WRF for this simulation covers North America with a horizontal resolution of $36 \mathrm{~km}$. The domain includes 165 columns and 
129 rows and 35 vertical layers. The outputs of WRF are not in a format to be utilized directly with CCTM, and need conversion.

\subsubsection{MCIP Model}

The Meteorology Chemistry Interface Processor (MCIP, Version.3) [Byun et al, 1999a] is required to convert WRF outputs to a format required for the CMAQ and the emission model (SMOKE). In this study, the MCIP model excluded the lateral boundaries of the WRF domain (165 columns $\times 129$ rows) and trimmed it into a smaller domain matching that of the CCTM (148 columns $\times 112$ rows). In addition, the MCIP model changes, if necessary, the vertical resolution of the meteorological data by "layer collapsing" from high resolution into user-defined vertical resolution. In this study, the MCIP model performed layer collapsing from the vertical resolution of 35 layers to 13 layers. The MCIP model is also capable of generating speciated and temporal dry deposition velocities required for CCTM. The characteristics and abilities of this model are described elsewhere [Byun et al, 1999a].

\subsubsection{SMOKE Model}

The Sparse Matrix Operator Kernel Emission (SMOKE) model [CEP, 2006] was used to simulate the emissions inputs required for CCTM. The SMOKE modeling system is a set of Fortran codes which process emission inventories and produce emission inputs required by air quality models. The emissions inventories are total annual emissions prepared for each emission source category (e.g., stationary, mobile, etc). The air quality models require emission data for each time step (interpolated from hourly values), in each grid cell (probably in each model layer) and for each species. Therefore, the main purpose of using the SMOKE model is to simulate the gridded, speciated, and temporally allocated emission files from emission inventories. This 
model simulates multiple criteria pollutants (e.g. carbon monoxide, volatile organic compounds, etc), particulate matter $\left(\mathrm{PM}_{10}, \mathrm{PM}_{25}\right.$, etc), and toxic pollutants (e.g., benzene, formaldehyde, etc). The speciation profile used in this study is the Statewide Air Pollution Research Center (SAPRC-99) chemical mechanism [Carter, 2000]. The SAPRC-99 includes 94 species, 235 chemical reactions and 30 photolytic reactions. The SMOKE model is able to process various emission sources; area sources (criteria stationary area sources, toxic non-point sources, criteria and toxic nonroad mobile sources), biogenic, mobile (criteria and toxic on-road sources), and point sources (including wildfire emissions). Area sources are assigned to the category of emissions that are spread spatially (e.g., a country). Examples of area sources are residential heating and architectural coatings [CEP, 2006]. The nonroad emissions are included in the area source category since nonroad emissions are assigned to movable sources that are not on roadways such as garden equipment, construction vehicles, and boating emissions. The mobile sources are simulated by computing emission factors in the MOBILE6 model and having activity data (vehicle kilometer traveled, VMT, and vehicle speed). Biogenic emissions are generated within the SMOKE model by using Biogenic Emission Inventory System 2 and 3 (BEIS2 and BEIS3) [CEP, 2006]. Point sources are industrial and nonindustrial stationary stacks that are identified by point locations and have significant air pollution emissions ( 1 tonne or more in a calendar year). Examples of point sources are industrial and commercial boilers, electric utility boilers, turbine engines, petroleum and chemical processing operations. The point sources are divided into electric generation utilities (EGUs) and non-EGUs. EGUs are the main sources of $\mathrm{NO}_{\mathrm{x}}$ and $\mathrm{SO}_{2}$. The wildfire emissions are processed in $\mathrm{SMOKE}$ as point sources, as information about their locations and day-specific emissions becomes available. The emissions input to SMOKE are Inventory Data Analyzer 
(IDA) format, annual or daily average emissions. A 6-digit integer code is assigned to IDA files to identify a country (US or Canada), state (or province), and county (or other region) for a particular source. The IDA emission inventories are different for area, point, and on-road mobile sources. For example, for point sources, the IDA inventories provide information about the location of point sources (e.g., country, state, and county codes), a plant identifier, a stack number, and a point identifier. For mobile sources, there is one IDA format file for activity data and one for emissions data. The IDA activity data format is used to input VMT and speed data to SMOKE [CEP, 2006]. For the US, the IDA files are prepared by EPA for officially released versions of the National Emissions Inventory (NEI) [US EPA, 2009]. In this study, the projection of emission inventories of 2002 was used. Emission projection is a function of changes in emission rates as well as growth/decline in population, land use patterns, transportation and industrial activities.

\subsubsection{CMAQ Performance Evaluation}

Each modeling simulation needs to be evaluated against observation data or similar simulation results from a model that has undergone extensive performance evaluations [Byun and Ching, 1999]. Evaluation of model performance determines the predictive skills of the model. The simulated concentrations of ozone were compared to the corresponding observation data in the domain. Accuracy of CMAQ predictions determines, to some extent, the reliability of source-receptor quantifications and sensitivity analyses in this study.

\subsubsection{Observation Data}

The evaluation was carried out for ozone using hourly data from urban, suburban and rural monitoring stations. For the United States, data were obtained from Air Quality 
System (AQS) ground-level observation sites [US EPA, 2010]. More than a thousand monitoring stations (urban, suburban, and rural) are now active in AQS that cover the majority of the continental US. For Canada, data were obtained from the National Air Pollution Surveillance (NAPS) Network that consists of 290 monitoring sites equipped with approximately 600 monitors for ozone and PM [Environment Canada, 2003]. The observation sites cover almost the entire CMAQ domain. The evaluation was carried out for the grid cells for which the observation data were available. For grid cells in the domain that were monitored with two or more sites, the average value was used. The CMAQ prediction was normalized by paired observation in each grid cell and time step. Table 4.2 shows the statistics that have been recommended by the US EPA to evaluate the CMAQ ozone performance, where, $C_{l}$ and $m_{l}$ are model predicted and measured (observation) concentrations respectively [US EPA, 2007].

\begin{tabular}{lc}
\hline Table 4.2 Model performance evaluation statistics [US EPA, 2007] \\
\hline Mean Normalized Bias & $M N B=\frac{1}{N} \sum_{i=1}^{N} \frac{C_{t}-m_{t}}{m_{t}} \times 100 \%$ \\
Mean Fractional Bias & $M F B=\frac{2}{N} \sum_{t=1}^{N} \frac{C_{t}-m_{t}}{C_{t}+m_{t}} \times 100 \%$ \\
Mean Normalized Error & $M N E=\frac{1}{N} \sum_{i=1}^{N} \frac{\left|C_{t}-m_{t}\right|}{m_{t}} \times 100 \%$ \\
Mean Fractional Error & $M F E=\frac{2}{N} \sum_{i=1}^{N} \frac{\left|C_{t}-m_{t}\right|}{C_{t}+m_{t}} \times 100 \%$ \\
\hline
\end{tabular}

In MNE and MFE statistics, the absolute value of the difference between prediction and observation is used. MNE and MFE are always positive, whereas MNB and MFB can be positive or negative. Positive values of MNB and MFB indicate overpredictions of the model and negative values indicate under-predictions of the model against observation. When the threshold gets very small the MNB increases 
significantly, thus, MFB is used instead to equally weight positive and negative bias. The statistics described above were calculated using hourly ozone measurements across the entire domain.

\subsubsection{Ozone Performance Evalaution}

The statistics for ozone performance for the duration of the episode across Canada and the Unites States are presented in Table 4.3. The cut-point (threshold) of $40 \mathrm{ppb}$ is normally used in the calculation of performance statistics, i.e., observations below 40 $\mathrm{ppb}$ are disregarded, as air quality models generally have poor predictive skills for nighttime (low) ozone concentrations. Additionally, higher concentrations are usually considered of higher importance. Here, $60 \mathrm{ppb}$ was also used for evaluation of prediction skills of CMAQ at high ozone concentrations as it provides as threshold closer to regulatory values. Model performance statistics are given for original CMAQ model (including aerosols and cloud formation processes) as well as the gasphase CMAQ used in backward sensitivity analysis. Performance statistics demonstrate an overall overestimation (positive MNB for threshold of $40 \mathrm{ppb}$ ) of daytime ozone concentrations and underestimation of high ozone concentrations (negative MNB for threshold of 60 ). The MNB is normalized by paired observation value whereas the MFB is normalized by an average value of observation and prediction, thus MFB can be slightly different in sign and/or magnitude than MNB. The overall MNB and MNE for the US and Canada are in an acceptable range suggested by EPA as $\pm 15 \%$ for MNB and $35 \%$ for MNE [US EPA, 1991 ]. 


\begin{tabular}{lcccc}
\hline \multicolumn{3}{r}{ Table 4.3 Ozone performance statistics for the duration of episode in Canada and the US } \\
\multicolumn{5}{c}{ CANADA } \\
\hline
\end{tabular}

Summer 2007 time series of simulated vs. observed maximum $8 \mathrm{~h}$-average ozone concentrations were calculated for three sites in the US near the border, where Canadian influences is high (Figure 4.5). Unlike the calculation of statistics, no cutpoint was used in construction of these time series plots. The maximum $8 \mathrm{~h}$-average ozone was predicted using US EPA CMAQ model, which also includes aerosols and cloud. The CMAQ model that only simulates gas-phase chemistry has a similar performance. The observation site in Michigan is selected as it is downwind of industrial Southern Ontario, and the observation site in New York is chosen as it is highly impacted by pollution transport from Canada in west-to-east direction. Summer time series of simulated vs. observed maximum 8h-average ozone concentrations for three Canadian sites impacted by cross-border pollution from the US, Ottawa, Barrie, and Winsor were also quantified (Figure 4.6). Model predicted maximum 8 h-average ozone concentrations show satisfactory consistency with observation data in these sites particularly in New York, Indiana, and Barrie. 
Indiana, US (county code=0004, $+41.09,-85.10)$

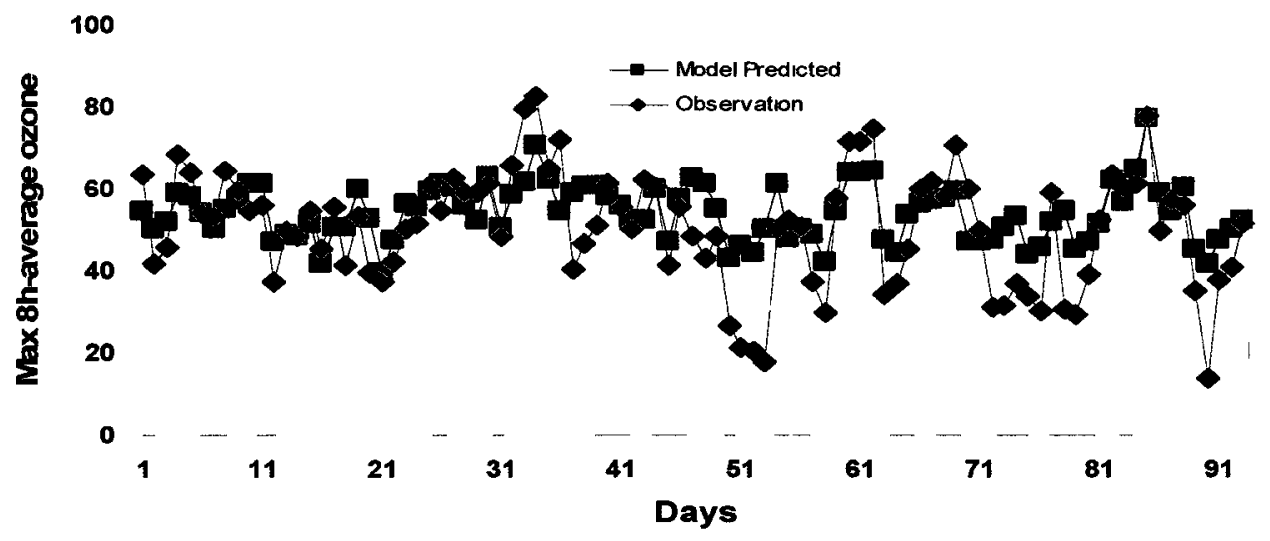

New York, US (country code $=005,+41.8,-73.3$ )
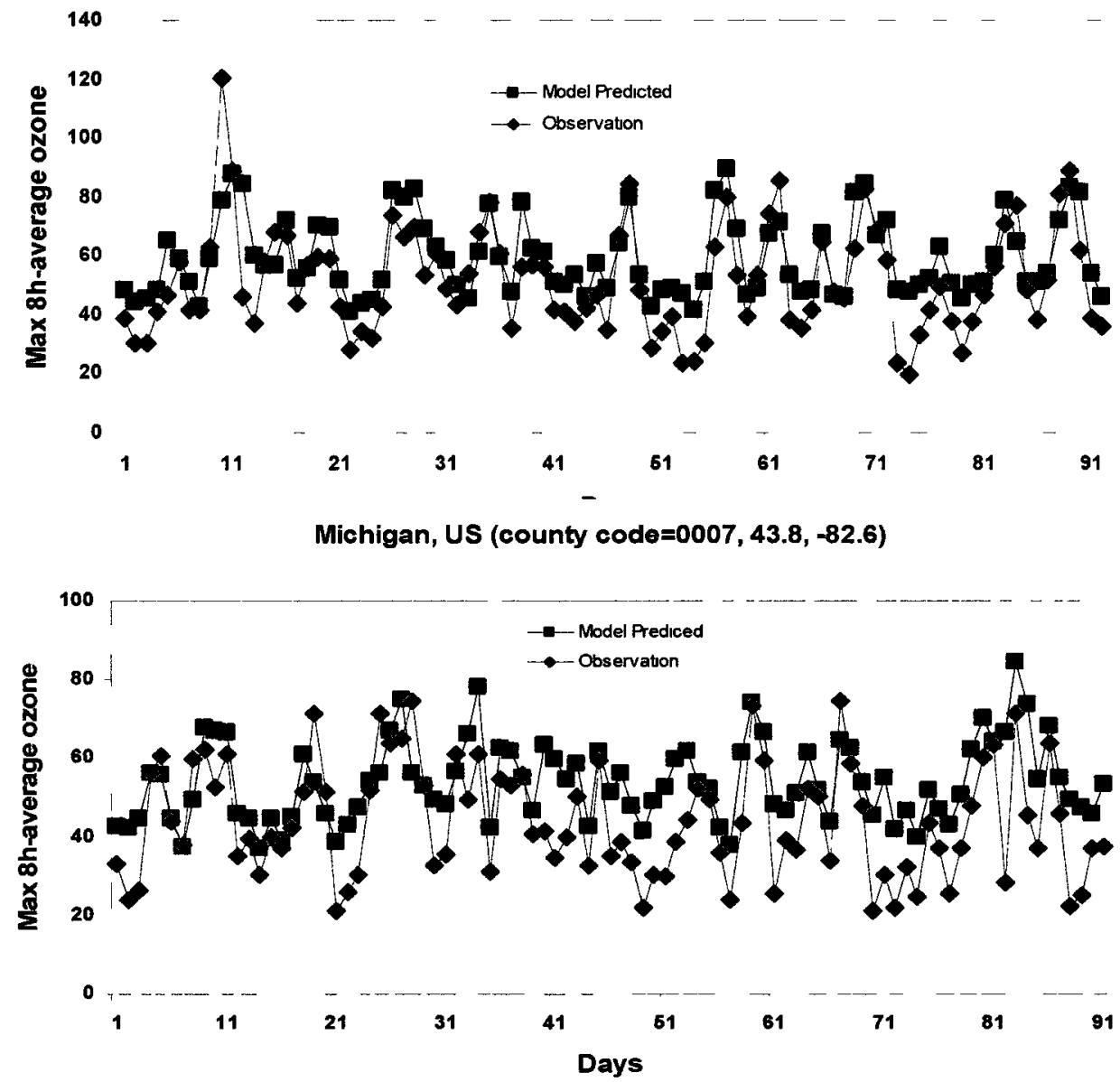

Figure 4.5 Time series of observed (red line) and simulated (blue) maximum 8 h-average ozone at three observation sites in the US 
Winsor, Ontario, Canada, (site ID=060204, 42.3, -83.04)

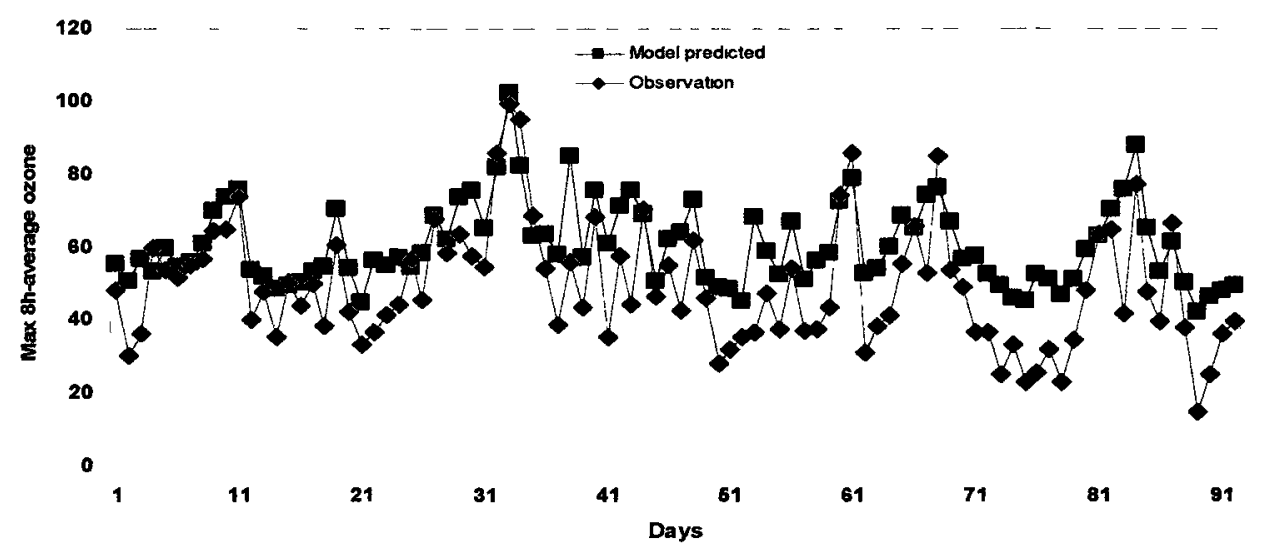

Ottawa, Ontario, Canada (site ID $=052401,+46.62,-76.01$ )

80

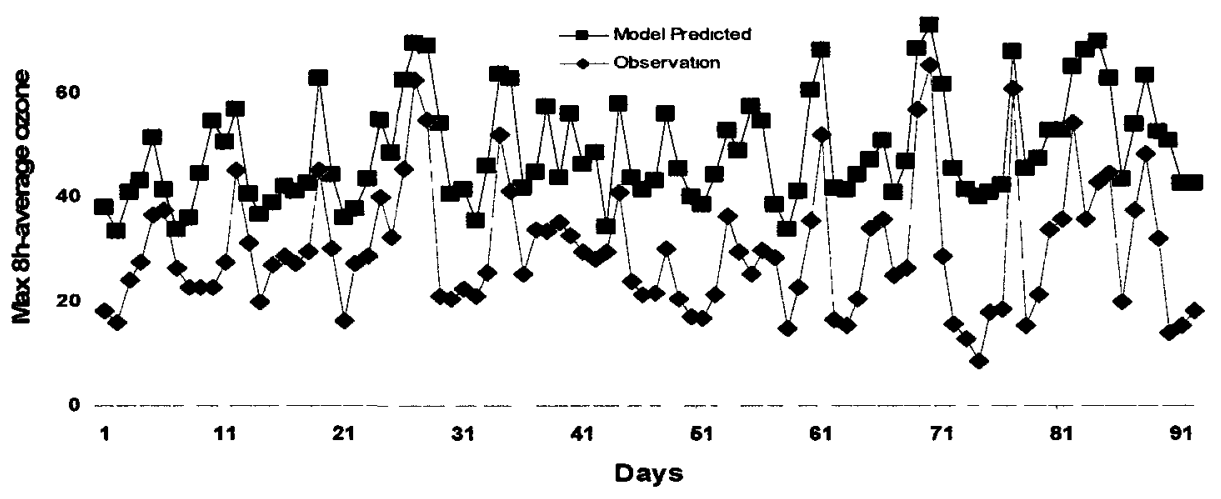

Barrie, Ontario, Canada (site ID $=065101,+44.05,-79.49$ )

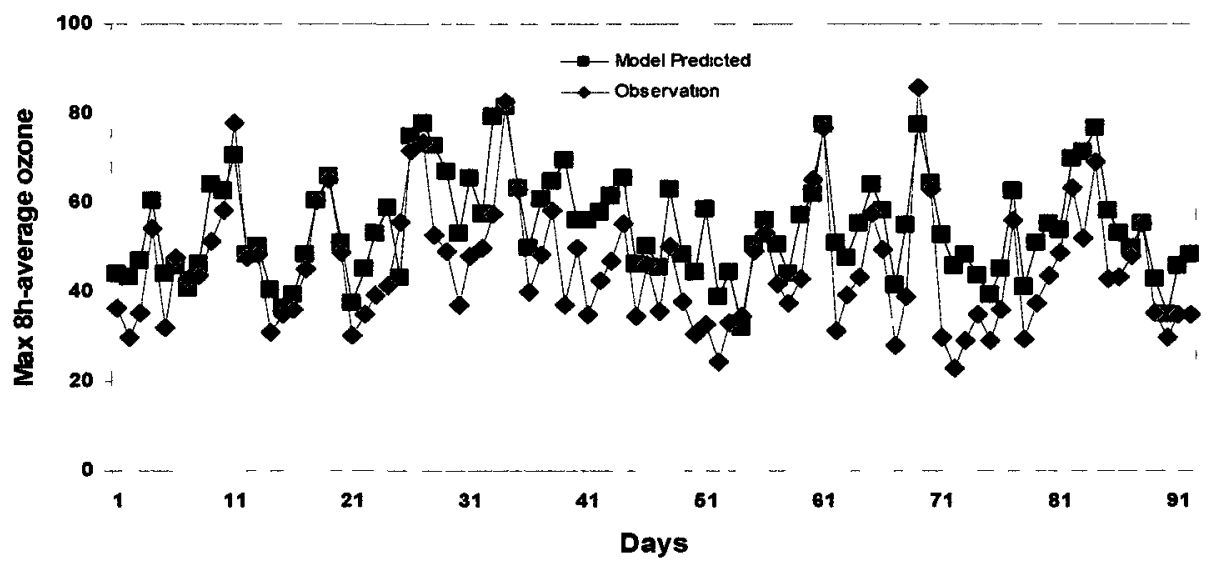

Figure 4.6 Time series of observed (red) and simulated (blue) maximum 8h-average ozone at three observation sites in Canada. 


\subsection{Methodology}

\subsubsection{Emission Zero-Out}

The aim of this method is to determine how ozone concentration in the receptor areas of each country is impacted by foreign emissions. This goal is achieved by following the approach of Wang et al. (2009), i.e. removing all anthropogenic emissions from each country and predicting the resulting ozone concentration in the receptor areas of the other. Doing so, enables calculation of the impact of cross-border transport of emissions from upwind sources as well as domestic emission sources on the surface ozone air quality in each country. Here, the impact on receptor areas are measured through two regulatory metrics: maximum $8 \mathrm{~h}$-average and daily average ozone, which are both calculated for grid cells over receptor areas of each country and for the duration of the Summer of 2007.

The maximum 8 h-average ozone metric is constructed using a moving average method in each grid cell. To implement the zero-out analyses, four simulation scenarios are carried out: the base case, Canadian emissions zero-out, American emissions zero-out, and North American emissions zero-out scenarios. The zero-out scenario in each country is defined as an elimination of the anthropogenic emissions in that country. The zero-out scenario in each country results in variations in the ozone metrics in the country and the neighboring country. The resulting reduction or increase in ozone metrics in each country is a measure of the total contribution of foreign (cross-border) emissions. 
The zero-out method quantifies the cross-border transport from this angle: what would be the air quality in each country in the absence of anthropogenic emissions from the other. The emission zero-out method is a source-oriented method as it perturbs the emissions at sources and quantifies the impacts in the receptor areas. This method is a true measure of contributions and does not rely on local sensitivities in the prediction. The method is straightforward and easy to implement. In addition, the zero-out method, like all source-based methods, provides information about the spatial variation of air quality improvement or impairment in the receptor areas of each country. Applying the zero-out method enables identification of the areas that are significantly influenced by cross-border emission flux in each country. However, the method, like all other source-based methods, lacks information about contribution of individual sources. Furthermore, as discussed in Chapter 3 the method lacks ability to calculate the local sensitivities of the ozone metrics with respect to the marginal changes in emissions. The zero-out method is not a practically relevant method as it only predicts the background concentrations that would exist if the anthropogenic emissions in neighboring country were zero. The air quality policy makers are tasked to develop practical reduction strategies, and therefore, it is more beneficial to quantify the impact of marginal changes in foreign and domestic emissions. Therefore, the response of ozone concentrations to a marginal reduction in foreign emissions is also quantified. In this approach the marginal sensitivity to emission changes is calculated using a $10 \%$ perturbation in emissions which results in sensitivity coefficients that are consistent with local sensitivities (BF sensitivities) [Hakami et al, 2003]. We attempt to examine whether the changes in ozone concentrations resulting from $10 \%$ reduction in emissions can be linearly extrapolated from the ozone response to a $100 \%$ reduction or vice versa. 


\subsubsection{Adjoint Sensitivity Analysis}

Developing regional regulations and effective control strategies that apply across countries or provinces requires knowledge about individual sources and their contribution to air pollution of the region. Adjoint (backward) sensitivity analysis results in the sensitivities of (ozone) concentration-based metrics with respect to the individual emission sources across the domain. In this work, adjoint sensitivity analysis is used to establish source-receptor matrices for the surface ozone concentrations in North America. As discussed in Chapter 3, the integration of the adjoint equation results in the adjoint variables which contain information about the sensitivity of the metrics with respect to ozone concentrations at various locations and times. The adjoint variable can then be used to calculate the sensitivities (gradients) of the metric with respect to emissions at each grid cell of the domain (or any other parameters of the model). The gradients of the cost function with respect to emissions can be calculated from the adjoint variables during backward integrations. The calculation of the gradient of the cost function $J$ with respect to the model input vector $I$ (e.g. emissions) employing the adjoint variable is as follows. The concentration vector $C$ is a function of model input vector $I$ :

$$
C=G(I)
$$

where $G$ is a nonlinear function due to the nonlinearity in gas-phase chemistry. A perturbation in each input (e.g., $\delta I)$ results in a perturbation in output $(\delta C)$ as shown in $\mathrm{Eq}(4-2)$ [Hakami et al , 2007]:

$\delta C=G^{\prime}(\delta I)$

where $G$ is a Jacobian matrix, gradient of $G$ with respect to the input vector $I$. The $G^{\prime}$ is also referred to as the tangent linear operator, linear version of $G$, which results in 
the sensitivities of model output $C$ with respect to the model input $I$ [Wang et al, 2001]:

$$
G^{\prime}=\left\{\begin{array}{ccccc}
\frac{\partial G_{11}}{\partial i_{1}} & \frac{\partial G_{12}}{\partial i_{2}} & \ldots & \ldots & \frac{\partial G_{1 n}}{\partial l_{n}} \\
\ldots & & & & \ldots \\
\ldots & & & & \ldots \\
\ldots & & & & \ldots \\
\frac{\partial G_{m 1}}{\partial l_{1}} & \frac{\partial G_{m 2}}{\partial i_{2}} & \ldots & \ldots & \frac{\partial G_{m n}}{\partial i_{n}}
\end{array}\right\}
$$

Now, if $J$ is defined as a scalar cost function of model output $C$, the perturbation in $J$ is calculated from Eq (4-4) [Wang et al, 2001]:

$$
\delta J=\left\langle\nabla_{C} J, \delta C\right\rangle
$$

where $\langle. .$.$\rangle is a inner product of \nabla_{C} J$ and $\delta C$. Substituting Eq (4-2) in Eq (4-4) results in the following equation [Wang et al, 2001]:

$$
\delta J=\left\langle\nabla_{C} J, G^{\prime} \delta I\right\rangle
$$

Applying duality principle to the inner product $\left(\langle C, L I\rangle=\left\langle L^{*} C, I\right\rangle\right.$, where $L^{*}$ is transpose of $L$, results in $\mathrm{Eq}(4-6)$ [Wang et al , 2001]:

$$
\delta I=\left\langle G^{* *} \nabla_{C} J, \delta I\right\rangle
$$

The gradient of the cost function with respect to the model input is calculated from Eq (4-7) as follows [Wang et al, 2001]:

$$
\nabla_{I} J=G^{* *} \nabla_{C} J
$$

where $G^{* *}$ is transpose of Jacobian matrix, and $\nabla_{I} J$ is gradient of cost function $J$ (e.g. average ozone) with respect to the input parameters vector $I$ (e.g., emission). A schematic of the relationship among model input vector $I$, model output or state $C$, Jacobian matrix, and adjoint matrix is shown in Figure 4.7. 


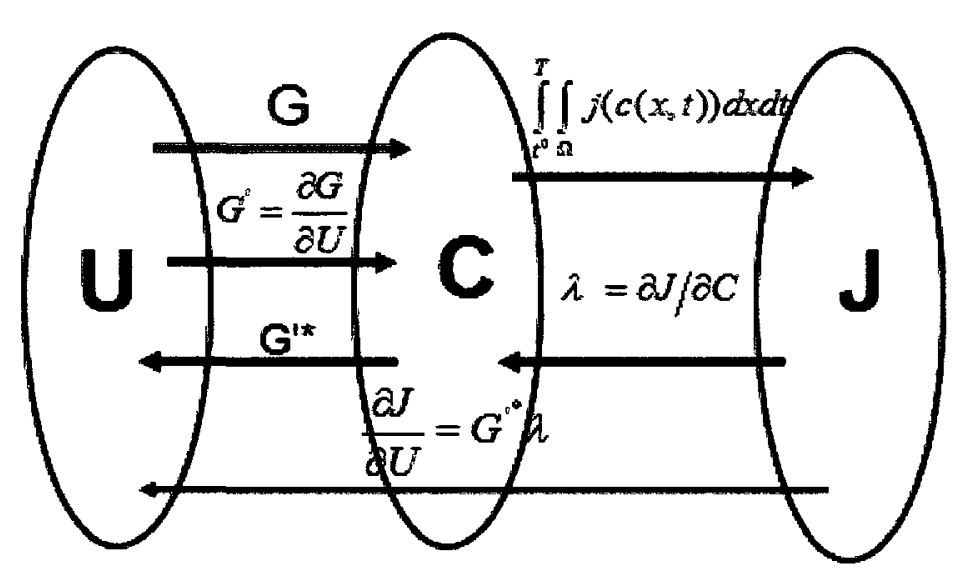

Figure 4.7 Schematic of Jacobian and adjoint matrices and their relationship [adopted from Wang et al., 2001]

As discussed, the adjoint method results in the local gradient (sensitivities) of the cost functions with respect to anthropogenic emissions in each grid cell across the domain. The semi-normalized sensitivities of the metric with respect to emission sources at each grid cell are generated using Eq (4-8) [Hakamı et al, 2006].

$$
\frac{\partial J}{\partial \varepsilon}=\iint_{t} E(w, t) \lambda(w, t) d w d t
$$

where $w$ is a specific spatial coordinate and $\varepsilon$ is an emission scaling factor and

$$
\frac{\partial J}{\partial \varepsilon}=\frac{\partial J}{\partial E / E}
$$

In this study, the adjoint method calculates the local gradient of daily average ozone with respect to all emission sources across the domain. For example, a sensitivity $(0.01 \mathrm{ppb})$ of average ozone (in the receptor area of Canada) to $\mathrm{NO}_{\mathrm{x}}$ emissions at a specific source (in the US) indicates that a $100 \%$ reduction in the emissions from that source will reduce the average ozone in the Canadian receptor area by $0.01 \mathrm{ppb}$. 
Backward simulation is carried out using the CMAQ-ADJ (gas-phase, Hakami et al., 2007) model in parallel mode. Unlike the forward simulation, the backward simulation is initiated at the final time step and progresses backward in time. The adjoint variable should be initialized to zero and is updated at each time step by local gradient of cost function with respect to concentration (forcing term). In any backward simulation of nonlinear processes (e.g. gas-phase chemistry) checkpoints are required to resolve the Jacobian matrix. Checkpoints are concentration files, which are stored at each synchronization time steps during the forward simulation. During the backward simulation, the checkpoints are read at the beginning of each synchronization time step [Hakami et al, 2007].

The adjoint method is a receptor-oriented approach that perturbs the receptor-based cost function and results in its sensitivities with respect to individual inputs, e.g. emissions. By doing so, the major contributing sources to the cost function are identified in a single simulation. The adjoint method is well suited for policy application as it focuses on the receptors and identifies high polluter sources that require ceiling and emission control. However, the method is not able to calculate the impact of large emission reductions such as zero-out. That is, the total contribution of a source region (all emission sources in a country) to a particular receptor is not quantified using this method. Furthermore, the adjoint method lacks details about each individual receptor as quantification of sensitivities of each receptor with respect to the emission sources requires distinct simulation, and, therefore, is computationally expensive and difficult to implement. 


\subsubsection{Flux Bookkeeping}

In this method, the budget of pollution export/import across the border is followed during the simulation episode (Summer 2007). Flux bookkeeping is a true measure of mass of individual pollutant $\left(\mathrm{NO}_{\mathrm{x}}, \mathrm{VOCs}\right.$, ozone) exported/imported to/from border grid cells. For implementation of this method, wind field direction and magnitude in each border grid and clear definition of the border (South-North and East-West) are required (Figure 4.8).

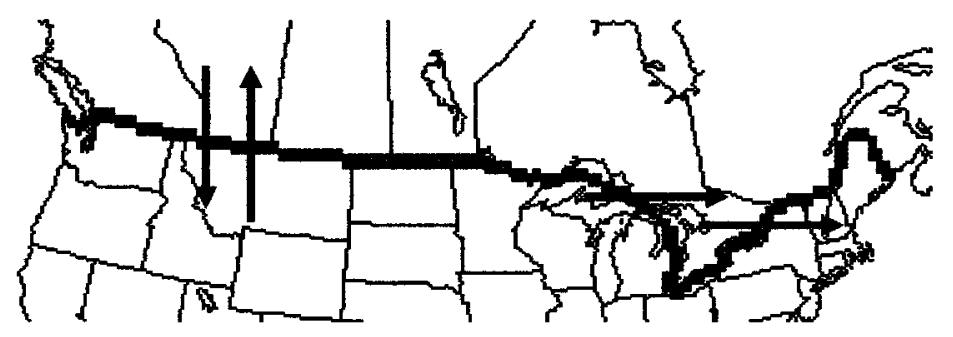

Figure 4.8 Latitudinal and longitudinal transport of pollution across the Canada-US border.

The Canada-US border is laid on west-east direction in most of the domain while in southern and southeastern Ontario the border has south-north sections (Figure 4.8). In this method the pollution export/import in latitudinal (y) (crossing the latitudes) and longitudinal $(x)$ (crossing longitudes) direction are calculated separately using different components of the wind. The following formulations are used to calculate the export/import of pollution in grid cells containing the border in $x$ or $y$ direction:

Flux in $x$ direction $(k g)=C_{t} \times \rho_{\text {arr }} \times \Delta x \times 2(Z F-Z H) \times U_{x} \times \frac{M_{\imath}}{M_{a r}}$

Flux in y direction $(\mathrm{kg})=C_{t} \times \rho_{\text {arr }} \times \Delta y \times 2(Z F-Z H) \times U_{y} \times \frac{M_{i}}{M_{\text {atr }}}$

where, $C_{I}$ and $M_{l}$ are the mixing ratio (ppm) and the molecular weight (gr/mole) of the pollutant $\imath$ respectively. The $\rho_{\text {arr }}$ is the altitude dependent density of air $\left(\mathrm{kg} / \mathrm{m}^{3}\right), U_{x}$ is the longitudinal and $U_{y}$ is the latitudinal $(\mathrm{m} / \mathrm{s})$ component of the wind. $Z F$ is the height of top and $Z H$ is the height of middle of each vertical layer of the model. A 
typical geometry of a border cell is shown in Figure 4.9. For quantification of the overall mass transport of each pollutant in the troposphere, integration over all vertical layers of the model is required.

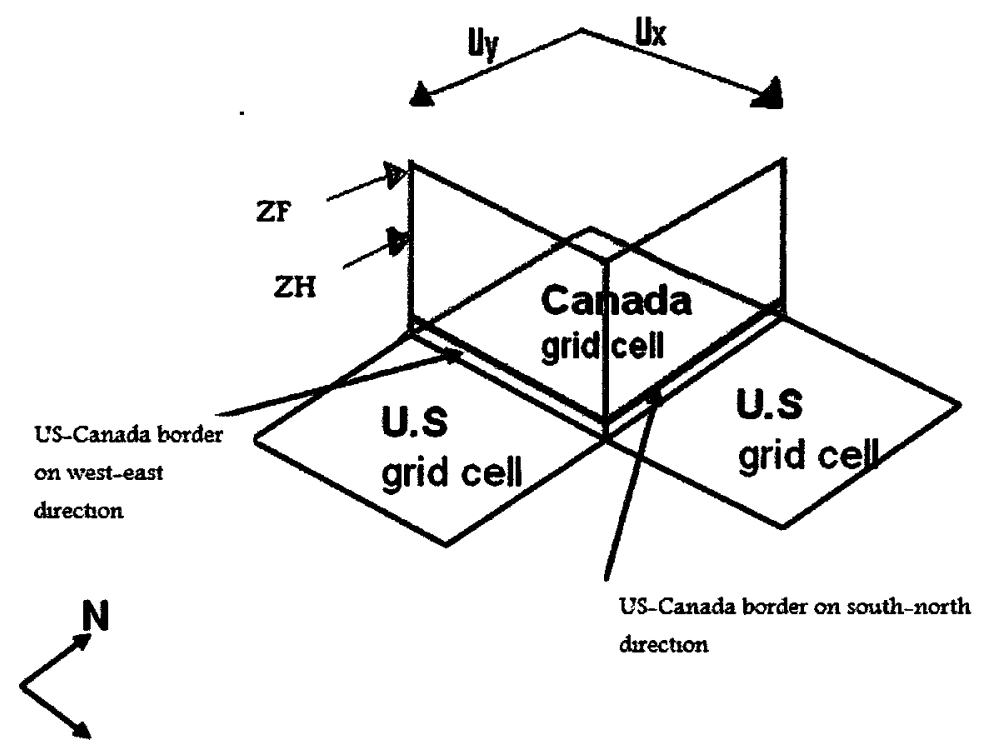

Figure 4.9 The mass export/import calculation schematic in the border area, between Canada (red grid) and US (blue grid) in both south-north and west-east directions

In this method, the variations in cross-border flux of ozone and $\mathrm{NO}_{\mathrm{x}}$ are also quantified in different layers of the atmosphere (boundary layer and free-troposphere). The comparison between transport in the boundary layer and in the free troposphere emphasizes on dependency of long-range transport on wind strength, lifetime of ozone and its precursors and their vertical distribution in the troposphere. Flux bookkeeping is a straightforward and computationally inexpensive method and provides information about the temporal and spatial variability in border export/import of pollution. This method gives a true measure of border-crossing, and, therefore, the main areas of import/export are easily identified by this method. However, unlike other methods used here, the flux bookkeeping is not able to establish source-receptor relationships. 


\section{Chapter 5: Results and Discussion}

\subsection{Overview}

As discussed earlier, the main objective of this study was to quantitatively evaluate the cross-border transport of ozone in North America. We have tried to achieve this objective by employing different methods to answer the overall question of longrange transport from different perspectives. Each method is a distinct approach, and provided a unique perspective in quantification of long-range transport. The zero-out method provided information about total contribution of each country to the surface ozone air quality of the other. The marginal zero-out method calculated the impact of marginal changes in upwind emission sources on surface ozone air quality. The adjoint method quantified the sensitivities of the average ozone in the receptor area of each country with respect to the emission sources in the other. In addition, the flux bookkeeping method enabled budgeting of the mass export/import of ozone and its precursors to/from each country across the border. Applying these methods allows for establishment of source-receptor relationships in US-Canada border area. While the previous chapter described the methods and their perspectives, the emphasis of this chapter is to present and discuss the results obtained from each approach. 


\subsection{Emission Zero-out}

The impact of the transport of emissions from upwind sources across the boundaries on the surface ozone air quality of border area in the each country was quantified by employing the zero-out method. The zero-out method calculated the ozone concentration that would exist in each country in the absence of anthropogenic emissions of the other country. In other words, the result of this method provided an insight into the total contribution of each country to the surface ozone concentration in the other. To quantify the total impact of foreign emissions on surface ozone air quality in the US-Canada border area, two metrics were defined and calculated in the receptor area of each country: daily average ozone, and maximum 8 h-average ozone. Daily average ozone reflects a measure of total transport while maximum $8 \mathrm{~h}$-average ozone has higher regulatory significance (both the US and Canada-wide standards use an 8h-average metric.) As discussed, for each country two scenarios were simulated: the base case scenario and the zero-out scenario. The zero-out simulation scenario in each country (i.e., eliminating the anthropogenic emissions) resulted in variations in the ozone metrics in both the sources and the neighboring countries. Such changes in the ozone metrics due to the removal of foreign anthropogenic emissions, averaged for the duration of the episode, are interpreted as a total contribution of cross-border emissions to the average or maximum $8 \mathrm{~h}$-average ozone in each country.

\subsubsection{Impact of Anthropogenic Emissions ( $\left.\mathrm{NO}_{\mathrm{x}}+\mathrm{VOCs}\right)$ Zero-out on}

\section{Maximum 8h-average Ozone}

The base case simulation scenario resulted in spatial distribution of surface ozone concentration across the domain. The maximum 8h-average ozone in the receptor areas of each country is averaged for the duration of episode (Summer 2007). The 
spatial variation in the maximum $8 \mathrm{~h}$-average ozone in different parts of the receptor area of Canada can be seen in the Figure 5.1(a). Lower than expected concentrations are simulated for western Canada where traditionally higher ozone episodes have occurred (e.g. Fraser Valley). This is most probably due to the lack of representation in western boundary conditions. Figure 5.1(b) shows the maximum 8h-average ozone that would exist in Canada during the summer 2007 in the absence of American anthropogenic emissions. The difference between Figure 5.1(a) and 5.1(b) shows the ozone enhancement in Canada resulting from American (foreign) anthropogenic emissions. Comparison between two spatial plots demonstrates that high ozone concentration in Canada (happening mainly in southern Ontario) is reduced significantly in the absence of American anthropogenic emissions.

a)

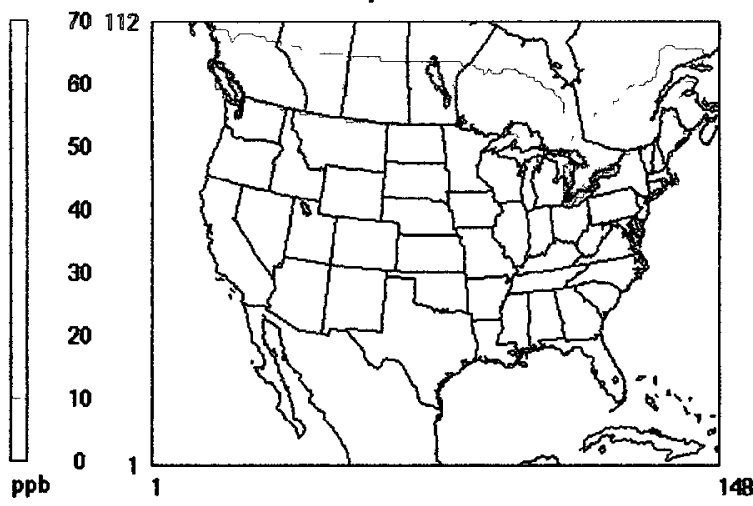

b)

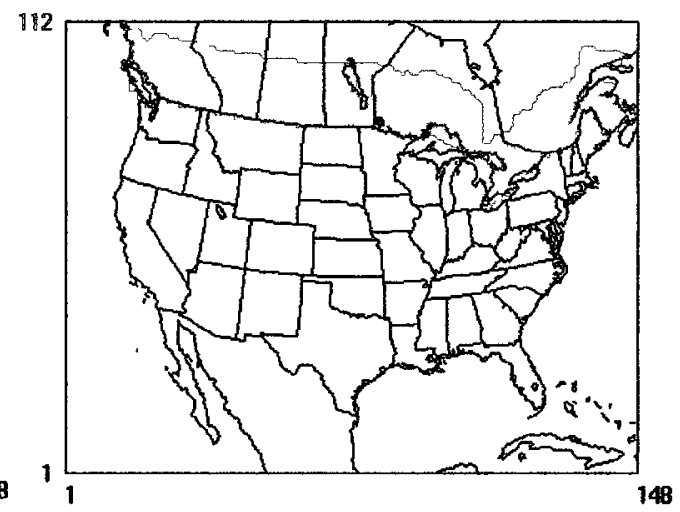

Figure 5.1 Maximum 8h-averge ozone in the receptor area of Canada, a) in base-case scenario b) in the absence of American anthropogenic emissions, averaged for the duration of the episode (90 days of summer)

The reduction in maximum $8 \mathrm{~h}$-average ozone in Canada due to elimination of American emission sources was calculated and shown in Figure 5.2. As seen in the figure the reduction in the maximum 8 h-average ozone achieves its largest value in southern Ontario. Maximum 8h-average ozone in southern Ontario was reduced in the 
absence of American emissions by $20 \mathrm{ppb}$ on average. These values are averaged for 90 days; daily values are substantially higher. This significant reduction of maximum 8h-average ozone shows the sensitivity of this area to American emissions and crossborder transport. This is due to the dominant west-east cross-border transport across the north-south portion of the border by the prevailing westerly winds in midlatitudes. The latitudinal (i.e. south to north) orientation of the US-Canada border in this area, makes southern Ontario particularly sensitive to cross-border pollution import from the US. Therefore, the air quality in this part of Ontario is sensitive to American emissions as it is mainly exposed to emission flux carried from the East.

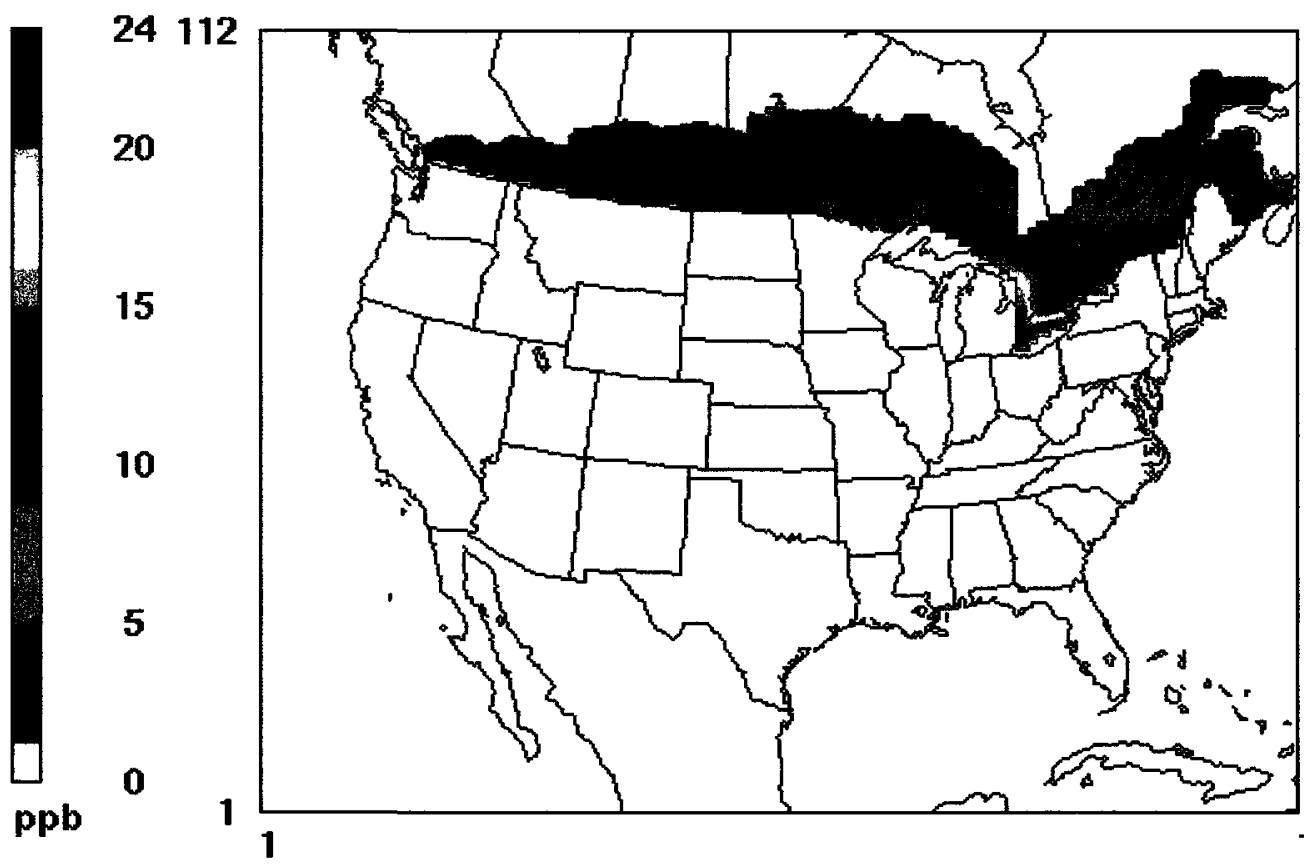

Figure 5.2. Reduction in maximum $8 \mathrm{~h}$-average ozone in the receptor area of Canada due to the removal of American emissions, averaged for the duration of the episode

The maximum $8 \mathrm{~h}$-average ozone concentration in the receptor area of the United States averaged for the duration of the episode (Summer 2007) is shown in Figure 5.3(a). The same is shown in Figure 5.3(b) but in the absence of Canadian emissions. Thus, comparison between plots 5.3(a) and 5.3(b) shows the changes in maximum 8h- 
average ozone in the receptor area of the US in response to Canadian emissions. The maximum 8h-average ozone in the US was not significantly impacted when Canadian anthropogenic emissions were eliminated. It is only a small area in the US (northeast) that shows relatively high sensitivities to Canadian emissions compared to rest of the domain.

a)

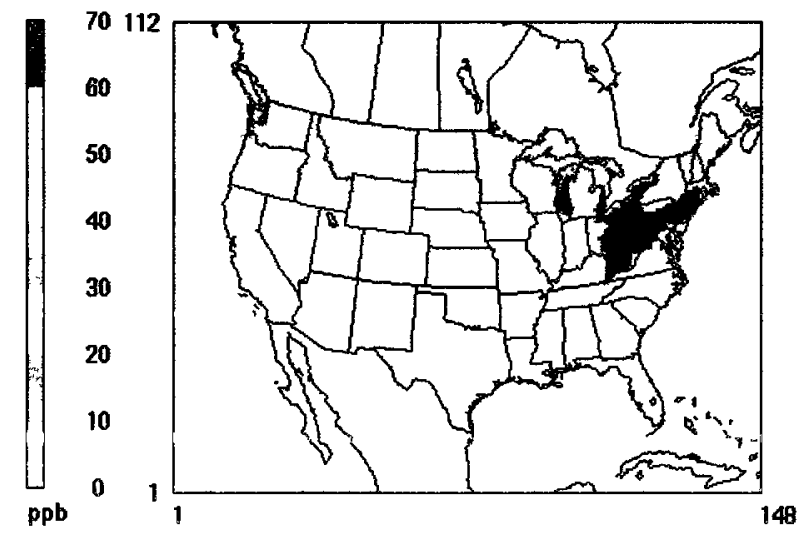

b)

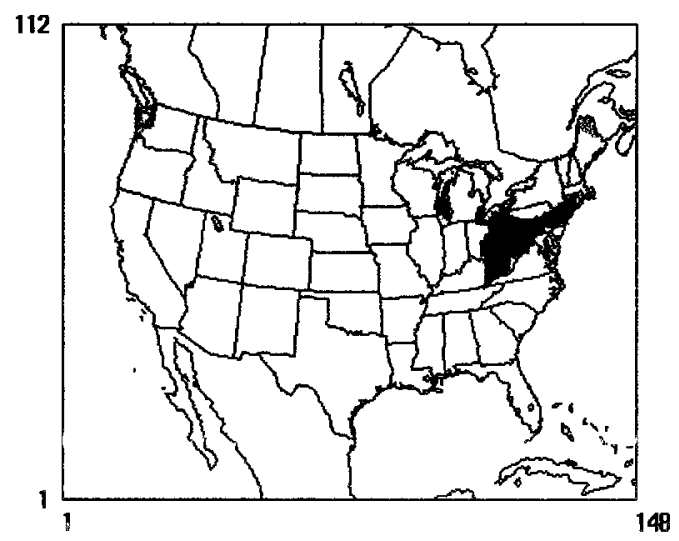

Figure 5.3 Maximum 8h-average ozone in the receptor area of the US a) base-case b) in the absence of Canadian anthropogenic emissions, averaged for the duration of the episode

The reduction in maximum $8 \mathrm{~h}$-average ozone in the US as result of removing Canadian emissions is shown in Figure 5.4. As shown in Figure 5.4, the area close to the US-Canada border (e.g., northeastern, New York) is most sensitive part in the US to Canadian emissions, reduced by $5 \mathrm{ppb}$ on an average. Again, sensitivity to the Canadian emissions in this area is due to the dominance of west-east transport by westerlies in mid-latitudes. A Comparison of Figures 5.2 and 5.4 reveals that during the Summer of 2007, the impact of American emissions on Canadian maximum 8haverage ozone concentration is significantly larger than that of Canadian emissions on the US maximum 8h-average ozone. Southern Ontario and northeast US are areas most affected by cross-border transport in Canada and the US, respectively. 


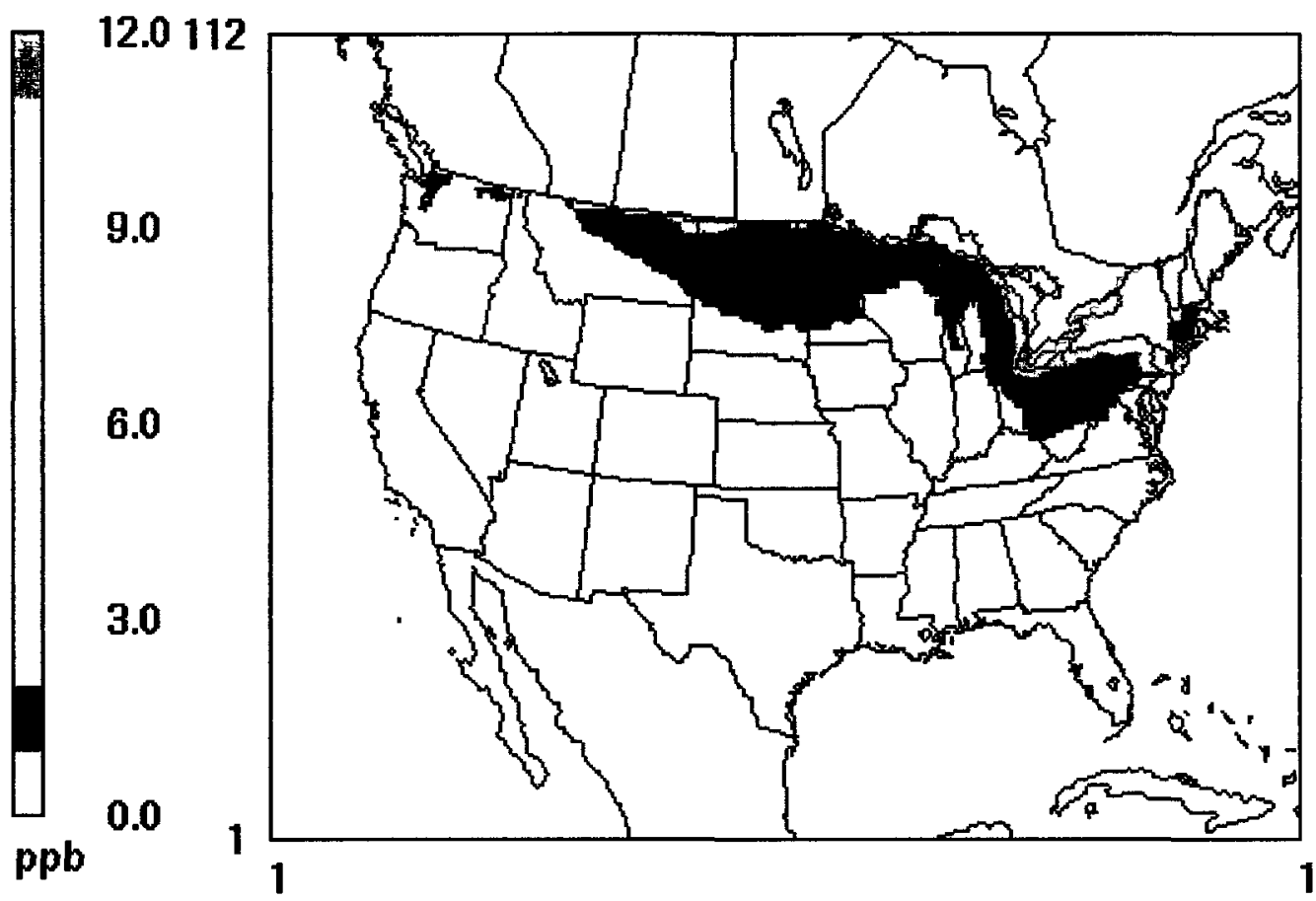

Figure 5.4 Reduction in maximum 8h-average ozone in the US receptor area due to the removal of Canadian emissions, averaged for the duration of the episode

The reductions in maximum 8 h-average ozone due to the absence of domestic emissions in Canada and US are depicted in Figure 5.5(a) and 5.5(b) respectively. Maximum 8h-average surface ozone in the border area of Canada (particularly in southeastern) is reduced more considerably when the American emissions are eliminated rather than domestic emissions. The impact of domestic emission removal in the US is also quantified (Figure 5.5(b)). Eliminating domestic anthropogenic emissions causes significant reduction in maximum $8 \mathrm{~h}$-average ozone in the US; from Eastern US to Minnesota surface ozone is reduced by 20 to $30 \mathrm{ppb}$ as an average. For this period, contributions from domestic emissions far outweigh Canadian contributions. It can be concluded that American emissions were the most important contributor to surface ozone air quality in the US-Canada border area as maximum 
8h-average ozone in both Canada and US border areas were reduced significantly when American emissions were eliminated.

a)

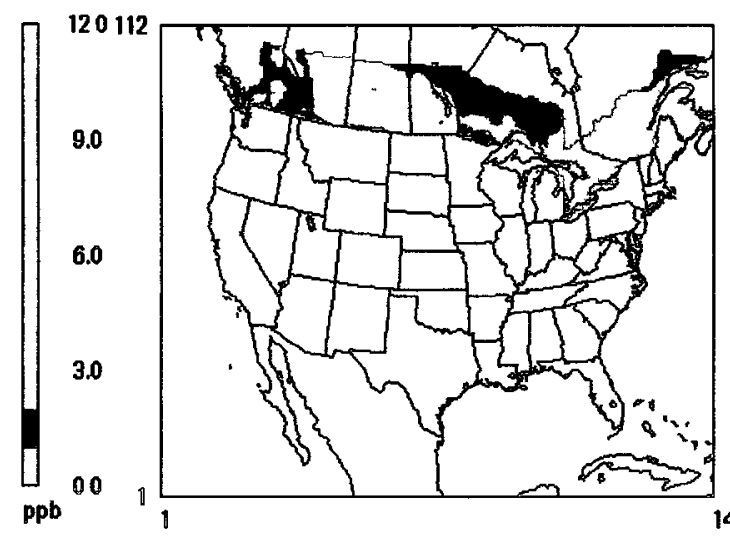

b)

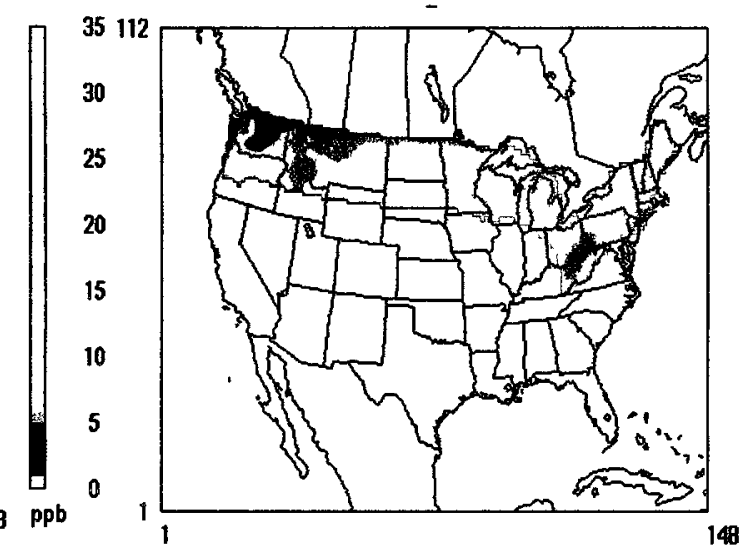

Figure 5.5 Reduction in maximum 8h-average ozone in a)Canada and b)United States, due to the absence of domestic emissions, averaged for the duration of the episode

\subsubsection{Impacts of Elimination of $\mathrm{NO}_{\mathrm{x}}$ Emissions (Foreign vs. Domestic) on Maximum 8h-average Ozone in Each Country}

In the previous section, the impact of removing anthropogenic emissions $\left(\mathrm{NO}_{\mathrm{x}}+\mathrm{VOCs}\right)$ on the maximum $8 \mathrm{~h}$-average ozone in each country was quantified. For further investigation, simulations were repeated for $\mathrm{NO}_{\mathrm{x}}$-only zero-out scenarios, where the impact of elimination of $\mathrm{NO}_{\mathrm{x}}$ emissions of each country on the maximum 8h-average ozone of the other were quantified. Doing so allowed for a quantitative evaluation of the impact of $\mathrm{NO}_{\mathrm{x}}$ emissions vs. total anthropogenic emissions in ozone abatement. This experiment has a practical value as $\mathrm{NO}_{\mathbf{x}}$ emissions have been controlled more drastically in the last couple of decades. Furthermore, $\mathrm{NO}_{\mathbf{x}}$ is the main source of nonlinearity in the response of tropospheric ozone to emission controls, and therefore, gaining insight into sensitivity to $\mathrm{NO}_{\mathrm{x}}$ emissions is 
particularly valuable. $\mathrm{NO}_{\mathrm{x}}$ reduction in the US also results in sizeable surface ozone reductions in Canada, highlighted by significant reductions in the southern Ontario (Figure 5.6).

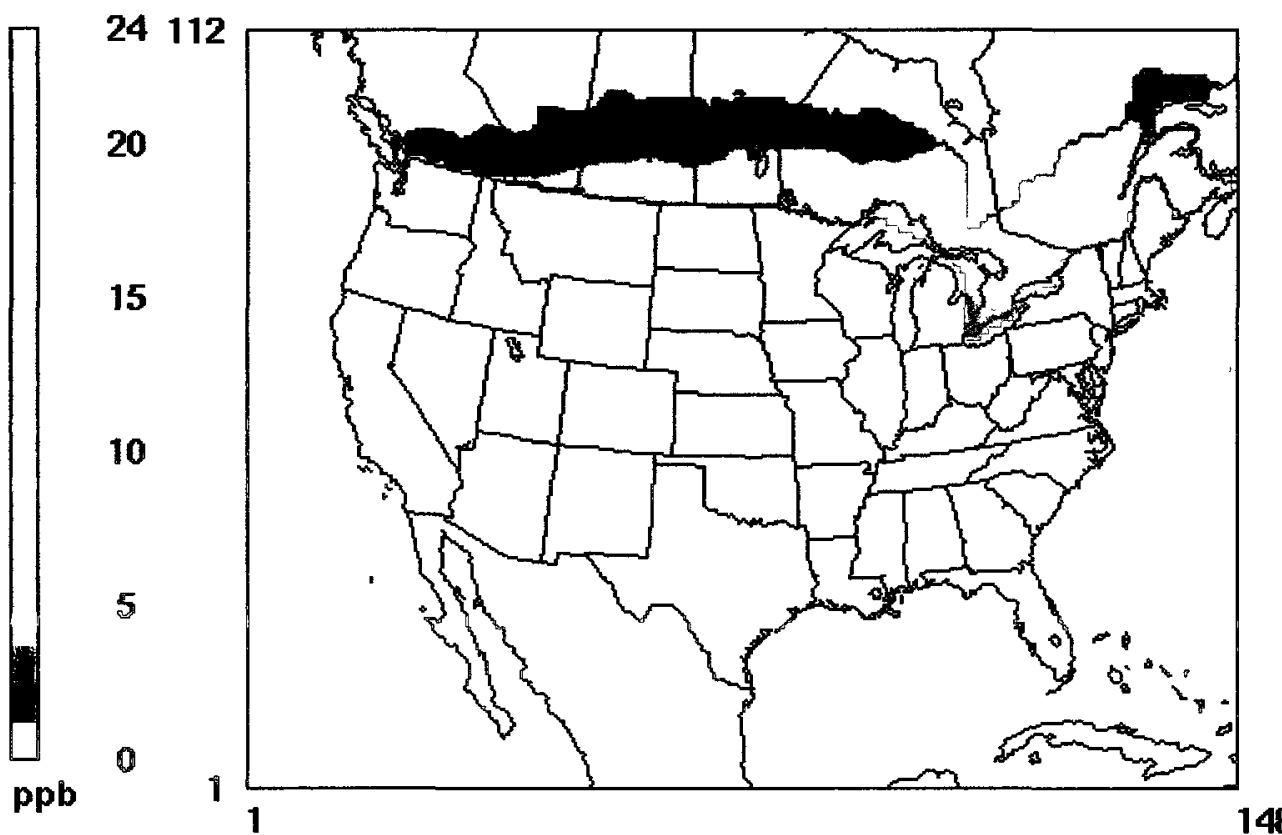

Figure 5.6 Reduction in maximum 8h-average ozone in Canada due to the elimination of American $\mathrm{NO}_{\mathrm{x}}$ emisisons, averaged for the duration of the episode

Similarly, the impact of Canadian $\mathrm{NO}_{\mathrm{x}}$ zero-out on the US border air quality is shown in Figure 5.7. Maximum $8 \mathrm{~h}$-average ozone in the US-Canada border area would be reduced more considerably in the absence of $\mathrm{NO}_{\mathrm{x}}$ emission compared to the anthropogenic $\left(\mathrm{NO}_{\mathbf{x}}+\mathrm{VOCs}\right)$ emissions. Comparison of the $\mathrm{NO}_{\mathrm{x}}$ zero-out scenarios and the anthropogenic emission zero-out scenarios, as expected, demonstrates that $\mathrm{NO}_{\mathrm{x}}$ emissions are to a great degree the most influential parameter affecting surface ozone. Given the nonlinear response of ozone to $\mathrm{NO}_{\mathrm{x}}$ reductions, the larger reduction in ozone concentration by removal of $\mathrm{NO}_{\mathrm{x}}$ emissions is reasonable. As discussed earlier in Chapter 2, the $\mathrm{VOC} / \mathrm{NO}_{\mathrm{x}}$ ratio affects ozone responses to the reduction of $\mathrm{NO}_{\mathrm{x}}$ and $\mathrm{VOC}$ emissions. By removing $\mathrm{NO}_{\mathrm{x}}$ emissions, the $\mathrm{VOC} / \mathrm{NO}_{\mathrm{x}}$ ratio increases 
(i.e. positioned firmly in the $\mathrm{NO}_{\mathrm{x}}$-limited regime) where lowering $\mathrm{NO}_{\mathrm{x}}$ emission results in lower peak of ozone rather than removing $\mathrm{NO}_{\mathrm{x}}$ and VOCs together. This fact can be easily described in ozone isopleths.

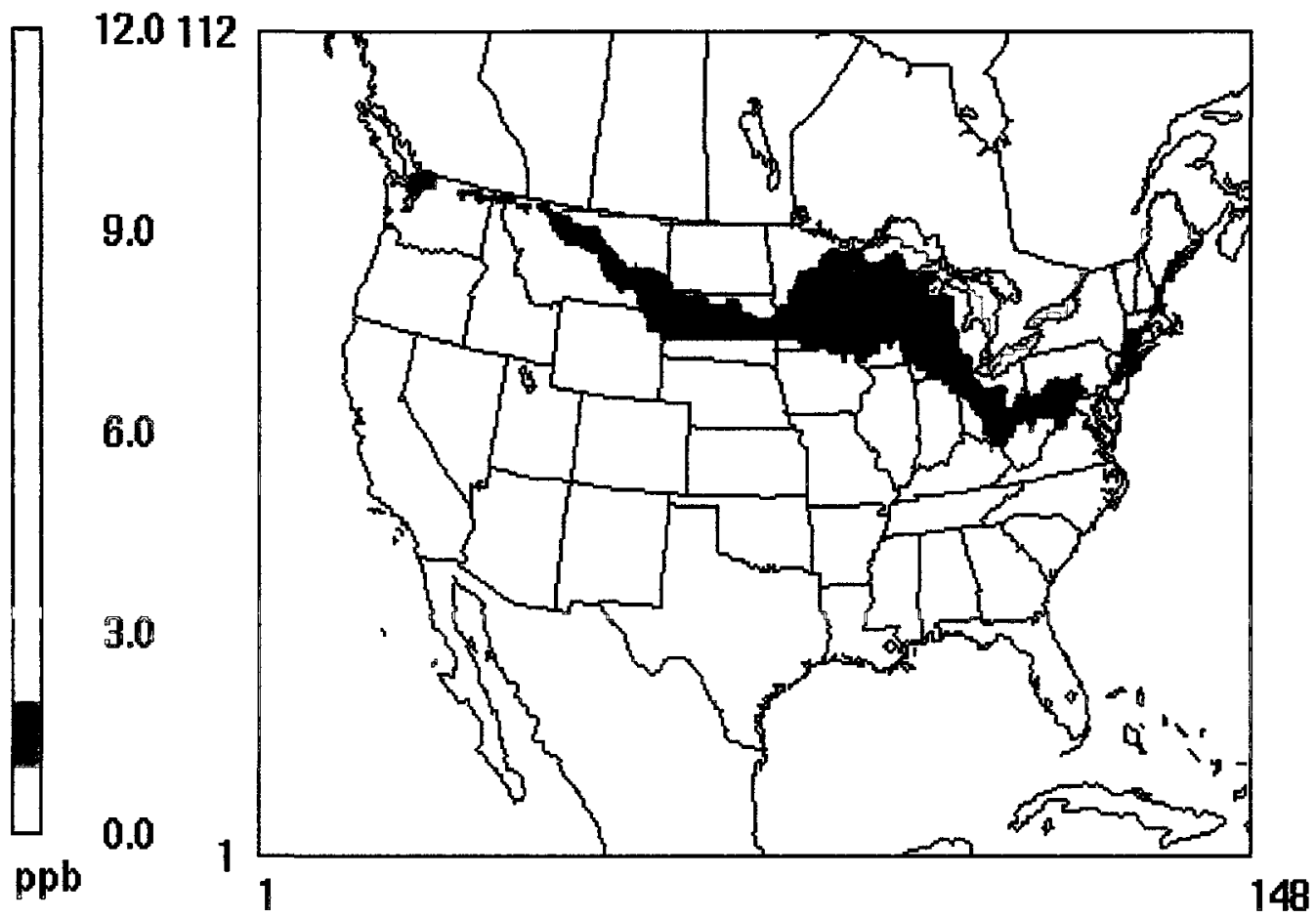

Figure 5.7 Reduction in maximum 8h-average ozone in the US due to removal of Canadian $\mathrm{NO}_{\mathrm{x}}$ emissions, averaged for the duration of the episode

\subsubsection{Policy Relevant Background (PRB) Ozone}

The impact of elimination of North American anthropogenic emissions (US and Canada and Mexico) on maximum $8 \mathrm{~h}$-average ozone in the receptor area of each country was also quantified. The remaining ozone in the absence of all North American emissions is usually referred to as Policy Relevant Background (PRB) ozone [US EPA, 2006]. Figure 5.8(a) shows the maximum 8h-average ozone concentration that would exist in the receptor areas of Canada in the absence of North American emissions. As seen in Figure 5.8(a), maximum 8h-average ozone in most of 
Canada has been reduced to $30-40 \mathrm{ppb}$ by elimination of North American anthropogenic emissions. As discussed earlier, the PRB has contributions from anthropogenic sources outside North America as well as natural sources inside the continent. Accordingly, background ozone concentration is not reduced under current control strategies in North America because it would exist even if there were zero anthropogenic emissions from North America. As seen in Figure 5.8(a) ozone concentrations in particular locations in Canada (e.g., the majority of British Columbia) remain rather high even without North American anthropogenic emissions, reflecting the sizeable impact of either natural emissions or anthropogenic emissions imported across the Pacific Ocean. Similarly, in Figure 5.8(b) the maximum 8haverage ozone in the US in the absence of North American emissions is presented. Again, $\mathrm{PRB}$ ozone shown in Figure $5.8(\mathrm{~b})$ is the minimum ozone concentration that could be achieved through North American emissions control. The PRB in the US ranges from 30 to $40 \mathrm{ppb}$ in most places, which is consistent with previous findings [Fiore et al, 2002, Wang et al, 2009].

a)

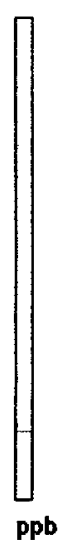

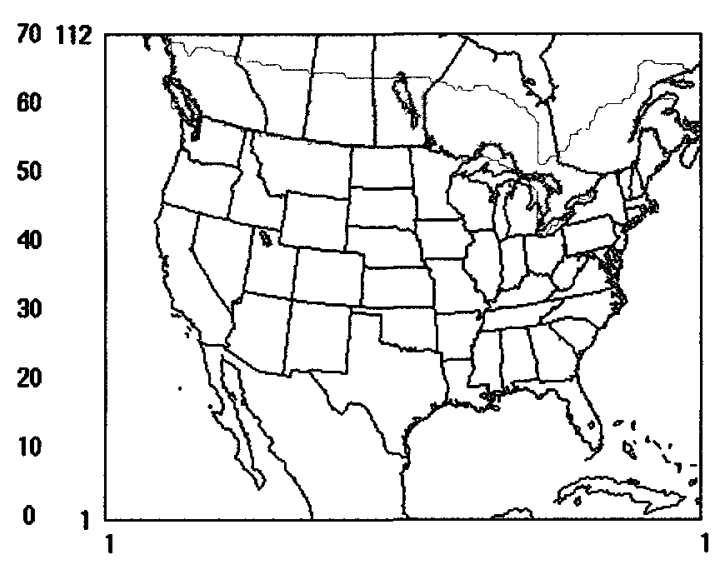

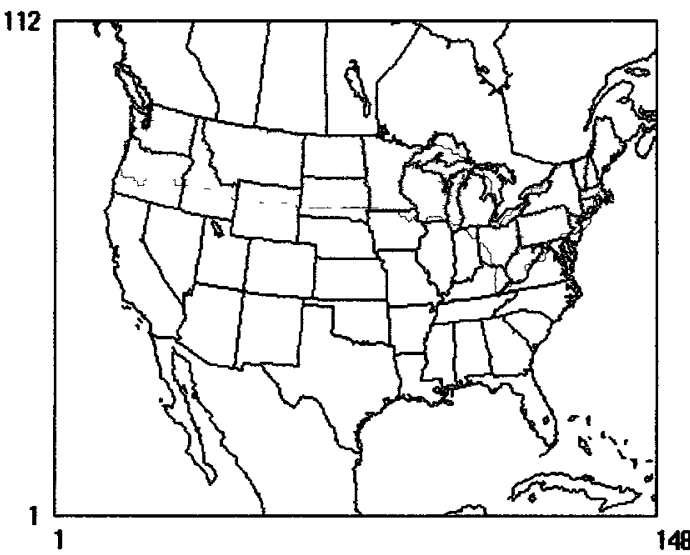

Figure 5.8 Maximum 8h-average ozone in a) Canada b) the United States in the absence of North American anthropogenic emissions (PRB), averaged for the duration of the episode 
The difference between Figure 5.8(a) and base case ozone was quantified and is shown in Figure 5.9(a). As such, Figure 5.9(a) shows the maximum reduction that can be achieved through the control of North American anthropogenic emissions. Likewise, the reduction in maximum 8 h-average ozone in the US due to the elimination of North American emission is shown in Figure 5.9 (b).

a)

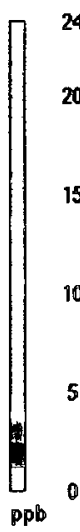

b)

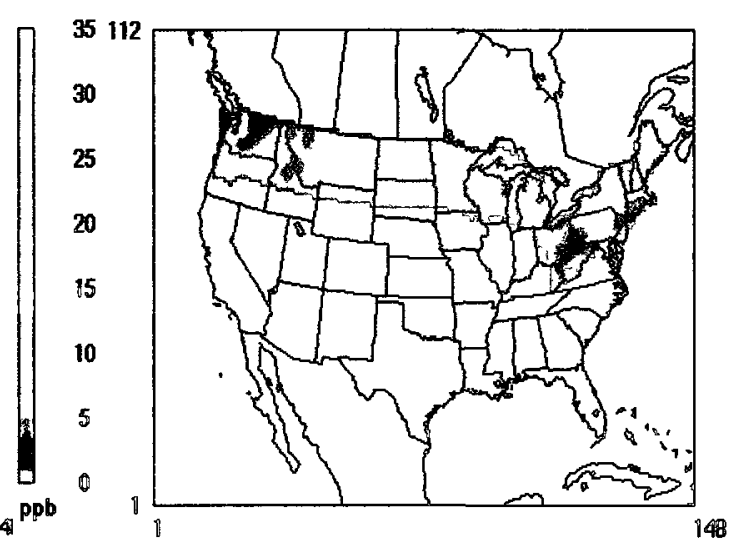

Figure 5.9 Reduction in maximum 8 h-average ozone in a) Canada b) the United States due to elimination of North American anthropogenic emissions, averaged for the duration of the episode

Several points can be made after comparison of Figures 5.9(a) and 5.9 (b). First, the impact of American emissions zero-out on the maximum 8h-average ozone in the US is similar to the impact of removing North American anthropogenic emissions. This point emphasizes the significant contribution of American anthropogenic emissions to domestic surface ozone pollution. Second, elimination of American emissions causes a reduction in the maximum $8 \mathrm{~h}$-average in Canada, almost to the same amount as elimination of North American emissions. This point has considerable importance for policy making, as it highlights the contribution of American emissions to ozone nonattainment in the US-Canada border areas. This point underlines the importance of coordinated emission reduction policies in North America. 


\subsubsection{Cross-Border Impact on Daily Average Ozone}

The second metric used in this study was daily average ozone. The impact of removal of anthropogenic emissions on daily average ozone in each country was calculated and presented in this section. While maximum $8 \mathrm{~h}$-average ozone reflects the impact on daytime high concentration areas, the average ozone metric also takes into account the impact of emissions zero-out scenarios on nighttime concentrations of ozone. The reductions in daily average ozone in the receptor area of Canada and in the receptor area of the US due to the removal of foreign emissions are shown in Figures 5.10 and 5.11 , respectively. The impacts of these scenarios are averaged for the duration of the episode.
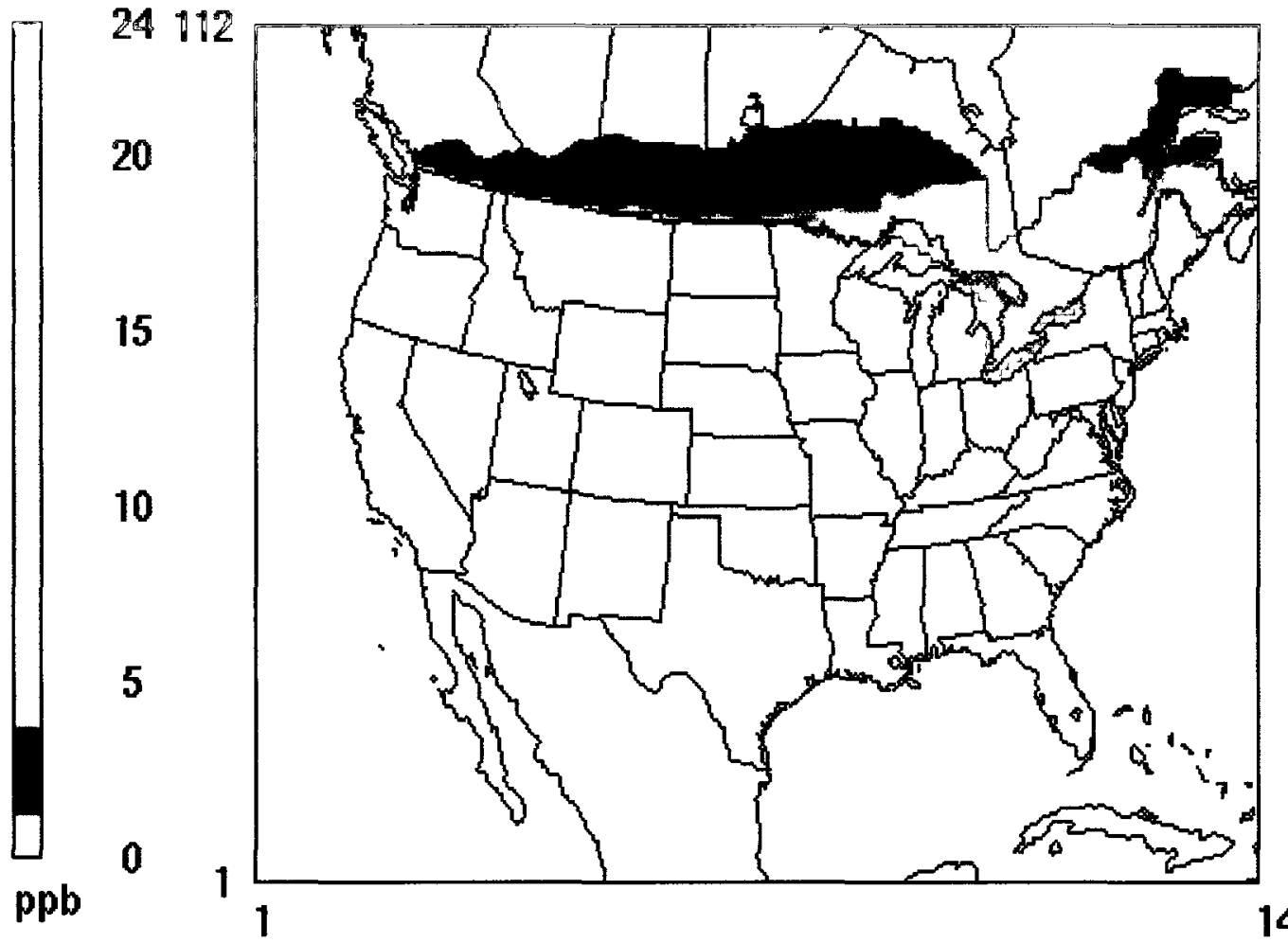

Figure 5.10 Reduction in daily average ozone in the receptor areas of Canada due to the absence of American emissions, averaged for the duration of the episode 
$\square$
12.0112

9.0

6.0

3.0

0.0 1 1

Figure 5.11 Reduction in daily average ozone in receptor areas of the US due to the absence of Canadian emissions, averaged for the duration of the episode

Comparison of zero-out effect between these two metrics demonstrates that the impact of zero-out scenarios is relatively higher on maximum $8 \mathrm{~h}$-average ozone metric compared to average ozone metric. Ozone generation is a daytime process driven by sunlight and generally the 8 hours over which average ozone is maximum occurs during the day. It can be concluded that the effects of the zero-out scenarios are larger during the day and when ozone concentrations are high. As discussed in Chapter 2, this is expected as ozone titrates $\mathrm{NO}_{\mathbf{x}}$ during the night and as such has a negative sensitivity with respect to its emissions. Therefore, removal of $\mathrm{NO}_{\mathrm{x}}$ would increase ozone at night and will partially compensate the overall ozone reduction due to zero-out. 
The impact of elimination of domestic emissions on daily average ozone is shown in Figure 5.12(a) and 5.12(b) for Canada and the United States, respectively. The negative numbers in Figure 5.12 (a) are an indication of an increase in average ozone in the absence of Canadian emissions. The blue points seen in Figure 5.12(a) are examples of such air quality impairment in major Canadian centers, Montreal, Toronto, Winnipeg, Saskatoon, Calgary, Edmonton and Vancouver, where the average ozone in these cities increases as result of removal of Canadian Emissions.

a)

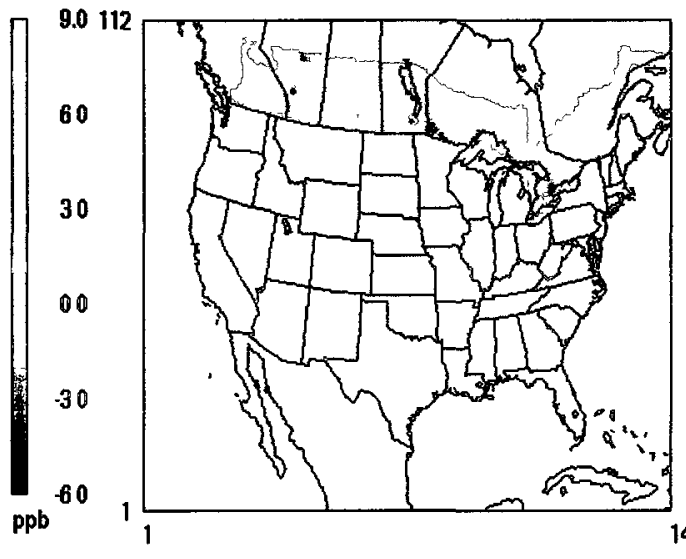

b)

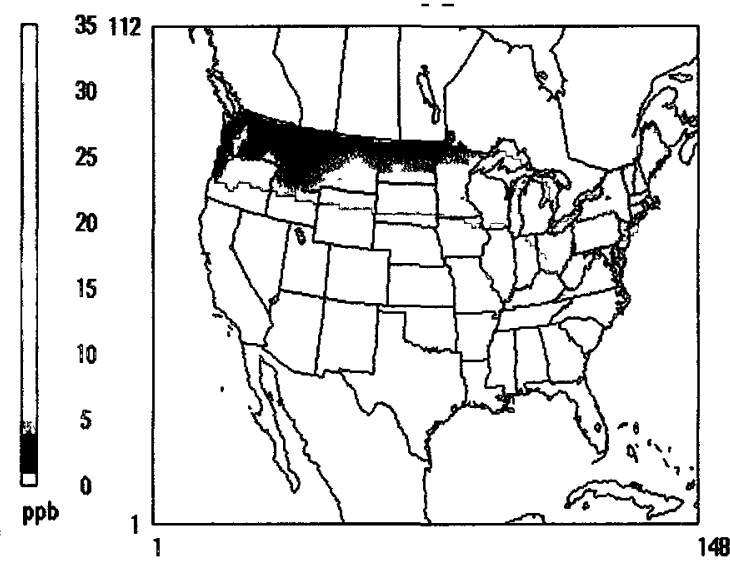

Figure 5.12 Reduction in daily average ozone in a) the receptor area of Canada b) in the receptor area of US due to the elimination of domestic emissions, averaged for the duration of episode

As discussed in Chapter 2, in highly polluted urban areas, $\mathrm{VOC} / \mathrm{NO}_{\mathrm{x}}$ ratio is low due to the large amount of $\mathrm{NO}_{\mathrm{x}}$ emissions from mobile and stationary sources. In these areas, reduction of $\mathrm{NO}_{\mathrm{x}}$ emissions increases the ozone concentration because the relatively high concentration of $\mathrm{NO}_{\mathrm{x}}$ scavenges the radicals that contribute to NO-to$\mathrm{NO}_{2}$ conversion and ozone formation. Therefore, decreasing $\mathrm{NO}_{\mathrm{x}}$, results in more radicals for VOC oxidization and ozone formation in $\mathrm{NO}_{\mathrm{x}}$-inhibited areas [Seinfeld \& Pandis, 1998]. Unlike the daily average ozone, maximum 8 h-average ozone did not increase in those urban centers. It is only upon averaging over 24 hours these enhancements appear. The reason is that $\mathrm{NO}_{\mathrm{x}}$ is titrated by ozone in the absence of 
sunlight during the night when the subsequent photolysis of $\mathrm{NO}_{2}$ to $\mathrm{NO}$ is not happening. Therefore, during the night, sensitivity of ozone with respect to $\mathrm{NO}_{\mathrm{x}}$ is negative and reduction of $\mathrm{NO}_{\mathrm{x}}$ causes ozone enhancement in $\mathrm{NO}_{\mathrm{x}}$-inhibited areas. Accordingly, increase in urban centers appears upon averaging over 24 hours. Figure 5.12(b) shows similar set of results for the US. Again negative numbers indicate the increase in average ozone in the US. However, ozone enhancement is only seen in few urban centers (New York, Seattle and Portland) in the US. As demonstrated in the previous section, ozone concentration is significantly reduced in the US by removing domestic emissions. Therefore, when averaging the changes in ozone concentration over 24 hours and for the duration of summer, the increase in ozone concentration (which mainly occurs at night) in urban centers is faded and cancelled out by large reduction in ozone concentration during the day.

\subsubsection{Discussion of Emissions Zero-Out Results}

Figure 5.13 presents the probability distribution function for ozone concentrations during the Summer of 2007 in the receptor area of Canada. The plot is constructed using hourly concentrations of ozone in all the grid cells in the receptor area of Canada. Shown in the figure are the model predicted surface ozone concentrations in the base case scenario, in the absence of American emissions, in the absence of Canadian emissions, and those in the absence of North American emissions (i.e., PRB). The means and standard deviations for the probability distributions are summarized in Table 5.1. 


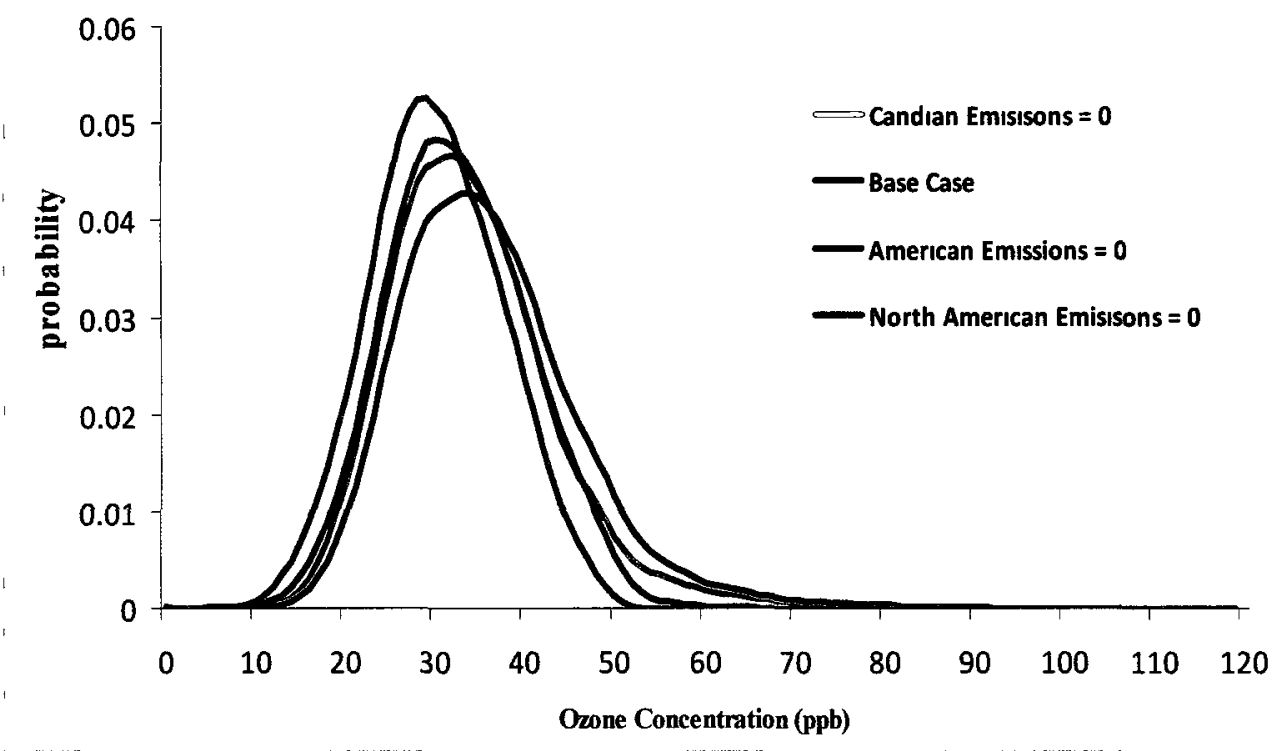

Figure 5.13 Probability distribution of hourly ozone concentration in all grid cells in the receptor area of Canada, when different scenarios were applied: the base case scenario is shown in black, the Canadian emissions zero-out scenario is in red, the American emission zero-out scenario is in blue and the ozone concentration in the absence of North American emissions (PRB) is in green.

Table 5.1 Means and standard deviations for probability distributions in Figure 5.13

\begin{tabular}{l|l|l}
\hline Scenarios & Mean & Standard deviation \\
Base Case & 37 & \pm 10.2 \\
Canadian emission zero-out & 35 & \pm 10 \\
America emissions zero-out & 34 & \pm 8 \\
Policy relevant background ozone & 31 & \pm 7.4 \\
\hline
\end{tabular}

As seen from the distributions or the summary table, elimination of American anthropogenic emissions has as large an impact as domestic emissions in Canada because the ozone probability distributions are rather similar when the US or domestic emissions were eliminated. Figure 5.13 also shows that the US zero-out curve has a greater frequency (larger occurrences) when ozone concentration is below $40 \mathrm{ppb}$. This shows effective ozone reduction in the receptor area of Canada under American emissions removal scenario. This fact is consistent with spatial plots which have been shown earlier for the zero-out effect of Canadian vs. American emissions in the 
receptor area of Canada (Figures 5.5(a) and 5.2). The probability distribution of ozone concentrations in (the receptor area of) the United States is shown in Figure 5.14, and the means and standard deviations for each scenario are also summarized (Table 5.2). Again the plot is constructed using hourly ozone in all grid cells in the receptor area of the US and uses the same color scheme as Figure 5.13.

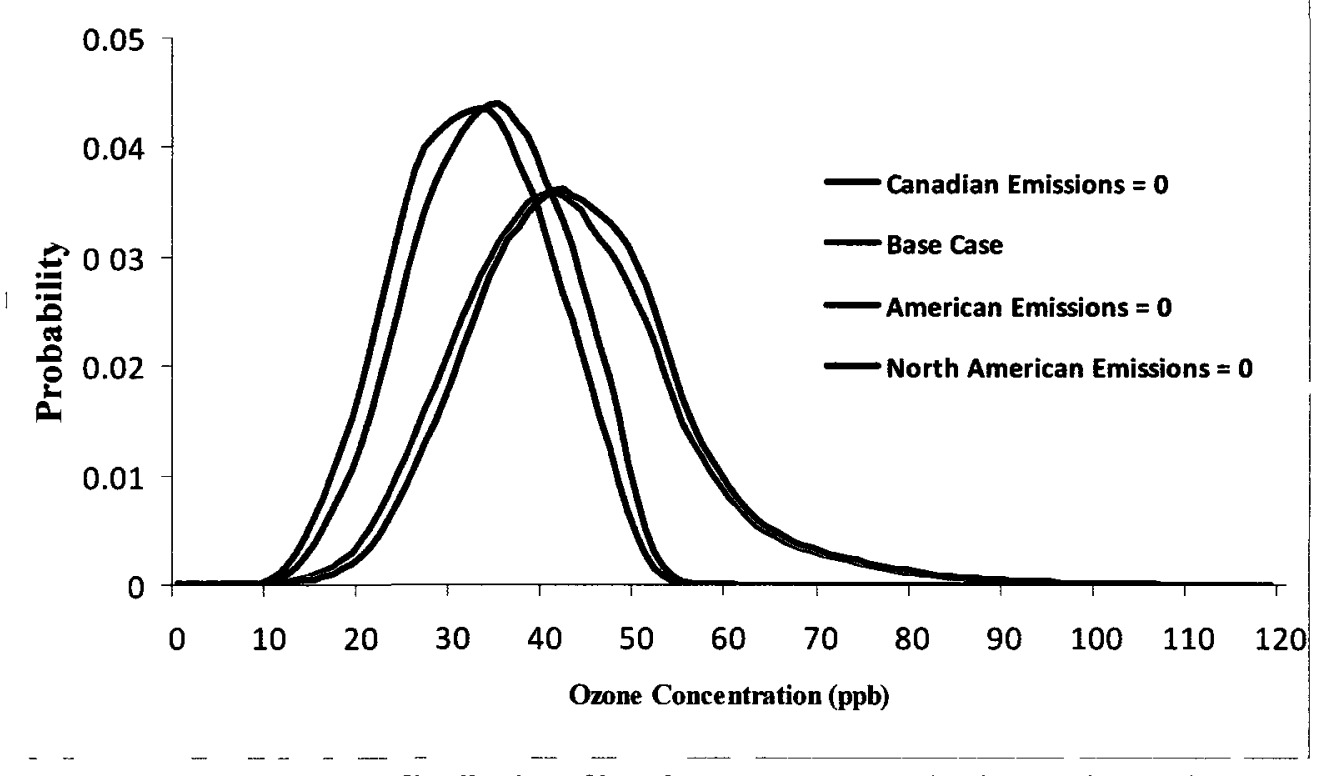

Figure 5.14 Probability distribution of hourly ozone concentration in all grid cells in the receptor area of the US, when different scenarios were applied: the base case scenario is shown in black, the Canada zero-out scenario is in red, the American zero-out scenario is in blue and the policy relevant background ozone is in green.

\begin{tabular}{l|l|l}
\hline \multicolumn{3}{c}{ Table 5.2 Means and standard deviations for probability distributions in figure 5.14 } \\
\hline Scenarios & Mean & Standard deviation \\
Base Case & 44.9 & \pm 15.6 \\
Canadian emission zero-out & 44 & \pm 12 \\
America emissions zero-out & 35 & \pm 8.3 \\
Policy relevant background & 33.2 & \pm 4.2 \\
\hline
\end{tabular}

Figure 5.14 suggests that Canadian zero-out impact is sizeable yet small, or in other words, that removing Canadian emissions does not make a significant change in the surface ozone concentrations in the border area of the US. This could also be inferred 
from the previous spatial plots that show the reduction in maximum $8 \mathrm{~h}$-average ozone in the US resulting from removal of Canadian emissions (Figure 5.4). By contrast, the impact of domestic emissions on the US air quality (of the receptor region) is very substantial. In fact, ozone concentrations in the absence of American emissions (US background) have a similar probability distribution function to that of the policy relevant background ozone (PRB). Again, these observations are consistent with the trends seen in spatial plots (Figures 5.5(b) and 5.9(b)). The cumulative distribution function of the change in ozone concentration in response to the removal of anthropogenic emissions (domestic vs. cross-border) in the Canadian receptor area was also quantified (Figure 5.15). The plot is constructed from changes in concentrations in all grid cells in the receptor area of Canada for each hour of the episode (90 days). Changes (improvements) in ozone concentration (x-axis) are binned in 0.1-ppb increments and the positive numbers are indication of a reduction and negative numbers are indication of an increase in ozone concentration.

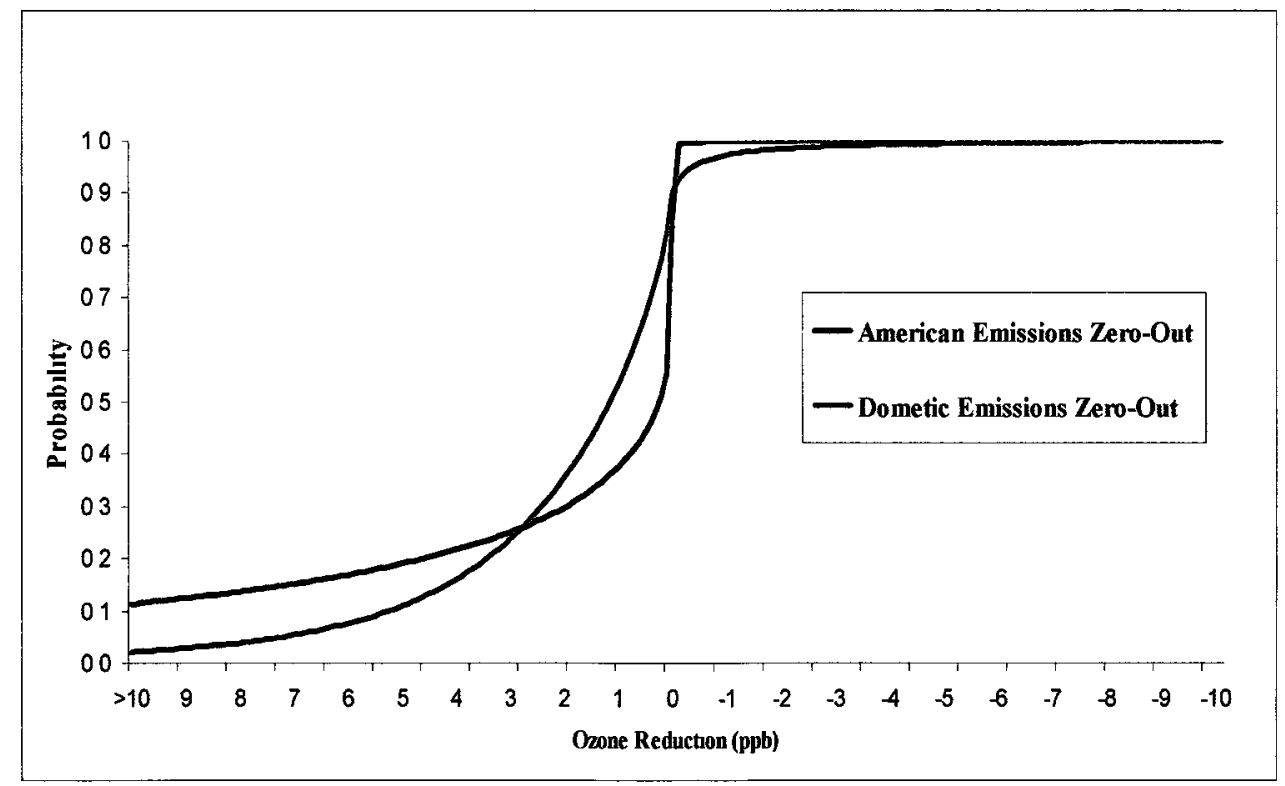

Figure 5.15 Cumulative Distribution Function (CDF) of zero-out impact of American (in blue) and Canadian (in red) emissions on hourly ozone concentration in Canada 
The foreign zero-out curve has an initial $(>10 \mathrm{ppb})$ value of $11.3 \%$, whereas the red curve starts at $2.35 \%$. Therefore, significant reductions occur much more frequently as a result of foreign rather than domestic reductions. In addition, the blue curve has a larger frequency for ozone reduction ranges from 3 to $10 \mathrm{ppb}$. However, removing domestic emissions in Canada has a larger likelihood of causing ozone reductions ranging from 0 to $3 \mathrm{ppb}$.

The same cumulative distributions are shown for the impact of domestic and crossborder emissions on American receptor area (Figure 5.16). About 35\% of the total grid-hours experience an improvement in ozone concentration larger than $10 \mathrm{ppb}$ as a result of domestic emission zero-out; whereas that number is only $0.7 \%$ in response to Canadian emission zero-out. The significant difference between these two values indicates that removing domestic emission control is by far the larger factor for ozone air quality improvement in the US.

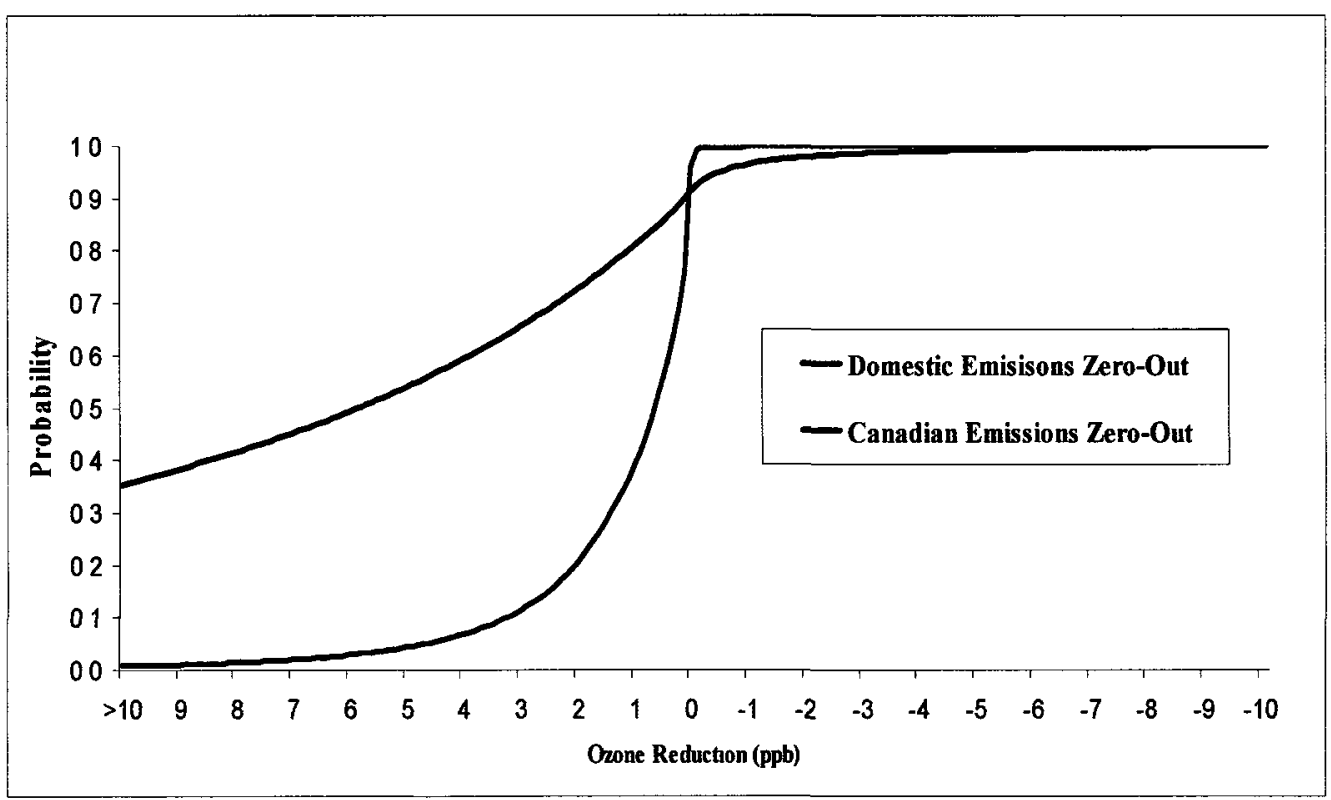

Figure 5.16 Cumulative Distribution Function of zero-out impact of Canada (in red) and zero-out impact of US (in blue) on hourly ozone concentration in the US 
An examination of the ozone air quality improvement in comparison with base concentration was also carried out for Canada and the US (Figures 5.17 and 5.18, respectively.) In these scatter plots improvements (reductions) in maximum $8 \mathrm{~h}$ average ozone for all cells and days in the receptor area of Canada (or the US, in Figure 5.18) are plotted against ozone concentrations. In other words, the figures show the magnitude of the impact for various ranges of concentrations. Again, the positive numbers show reduction and negative numbers are an indication of an increase in ozone concentration. While there are few occasions (in Figure 5.17) in which high values of daily maximum $8 \mathrm{~h}$-average ozone in Canada was not affected significantly by the US emissions, for the most parts largest improvements (peaking at $72 \mathrm{ppb}$ when maximum $8 \mathrm{~h}$-average ozone is 111) occur in areas of higher concentrations (particularly for ozone concentration above 65). This is of particular policy importance as these points are typically those that drive the regulatory process. Also, spatial plots shown before indicate that these points are generally located at some of the most populated areas in Canada, i.e. southern and southeastern Ontario. 


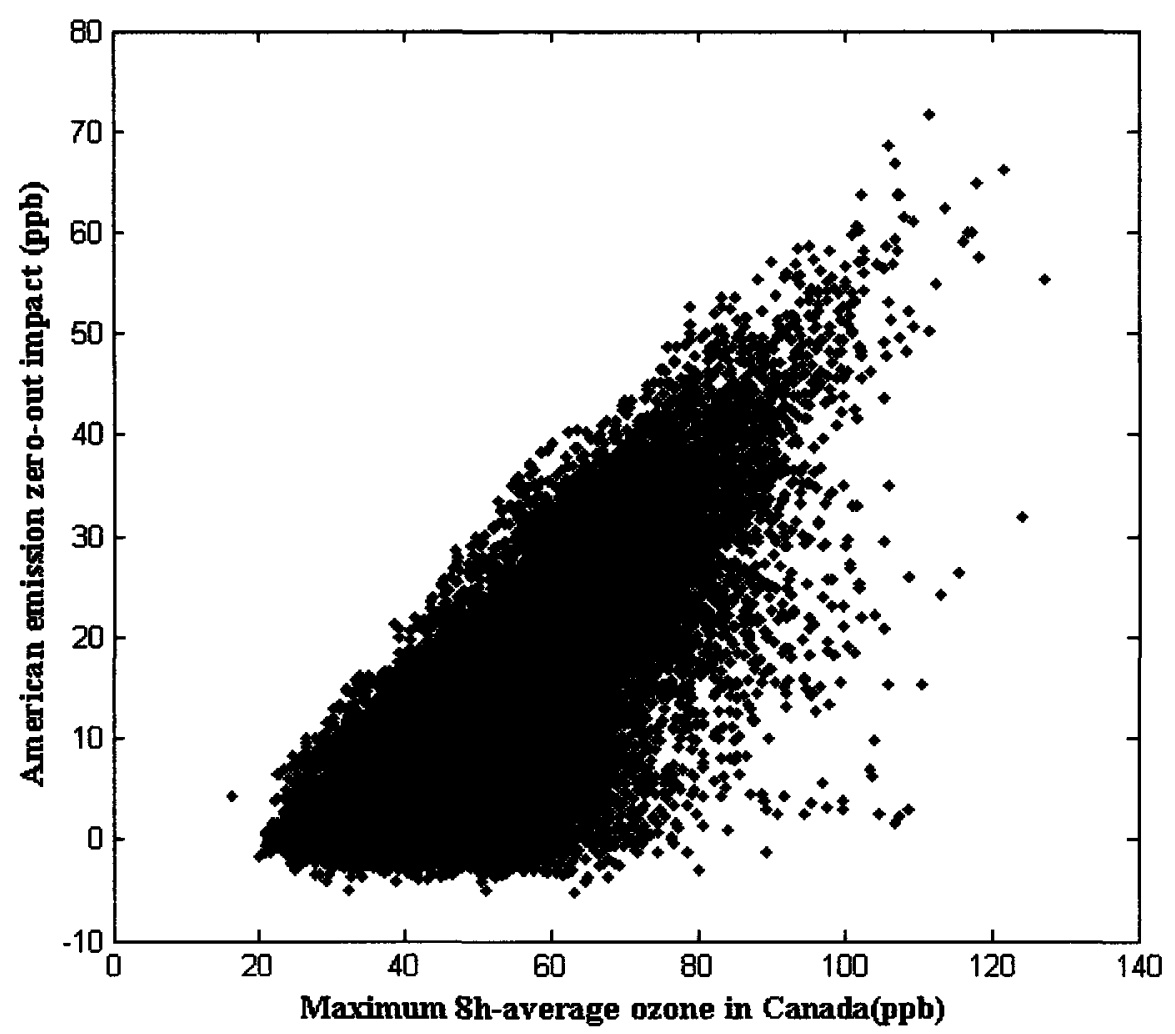

Figure 5.17 Changes in maximum $8 \mathrm{~h}$-average ozone in the receptor area of Canada resulting from $100 \%$ reduction of American emission (zero-out) plotted as a function of maximum $8 \mathrm{~h}$ average ozone during the episode, positive numbers are indication of reduction in maximum $8 \mathrm{~h}$ ozone and negative numbers show increases.

This relationship between the magnitude of ozone improvement and base case concentrations is also seen for the receptor area of the US but at a much more diminished level (Figure 5.18). Compared to the Canadian case, there are far fewer high concentration points that are greatly impacted by Canadian emissions. Most of these points are located in northeast US where east-west transport results in large cross-border influences (see Figure 5.4). Overall, a much lower degree of correlation exists between the level of improvement and base case concentration. In fact, quite a few areas in the US receptor region experience ozone impairment (increase in ozone concentration), albeit small, in the absence of Canadian emissions. It is noteworthy that the level of improvement in US ozone concentration seen in our study (maximum 
of $42 \mathrm{ppb}$ in northeast US when maximum $8 \mathrm{~h}$-average ozone is 105) is in good agreement with the study by Wang et al. (2009) using the coarse-grid global model GEOS-Chem. They conclude that for certain areas of the US (northeast, particularly upstate NY), contributions from Canadian sources are at about the same order of magnitude as those from domestic power plants (peaking at $33 \mathrm{ppb}$ ). Our study finds that while their statement may be correct for few areas in a particular region, it does not reflect the overall dynamics of cross-border transport. In contrast, the statement about influence on Canadian ozone air quality is much closer to what we observed in our study.

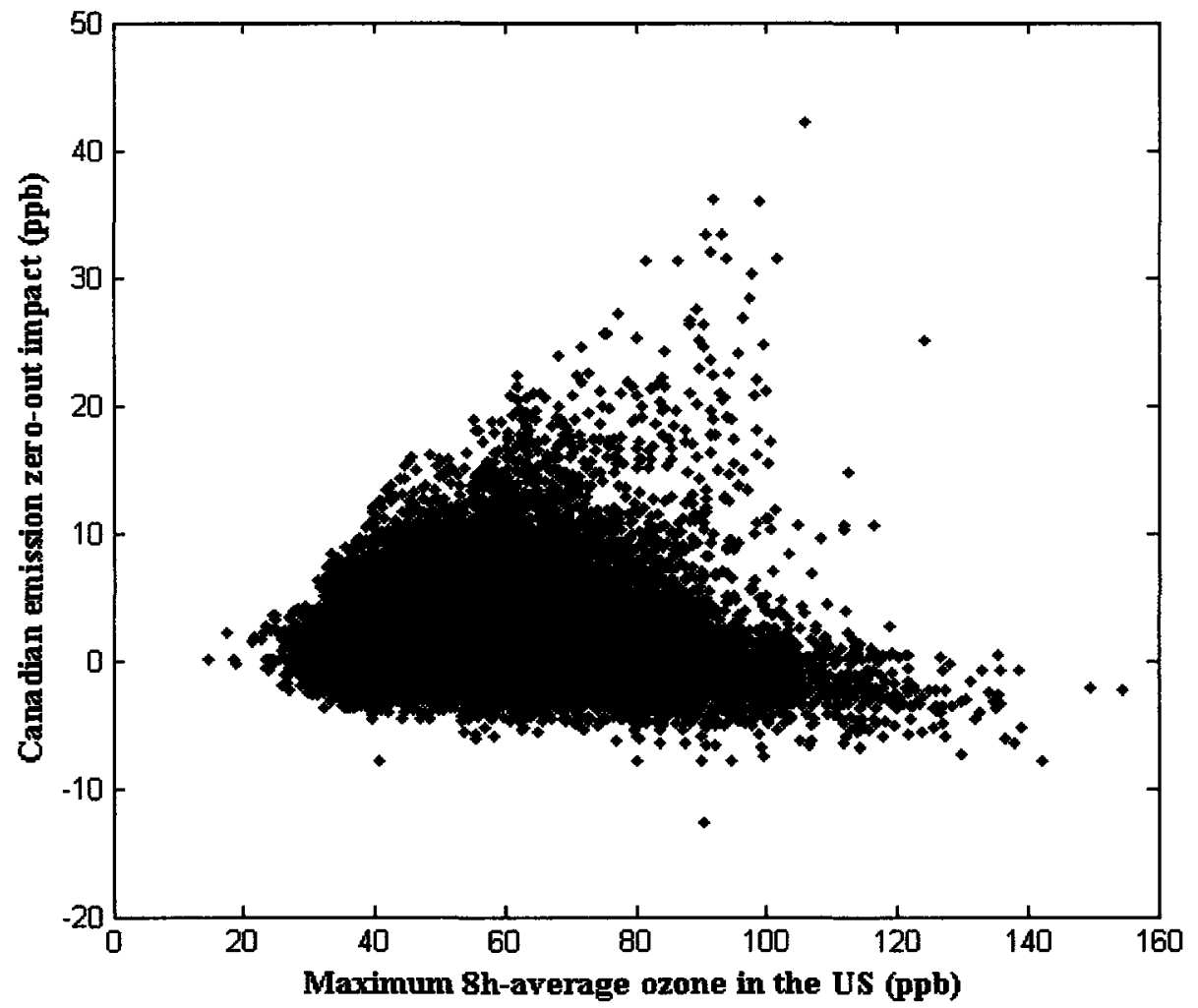

Figure 5.18 Change in maximum $8 \mathrm{~h}$-average ozone in the receptor area of the US resulting from $100 \%$ reduction of Canadian emissions (zero-out) plotted as a function of maximum 8 h-average ozone, positive numbers are indication of reduction in maximum $8 \mathrm{~h}$ ozone and negative numbers show increases. 
The magnitude of reduction in the US resulting from elimination of foreign (crossborder) emissions is much smaller than the reduction in Canada due to the foreign emissions zero-out. The maximum reduction in maximum $8 \mathrm{~h}$-average ozone concentration in Canada due to the elimination of foreign emissions is $72 \mathrm{ppb}$, whereas this value in the US is no higher than $42 \mathrm{ppb}$. In other words, the United States has a considerable contribution to the ozone exceedance above the Canadawide standards events in Canada (above 65ppb). Canadian contributions to ozone exceedance events in the US seem to be much fewer in number.

\subsection{Marginal Emission Reduction and Cross-Border Transport}

The zero-out simulations where the responses of ozone concentrations in one country are modeled to reflect a $100 \%$ reduction in emissions from the neighboring country are of hypothetical value only. Emission zero-out is not a practical strategy and only provides information about the policy relevant background ozone. It is of more practical importance to quantify the impact of marginal changes in foreign and domestic emissions. Previous works [Hakamı et al, 2003; Cohan et al, 2005] show that small level of perturbation (i.e., $5 \%$ to $20 \%$ ) results in sensitivity coefficients that are consistent with local sensitivities. In this section, the response of ozone concentrations to a $10 \%$ reduction in foreign emissions is quantified. We attempt to examine whether the changes in ozone concentrations resulting from $10 \%$ reduction in emissions can be linearly extrapolated from the ozone response to a $100 \%$ reduction or vice versa. In this approach the BF sensitivity to emission changes is calculated using a $10 \%$ perturbation in emissions. These sensitivity coefficients are calculated by extrapolating results from $10 \%$ reduction to $100 \%$ range (i.e., multiplying by 10). Figure 5.19 compares the ozone response to the reduction of American anthropogenic emissions by $10 \%$ (a) against ozone response to that case of 
$100 \%$ reduction (b). As seen in the spatial plots, for the majority of the locations in the receptor area of Canada $10 \%$ perturbations of American emissions result in generally smaller sensitivities than zero-out reductions, particularly in southern Ontario. This indicates a largely nonlinear ozone response to foreign emission reductions.

a)

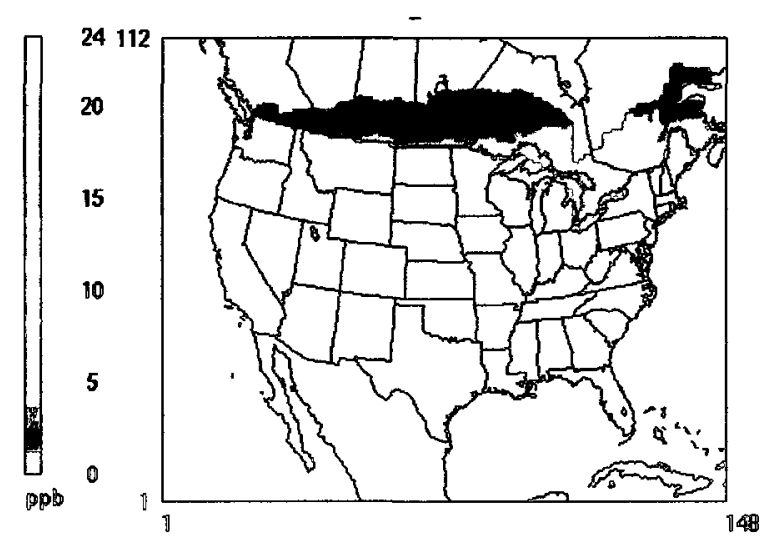

b)

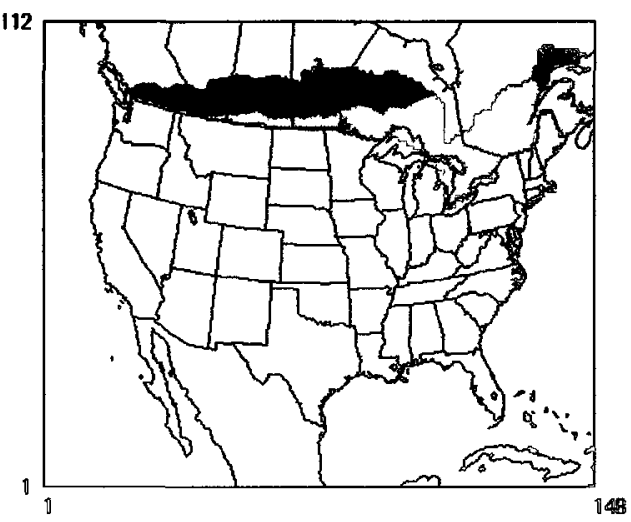

Figure 5.19 Reduction of maximum 8h-average ozone in Canada due to the reduction of American emissions, averaged for the duration of the episode a) BF sensitivities b) Zero-out sensitivities

As shown earlier ozone response to the reduction of entire anthropogenic emissions was similar in spatial distribution and magnitude to the ozone response to $\mathrm{NO}_{\mathrm{x}}$ emission reduction, which is by far the most important emitted species affecting ozone. Second order sensitivity coefficient can be used to determine the curvature of concentration-emissions function. Negative second-order sensitivity indicates a concave response of ozone to $\mathrm{NO}_{\mathrm{x}}$ (slope of function decreases when emissions increase) [Hakami et al, 2004]. The larger response of maximum 8h-average ozone in southern Ontario to the zero-out of anthropogenic emissions compared to marginal changes indicates a daytime convex response of ozone with respect to $\mathrm{NO}_{\mathrm{x}}$ in this 
region where reduction of $\mathrm{NO}_{\mathrm{x}}$ in large amounts (zero out) creates an increasingly $\mathrm{NO}_{\mathrm{x}}$-limited environment and more significant response.

Similarly, Figure 5.20 compares the BF sensitivities of the maximum 8 h-average ozone in the US border area resulting from Canadian emissions reduction. In most of the US, BF sensitivities are close to the zero-out sensitivities except in the Northeast in which BF sensitivities are slightly larger than zero-out sensitivities.

a)

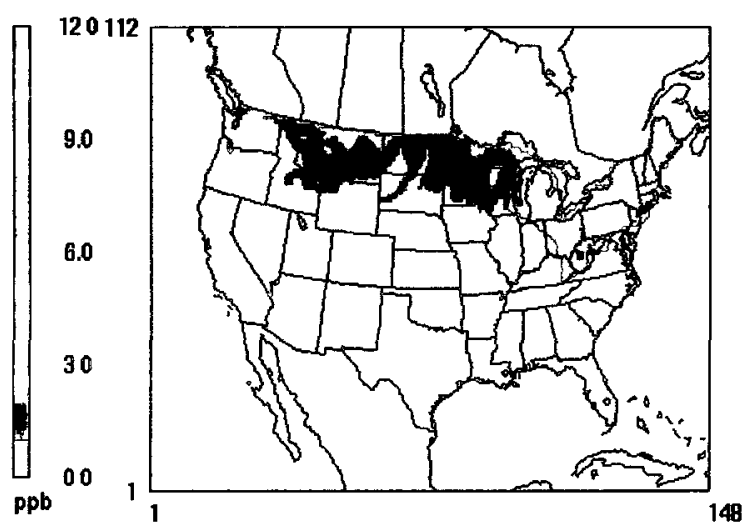

b)

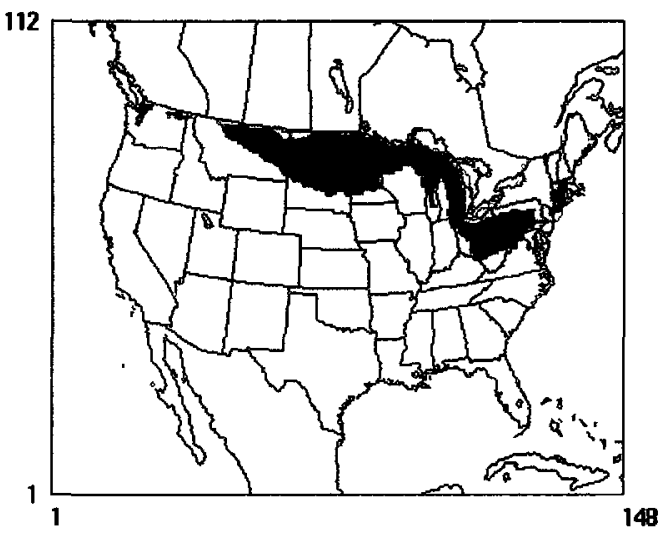

Figure 5.20 Reduction in maximum 8h-average ozone in the US due to the reduction of Canadian emissions, averaged for the duration of the episode a) BF sensitivities b) Zero-out sensitivities

A similar pattern of nonlinearity in the response of maximum 8h-average ozone can be seen in scatter plots of Figures 5.21 and 5.22 for Canada and the US, respectively. These plots show the zero-out or BF sensitivity of daily maximum $8 \mathrm{~h}$-average ozone in the receptor area of each country resulting from cross-border emission reductions. The scatter plot is constructed from daily maximum 8 h-average ozone in all grid cells of the receptor area for every day in the simulated episode. In other words, while the values in Fugures 5.19 and 5.20 are averaged over the entire episode ( 90 days), each point in Figures 5.21 and 5.22 represent a single day. Again, for Canada, a largely 
nonlinear behavior is observed while for the US deviations from linearity ( 1 on 1 line) are smaller.

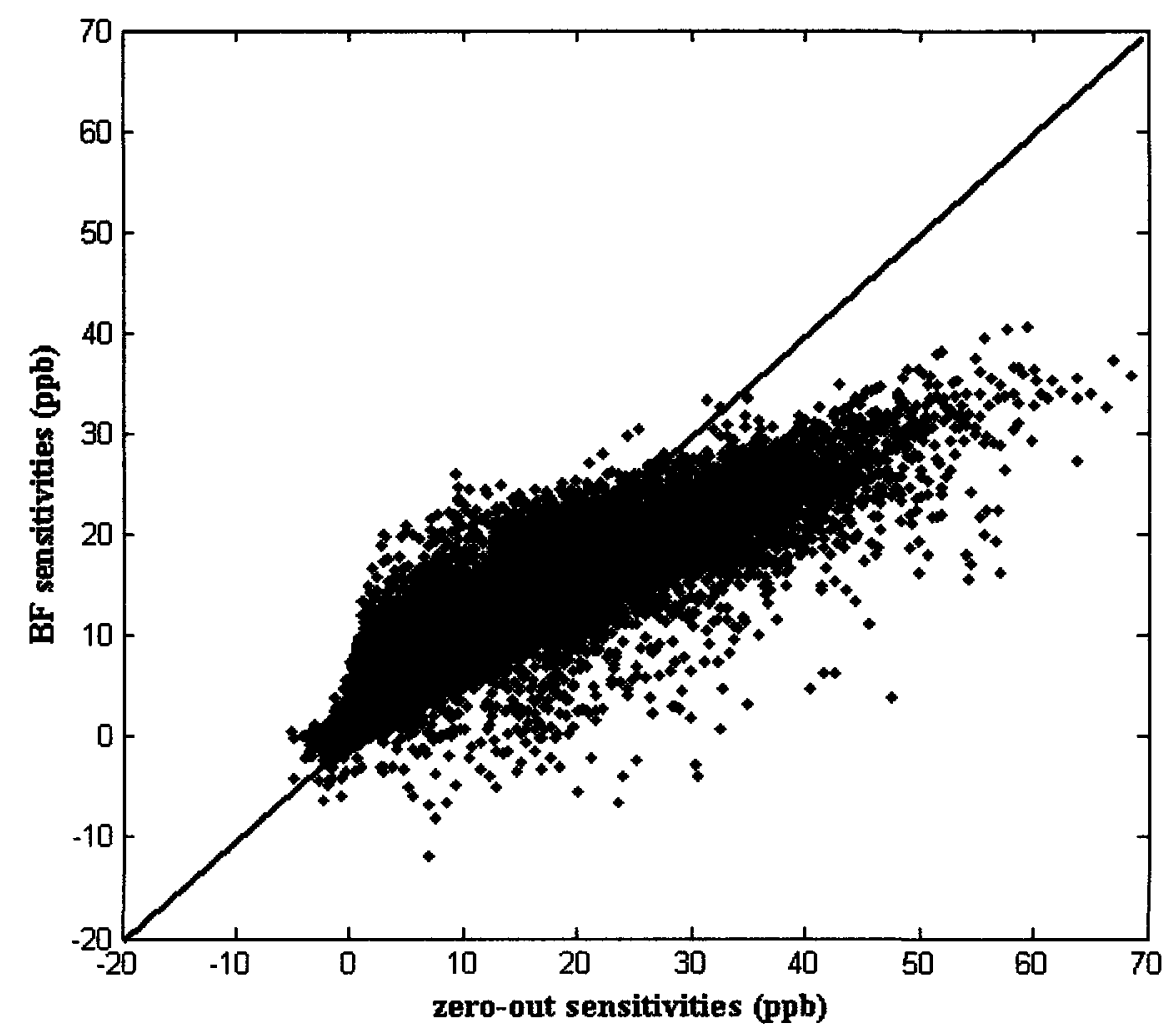

Figure 5.21 Responses of maximum 8h-average ozone in the receptor area of Canada to perturbations in American emissions $(10 \%$, and $100 \%)$, the ordinates shows the BF sensitivities $(10 \%)$ and the abscissa shows the zero-out sensitivities, the 1:1 line shows the linearity of relationship

The difference in nonlinear behavior in Canada and the US can be explained by examining the nature of nonlinearity. Generally, nonlinearity in ozone response to $\mathrm{NO}_{\mathrm{x}}$ availability occurs when a change in the prevalent chemical regime happens, e.g. reduction of emissions shifts an urban mass from the $\mathrm{NO}_{\mathrm{x}}$-inhibited into $\mathrm{NO}_{\mathrm{x}}$-limited regime [Hakami et al., 2004]. The impact of American emissions on the chemical regime in Canada is substantial enough to trigger a regime change and the consequent nonlinear behavior. By contrast, the impact of Canadian emissions on the overall composition and making of the US atmosphere is much smaller, and in general (with 
the exception of northeast US) not large enough to cause enough of a shift in the chemical regime. As a result, the overall behavior seen in Figure 5.22 is closer to a linear response than that of Figure 5.21.

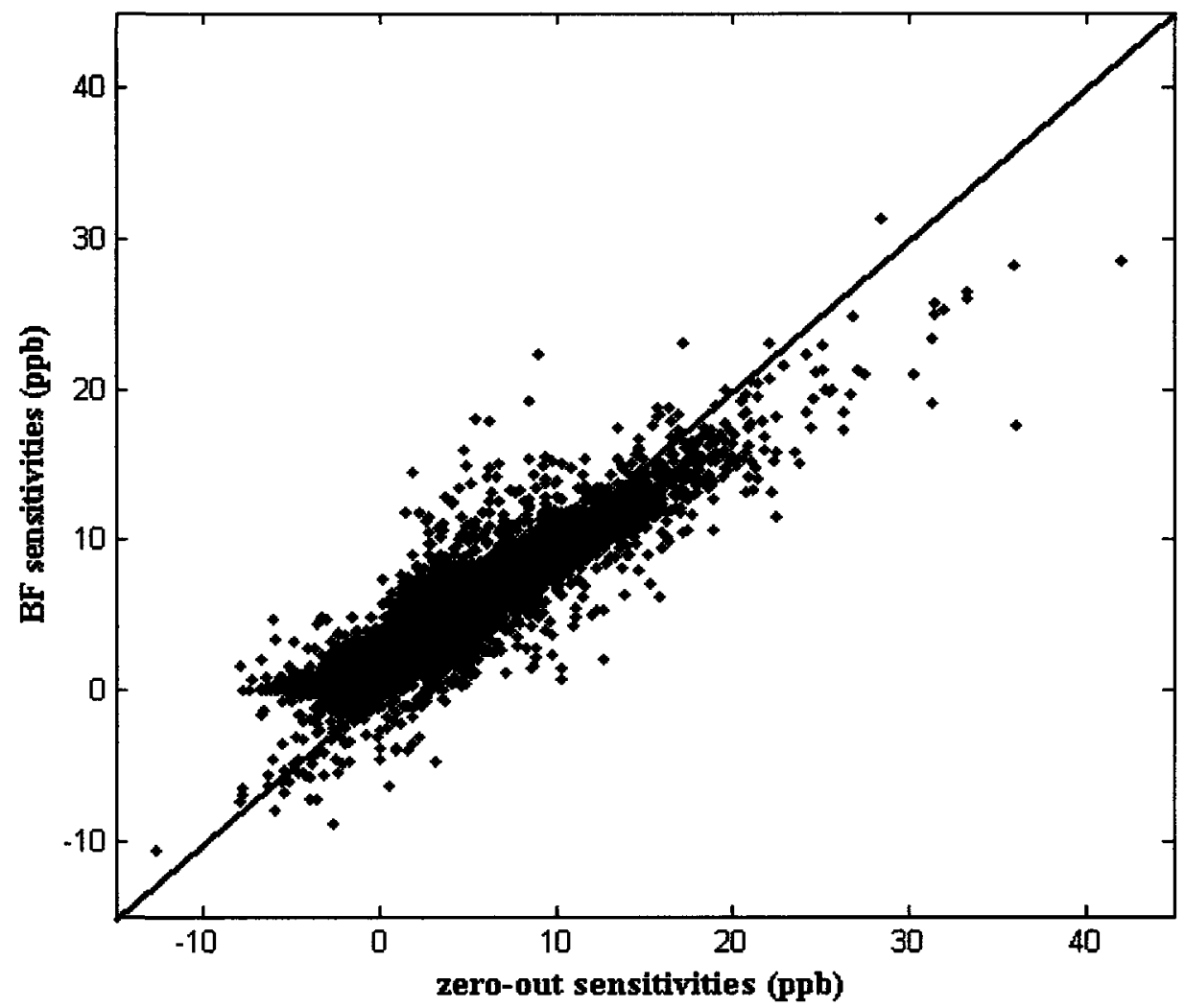

Figure 5.22 Response of maximum $8 \mathrm{~h}$-average ozone in the receptor area of the US to perturbations in Canadian emissions $(10 \%$ and $100 \%)$, the ordinates shows the BF sensitivities $(10 \%)$ and the abscissa shows zero-out sensitivities, the 1:1 line shows the linearity of relationship 


\subsection{Adjoint Sensitivity Analysis}

The adjoint of gas-phase CMAQ [Hakami et al , 2007] was employed to establish the source-receptor relationships in North America during the Summer of 2007. The adjoint method enables calculation of sensitivities of a selected metric, average ozone, defined in the receptor area of each country, with respect to the $\mathrm{NO}_{\mathrm{x}}$ emission sources across North America. As discussed, adjoint variables contain information about the sensitivity of the metrics with respect to ozone concentrations at various locations and times [Hakami et al, 2007]. The adjoint variables, as shown in the previous chapters, can be used to generate the semi-normalized sensitivities of the metrics with respect to emission sources at each grid cell of the domain. The sensitivities of average ozone (integrated over the grid cells in the receptor area of Canada) with respect to $\mathrm{NO}_{\mathrm{x}}$ sources in the continental US are shown in Figure 5.23. The sensitivities are seminormalized (to the amount of emissions in each grid cell), presented in ppb, and averaged for each month of summer. For example, a sensitivity of $0.002 \mathrm{ppb}$ to $\mathrm{NO}_{\mathrm{x}}$ emissions at a grid cell indicates that a $100 \%$ reduction in the emissions in that grid cell will reduce the average ozone in the Canadian receptor area by $0.002 \mathrm{ppb}$ over the entire month. Accordingly, the sensitivity of the metric to certain amount of reduction in the emissions of that grid cell (e.g. by $\delta \%$ ) would be equal to $0.002 \times \delta \%$. Adjoint results have been validated with brute-force and DDM sensitivities elsewhere [Hakami et al, 2007]. Employing adjoint method enabled the calculation of the contribution of individual sources across the domain to surface ozone air quality in the receptor region of each country. It should be noted however, that contributions calculated by local sensitivities (such as adjoint gradients) are only first-order approximations and do not take into account nonlinearity in response. 


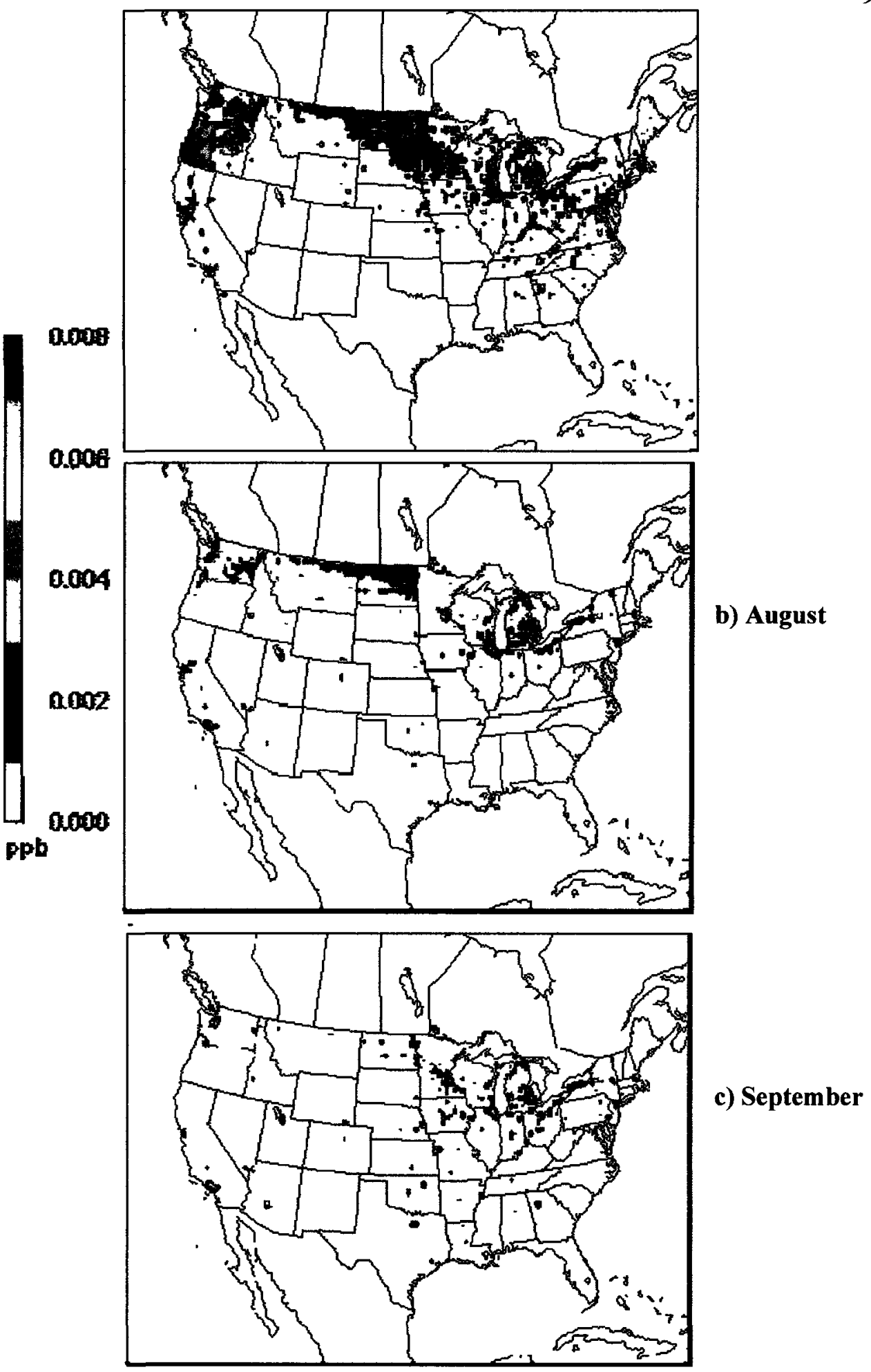

Figure 5.23 Sensitivities of average ozone (integrated in receptor area of Canada) with respect to $\mathrm{NO}_{\mathbf{x}}$ emissions in each grid cell in the Continental US, sensitivities are semi-normalized (ppb) and integrated over 30 days of the month of a)July, b)August, and c)September, results are averaged for each month 
Figure 5.23 shows the contribution of each individual emission source across the US to the average ozone in the receptor area of Canada, i.e. sensitivities of average ozone to emissions of each grid cell in the US. By applying the adjoint method, information can be obtained about the main contributing sources to the surface ozone concentrations of US-Canada border area. As seen in the figures, average ozone in Canada is sensitive to the urban centers in the US. This high sensitivity is more obvious in the plot (a) for the July 2007 . Urban centers in the US particularly close to the border have the largest influences on average ozone concentrations in the receptor area of Canada. Among these cities New York, Cleveland, Detroit can be easily distinguished. More interestingly, $\mathrm{NO}_{\mathbf{x}}$ emissions from Los Angeles also affect average ozone in the receptor area of Canada. The adjoint sensitivity analysis enables the definition of various metrics of interest that deal with air quality (e.g., ozone nonattainment, or ozone related mortality) and the identification of the locations whose emissions are the main causes of these concerns. Note that the adjoint cost function (i.e. the metric the sensitivity of which is being calculated) is defined as the average ozone over the entire receptor area. As mentioned before, the adjoint method is not capable of providing detailed information on individual receptors. From a theoretical point of view, the adjoint cost function can be defined over a smaller area or even a single grid cell. However, it would be computationally prohibitively expensive to calculate sensitivities of each individual receptor as each cost function will require a new set of adjoint calculations.

It is important to note the philosophical difference between forward sensitivity approaches (such as zero-out) and the backward sensitivity (adjoint) method. While forward approaches provide spatially and temporally distributed sensitivity 
information about receptors, backward analysis provides spatially and temporally distributed information about sources. In that sense, forward and backward methods are truly complementary as they address different aspects of the question.

Similarly, Figure 5.24 shows the spatial distribution of the semi-normalized sensitivities of average ozone with respect to the $\mathrm{NO}_{\mathrm{x}}$ emission sources in Canada. As seen, average ozone in the receptor area of the US shows the maximum sensitivity (red points) to Canadian centers from east to west, Montreal, Toronto, Hamilton, Winnipeg, Regina, Saskatoon, Calgary, Edmonton and Vancouver. The major contributing source regions in Canada are city centers due to high $\mathrm{NO}_{\mathrm{x}}$ concentration. Southern/southeastern Ontario also shows relatively high contribution in average ozone concentration in the US as most Canadian industries are located in this region. There are temporal variations in sensitivities of average ozone from July to September seen in both figures. The average ozone seems to be more sensitive to the $\mathrm{NO}_{\mathrm{x}}$ emission sources in July compared to the rest of the summer specifically with respect to American emission sources. It is difficult to assess the exact nature of these variabilities but the overall magnitude of the impact depends on a myriad of factors including transport and chemistry. 


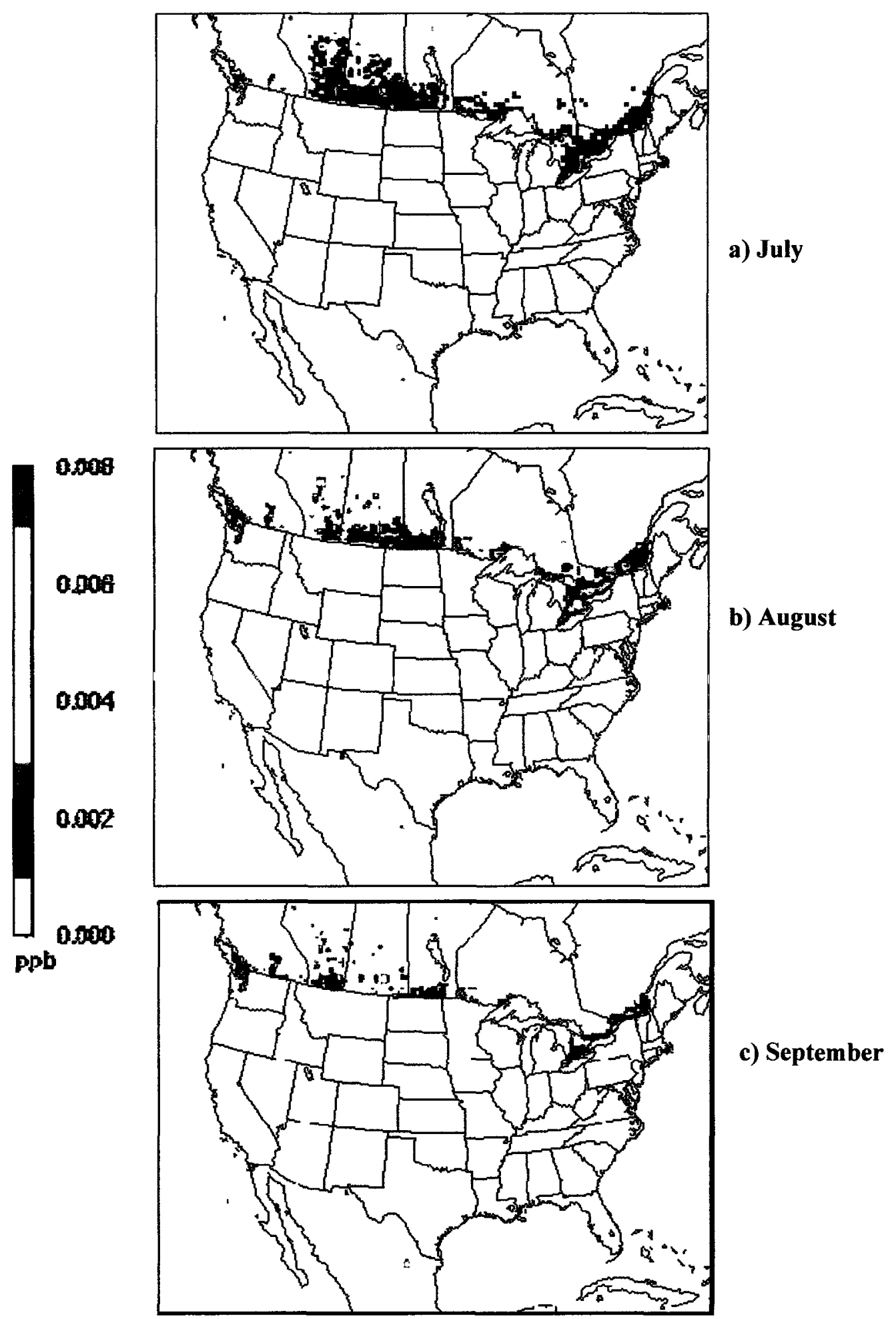

Figure 5.24 Sensitivities of average ozone (integrated in the receptor area of the US) with respect to the $\mathrm{NO}_{\mathrm{x}}$ emissions in each grid cell in Canada, sensitivities are semi-normalized (ppb) and integrated over 30 days of the month of a) July, b) August, and c) September, results are averaged for each month 


\subsection{Flux Bookkeeping}

The analyses in the previous sections were focused on the impact of cross-border emission sources on ozone air quality through various sensitivity analysis approaches. As expected, it was simulated that some border locations are more impacted by crossborder pollution flux due to the prevalent west-to-east wind direction. The motivation behind this part of our study was to calculate the actual mass of pollution that crosses the border into each country, particularly into southeastern Ontario and the northeastern Unites States where sensitivity-based methods predict a larger impact. Therefore, the transport of ozone and its precursors across the US-Canada border was budgeted. As described in Chapter 4, in grid cells containing US-Canada border, the budget of transport of masses of air and individual pollutants was maintained. The longitudinal (west to east) and latitudinal (north to south) export of masses were calculated separately considering the border location and the wind direction towards the border. In the following section, the export of masses of air, ozone, and its precursors in anthropogenic $\mathrm{NO}_{\mathrm{x}}$ and VOCs across the border is investigated. Unlike the previous approaches, this method of evaluating cross-border transport is not based on sensitivity analysis and is a simple case of bookkeeping at the border.

\subsubsection{Longitudinal and Latitudinal Export of Pollution Flux in the}

\section{Border}

The temporal and spatial variation of pollution export happening in the troposphere in both latitudinal and longitudinal directions in border grid cells has been quantified. The mass of air transported in these directions were also calculated in order to explore whether there is correspondence between transport of air and the pollutants or not.

Figure 5.25 represents the latitudinal (north to south) transport and Figure 5.26 shows 
the longitudinal (west to east) transport of masses of pollutants in the border grid cells. The values are daily and integrated over all vertical layers in the troposphere. This representation shows the daily variation of mass transport (in each direction separately) in border grid cells during the episode. The mass exports appear in the columns or rows within which the border extends. For example, for west-east (longitudinal) transport, the plot will only include the north-south extent of the border, i.e. row numbers 75 to 95 .

\section{Latitudinal Transport}

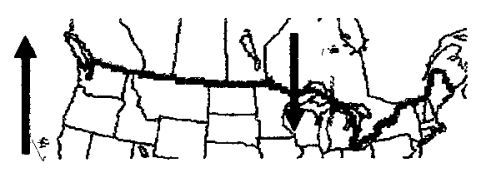

\section{a) Ozone}

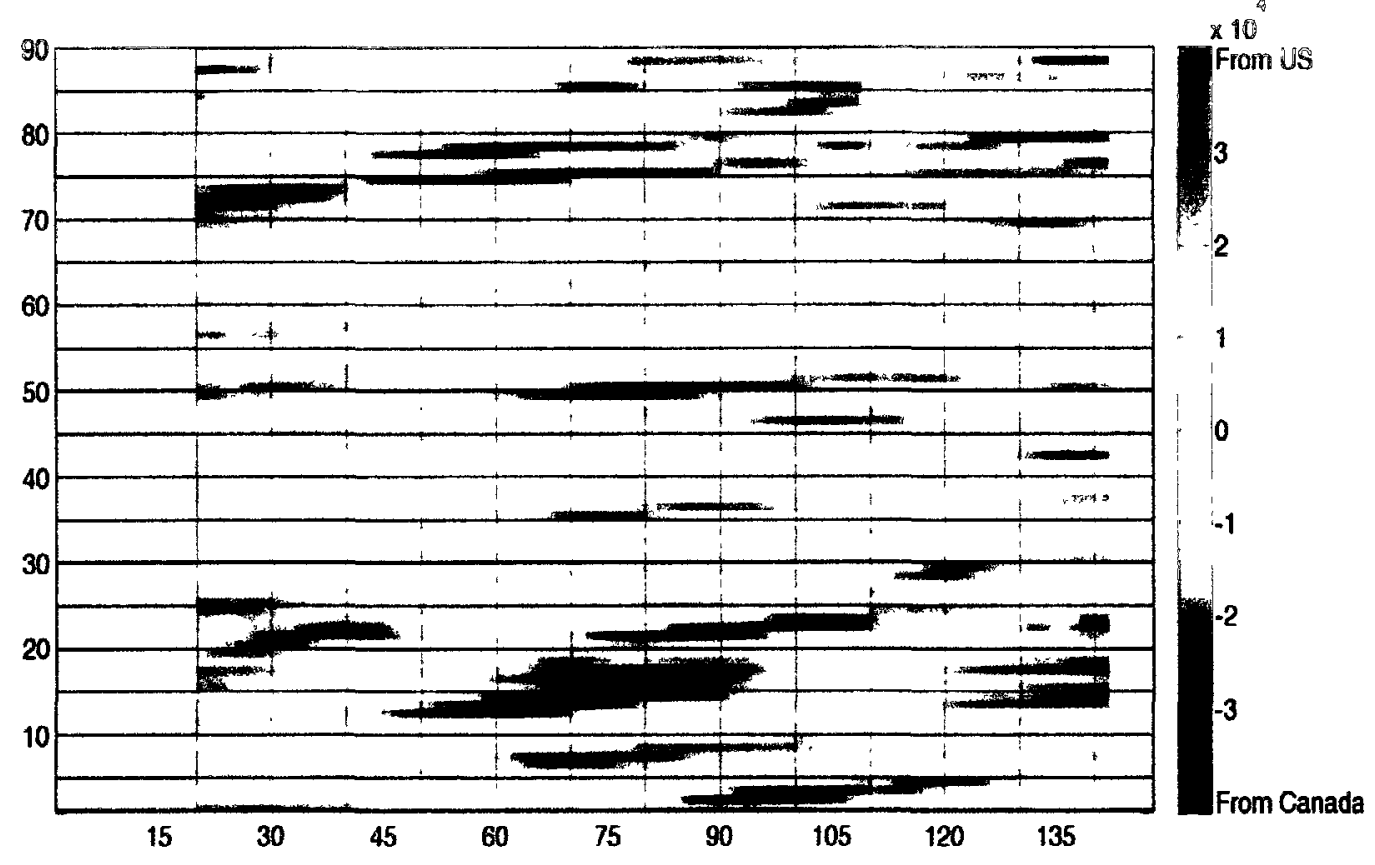


b) $\mathrm{NO}_{\mathrm{x}}$

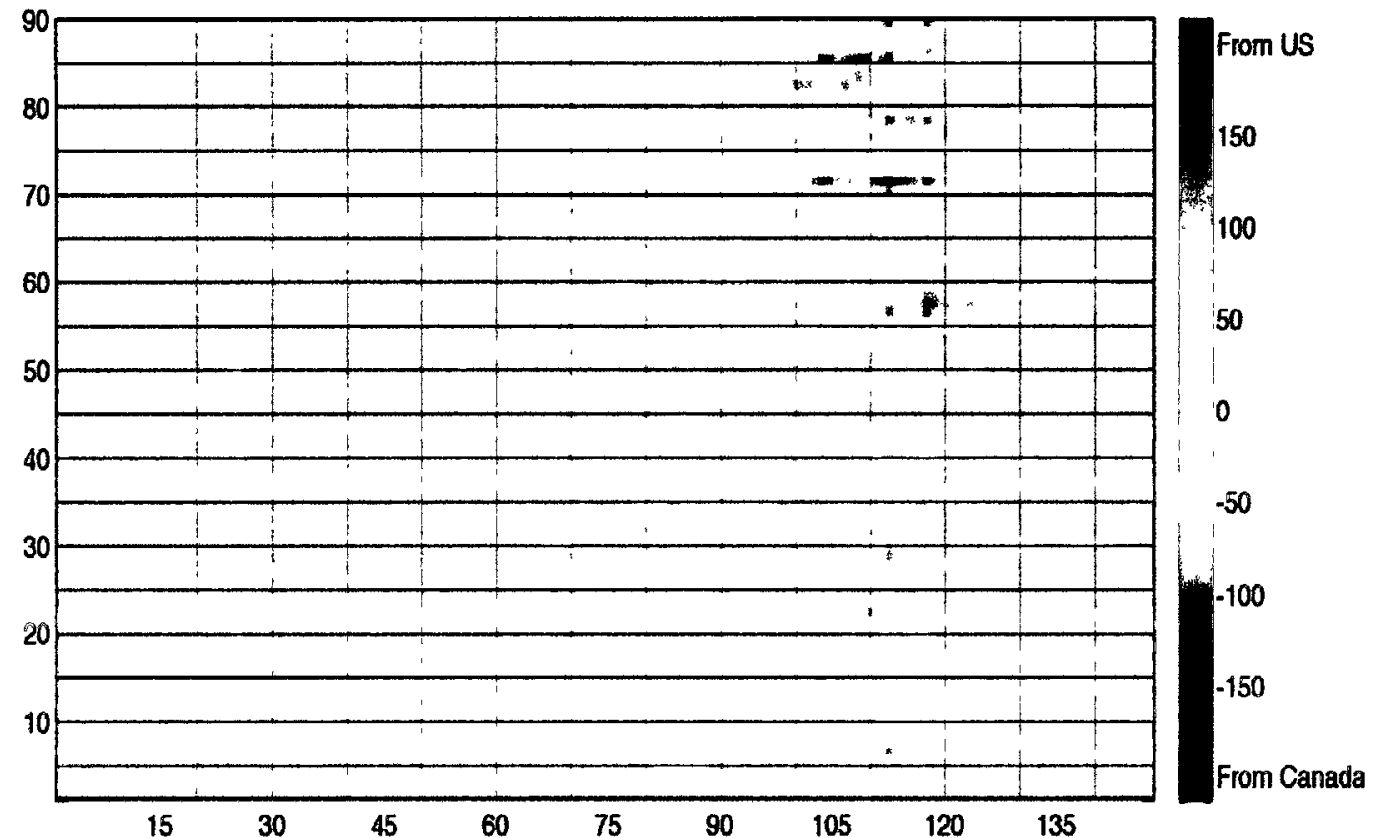

d) Ethylene (VOCs)

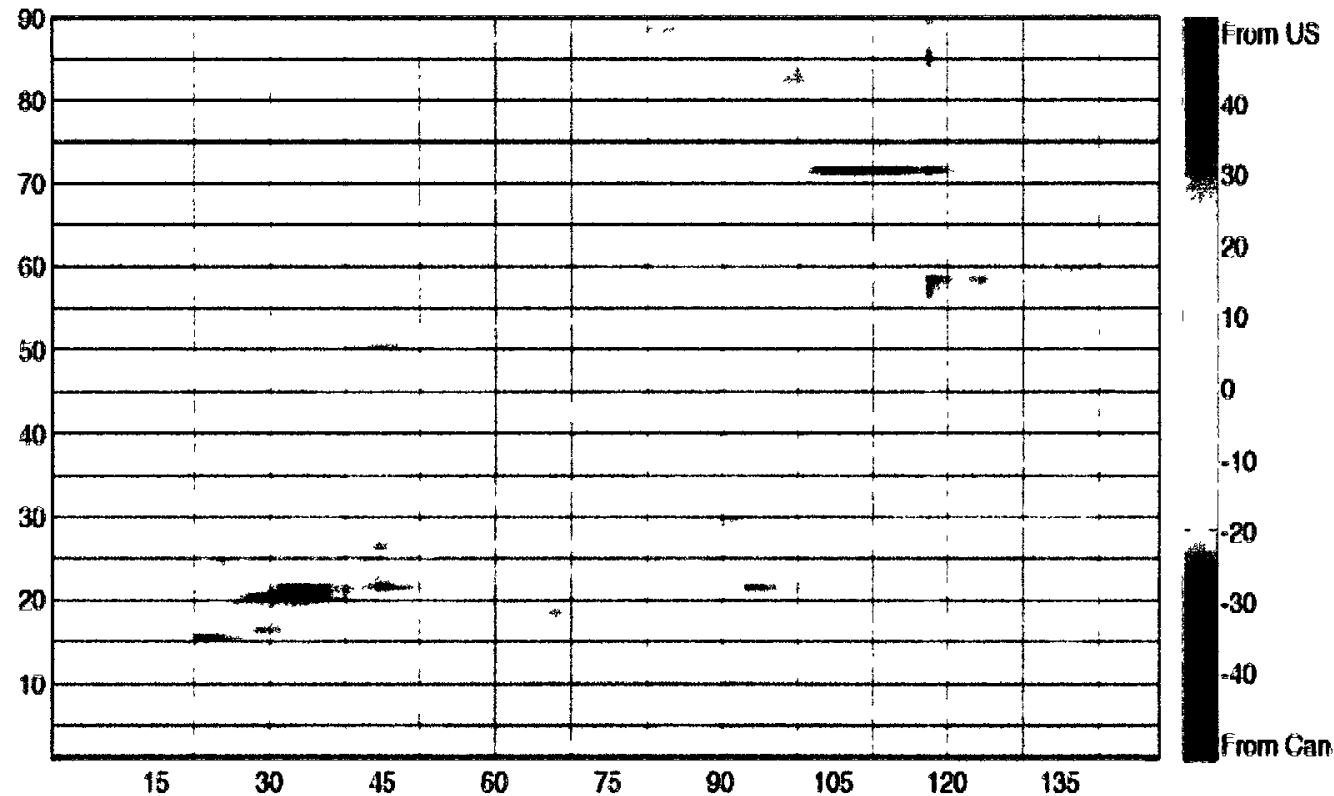


d) Air

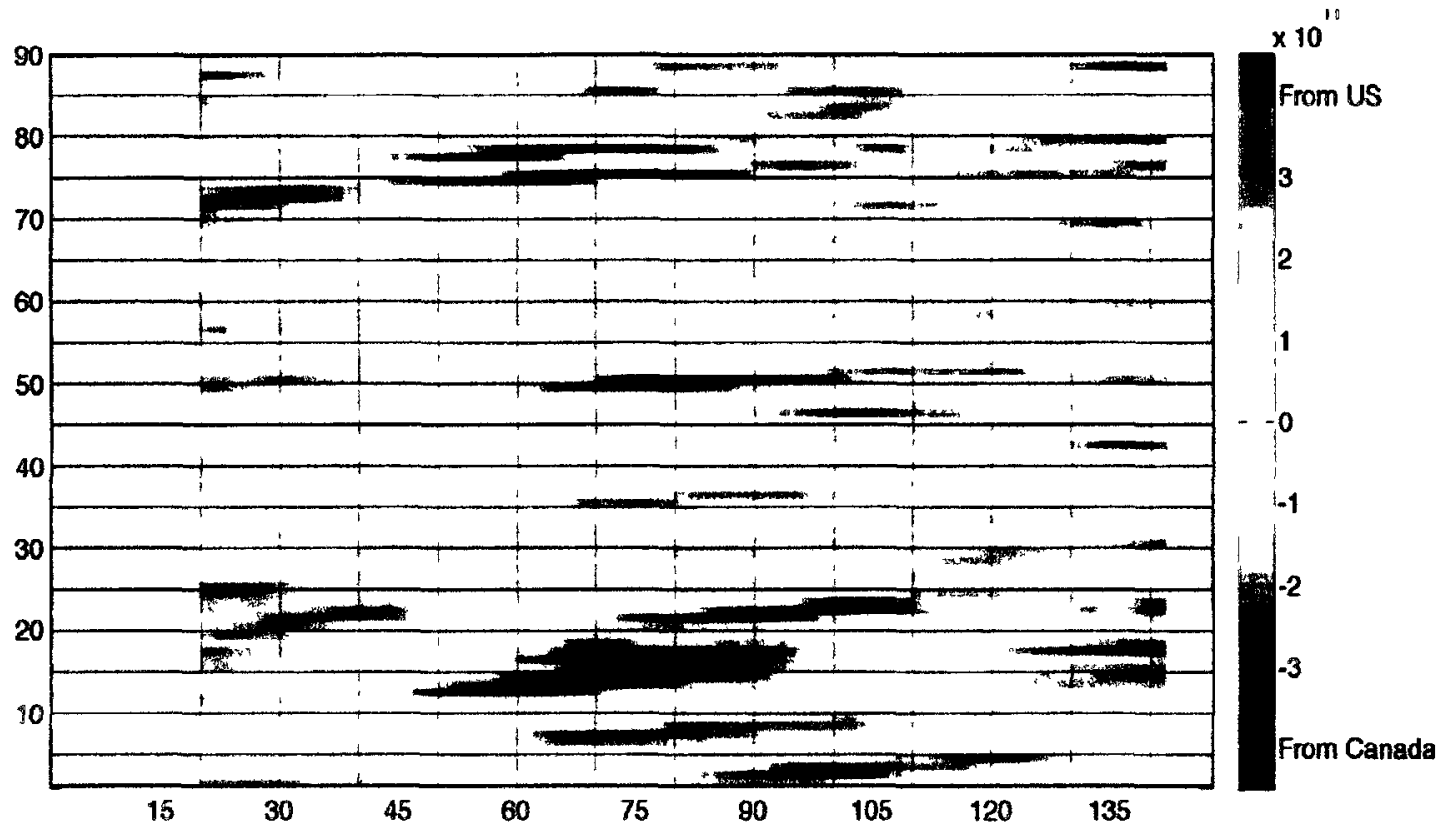

Figure 5.25 Latitudinal mass export (tonnes) of different pollutants in the troposphere during the summer 2007. The red color is indication of export of pollutants from the US to Canada and blue color shows the export of pollutants from Canada to the US. The y-axis shows the 90 days of simulation and the $x$-axis shows the 148 columns included in the domain.

Obviously, cross-border transport of ozone can happen in the form of ozone itself or import/export of its precursors, and therefore, all species (or their representatives) are budgeted in this section. Plot 5.25(a) demonstrates the spatial structure and temporal variation of border transfer of ozone happening in latitudinal direction during the simulation episode. Ozone export from Canada mostly occurs across midwestern states/provinces for the majority of the days. In contrast, the export from the US to Canada mainly happens in the east and west during this episode. Plot 5.26(a) shows the ozone transfer happening in the longitudinal direction. The export of ozone in this direction mainly occurs from the US to Canada by prevailing westerlies. Surface air quality impairment in Southeastern Canada results from such west to east pollution export from the US. There are few days in which the US receives ozone export from 
Canada. It should be noted that values in Figures 5.25 and 5.26 are net export/import. In other words, a case of a positive value in the plots indicates that the US export outweighs Canadian exports at a particular border crossing and for a specific day. That does not imply that Canadian exports do not occur, nor does it suggest that US exports are always larger than Canadian exports during various hours of that day or different atmospheric heights. In fact, there is likely to be a great deal of diurnal and vertical variability in border export/import behavior that is summed out in the plots and as such Figures 5.25 and 5.26 should be only regarded as an overall picture of cross-border transport. Furthermore, for some border rows, crossing happens at two locations. In other words, an air mass traveling along a westerly wind that crosses the border from the US into Canada in southern Ontario can later on return to the US on the same row. Again, the value seen for that particular row reflects the net impact and does not include information about individual crossings. 
a)Ozone

\section{Longitudinal Transport}
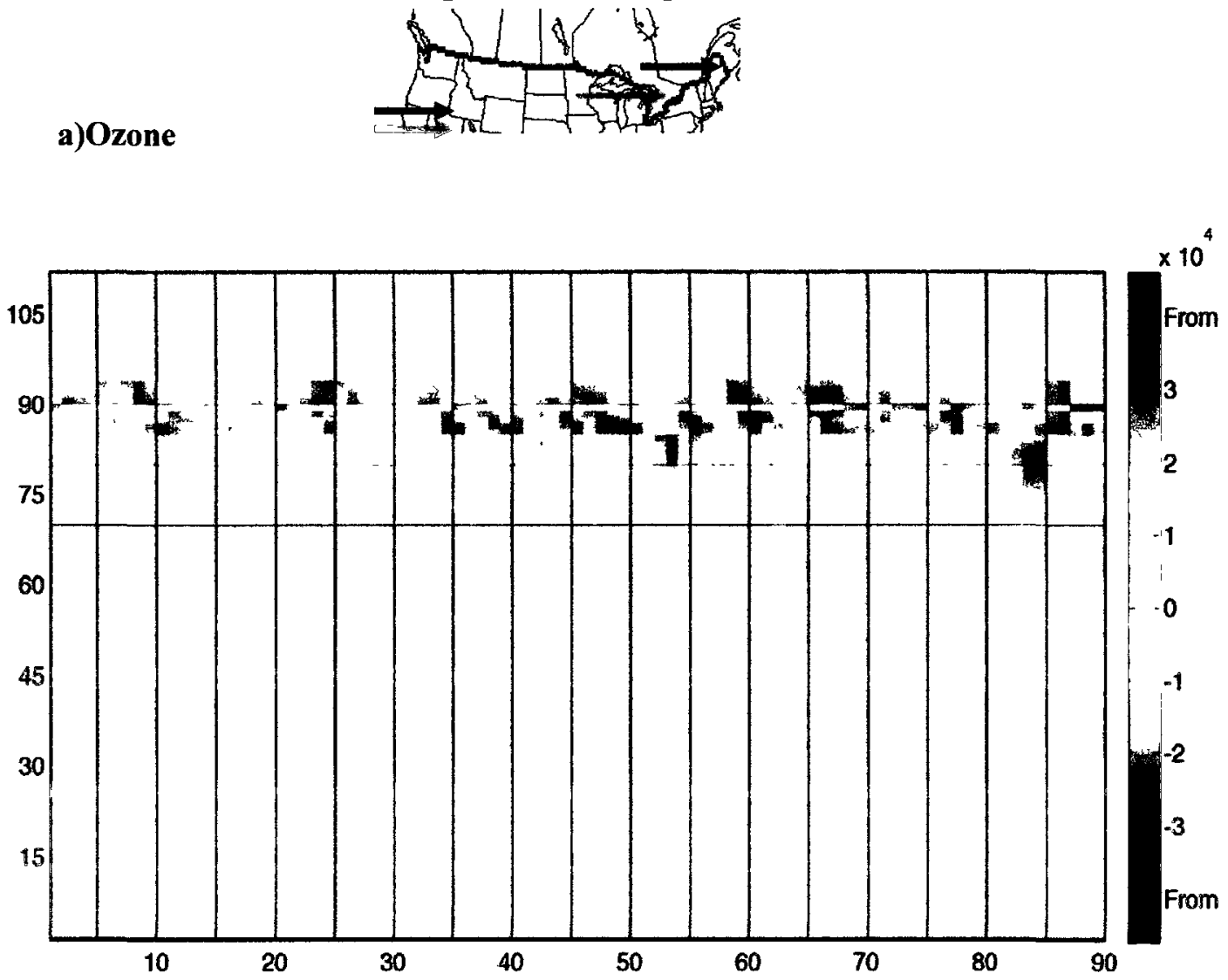

b) $\mathrm{NO}_{\mathbf{x}}$

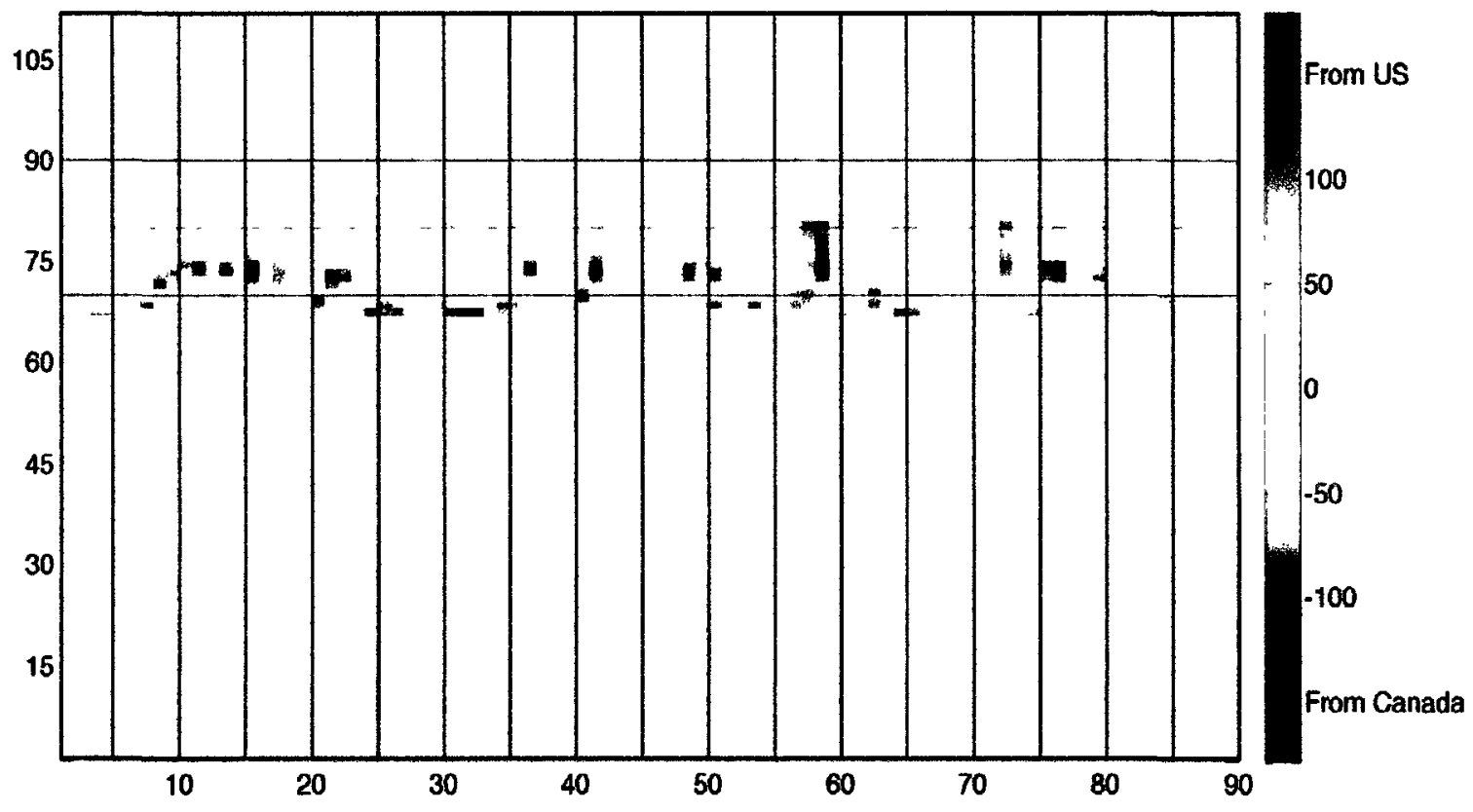


c) Ethylene (VOC)

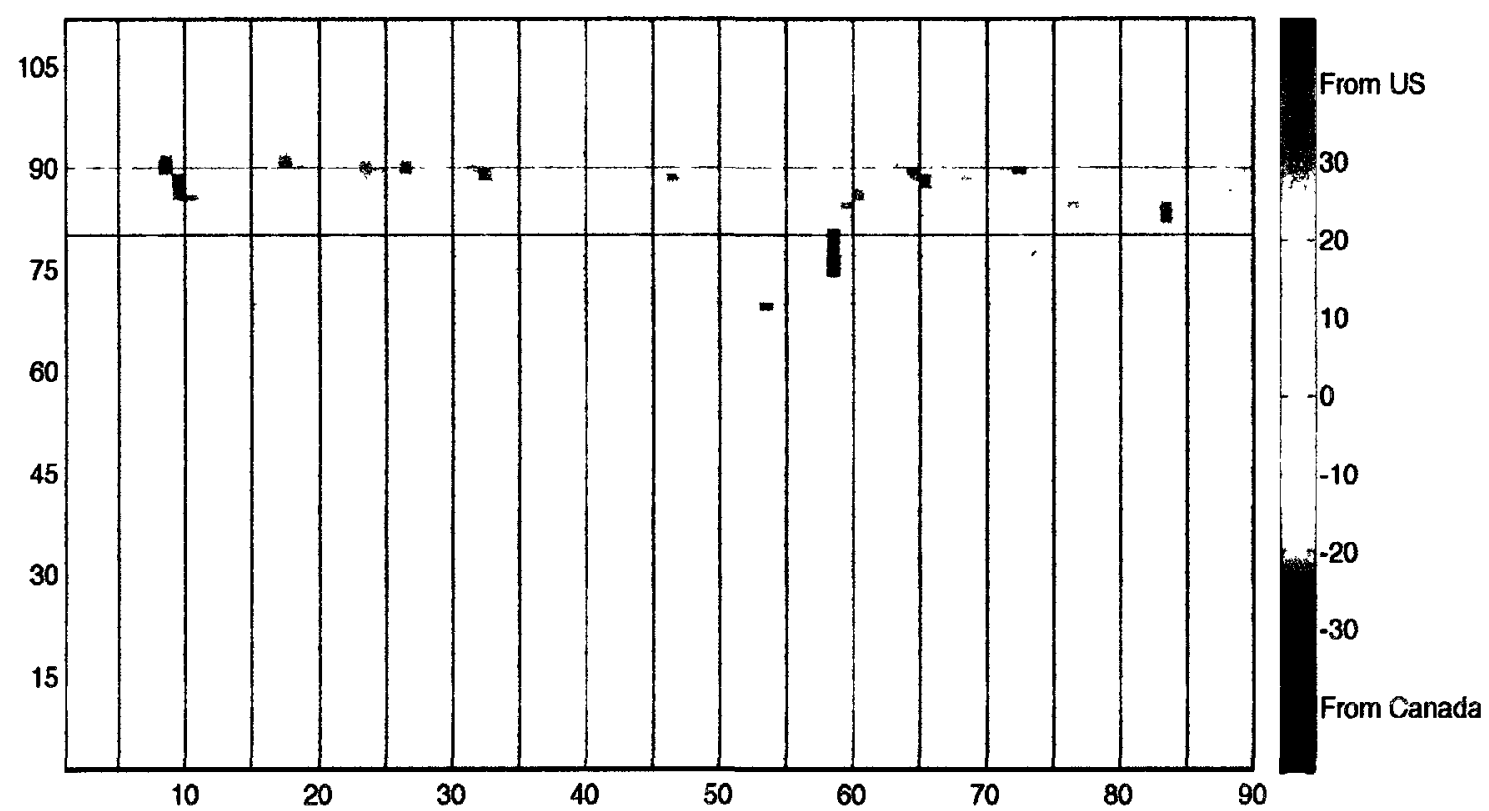

d)Air

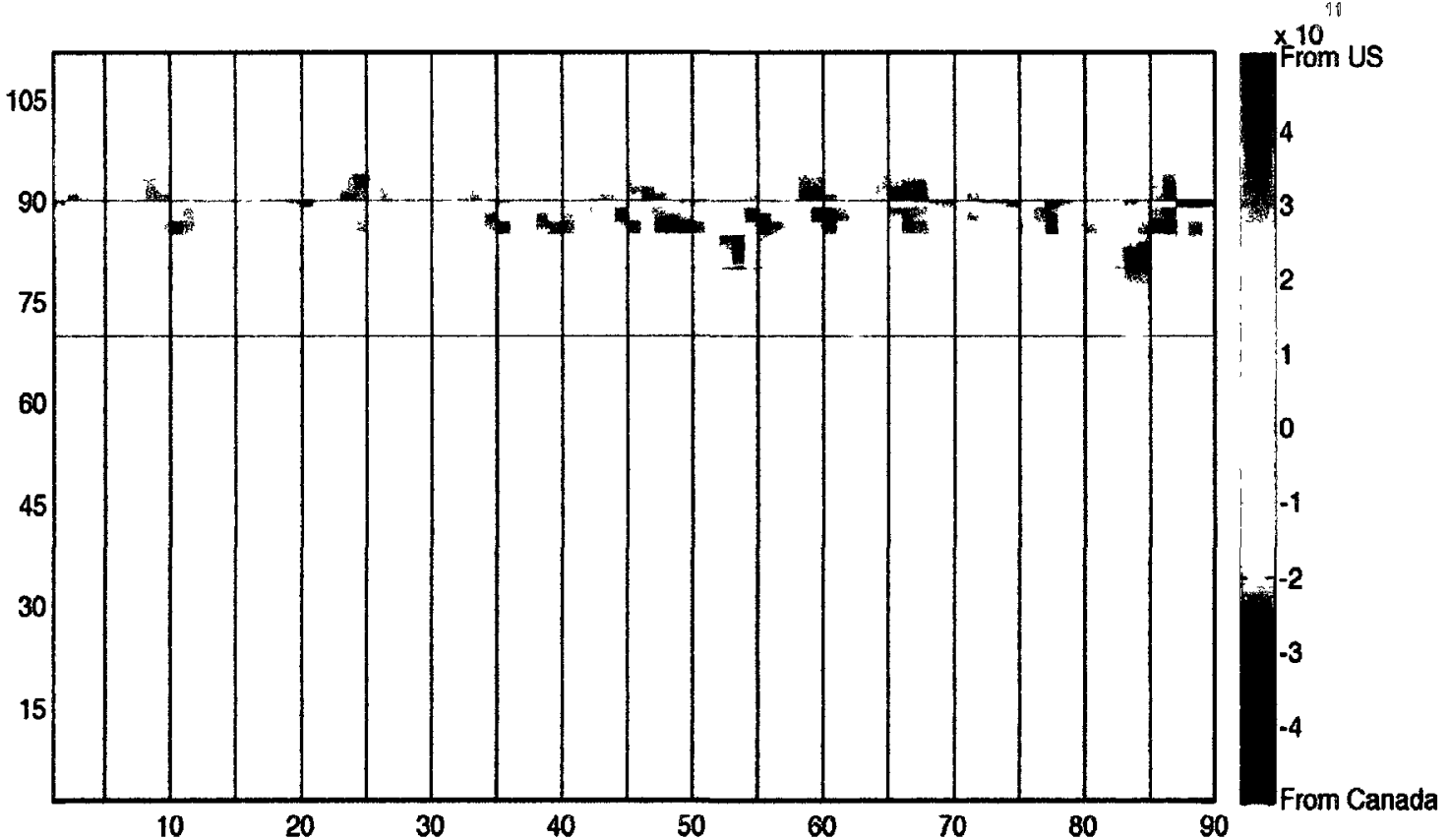

Figure 5.26 Longitudinal mass export (tonnes) of different pollutants in the troposphere during the summer 2007. The red color is indication of export of pollutants from the US to Canada and blue color shows the export of pollutants from Canada to the US. The y-axis shows the shows the 112 rows included in the domain and the $\mathbf{9 0}$ days of simulation are shown in the $\mathbf{x}$-axis. 
Spatial structure and temporal variation in mass transfer of $\mathrm{NO}_{\mathrm{x}}$ and VOCs in latitudinal and longitudinal directions were also calculated. Such quantifications enabled the formation of logical connections between the high ozone concentration seen in each country and the export of emission precursors. The mass export of $\mathrm{NO}_{\mathrm{x}}$ across the border from south to north and from west to east are shown in Figures 5.25 (b) and 5.26(b), respectively. The plots demonstrate that latitudinal $\mathrm{NO}_{\mathrm{x}}$ export mainly occurs from the US to Canada specifically at the end of the summer. However, a fairly equal exchange rate of $\mathrm{NO}_{\mathrm{x}}$ emissions is seen in longitudinal direction across the US-Canada border. Mass transport of ethylene (as a representative for anthropogenic VOCs) in latitudinal and longitudinal directions were also quantified (Figures 5.25(c) 5.26(c)). The spatial and temporal variations of latitudinal export of VOCs are similar to that of $\mathrm{NO}_{\mathrm{x}}$ but smaller in magnitude (by one order of magnitude difference). However, there is also export of emissions from Canada to the US in Midwestern in the first month of the summer. The longitudinal export of VOCs (Figure 5.26(c)) occurs in a fairly equal rate between two countries. It can be concluded that ozone export in longitudinal direction mainly occurs from US to Canada, whereas, the $\mathrm{NO}_{\mathrm{x}}$ and VOCs emissions (ozone precursors) are exported equally between Canada and the US.

The spatial and temporal variation of transport of masses of the air to/from each country in the border areas were also quantified (latitudinal in Figure 5.25(d) and longitudinal in 5.26(d)). These two plots are prepared to explore the existing resemblances between the export pattern of the air and the pollutants during the summer. Comparison of the plots shows that the spatial and temporal variations of ozone and the air in both directions are similar. Ozone has a much longer atmospheric 
lifetime (few days to several weeks) than $\mathrm{NO}_{\mathrm{x}}$ or ethylene (hours), and therefore, it has much more homogeneous distribution in the atmosphere than $\mathrm{NO}_{\mathrm{x}}$ or VOCs. As a result, the observed resemblance between export/import behavior of ozone and air is expected while the lack of such resemblance for $\mathrm{VOC} / \mathrm{NO}_{\mathrm{x}}$ is not surprising.

The time series of total masses (net value) of pollutants (Ozone, $\mathrm{NO}_{\mathrm{x}}$ and VOCs), exported from the US to Canada or Canada to the US, in latitudinal and longitudinal directions in each day of Summer 2007 are presented in Figure 5.27. A great deal of temporal variabilities is seen in the time series of border mass transfer for all pollutants. Time series plots of ozone and its precursors show (as do spatial plots in Figure 5.25 and Figure 5.26) two order of magnitude differences in species transport, reflecting the expected difference in atmospheric abundance. Also, it can be seen in the Figure 5.27 (a) that ozone is exported in longitudinal (west-to-east) direction mainly from the US to Canada. However, plot (b) and (c) represent that $\mathrm{NO}_{\mathrm{x}}$ and VOCs are exported in latitudinal (south-to-north) direction from the US to Canada. For all other cases, there is a fairly equal rate of export between Canada and the US. 
a)

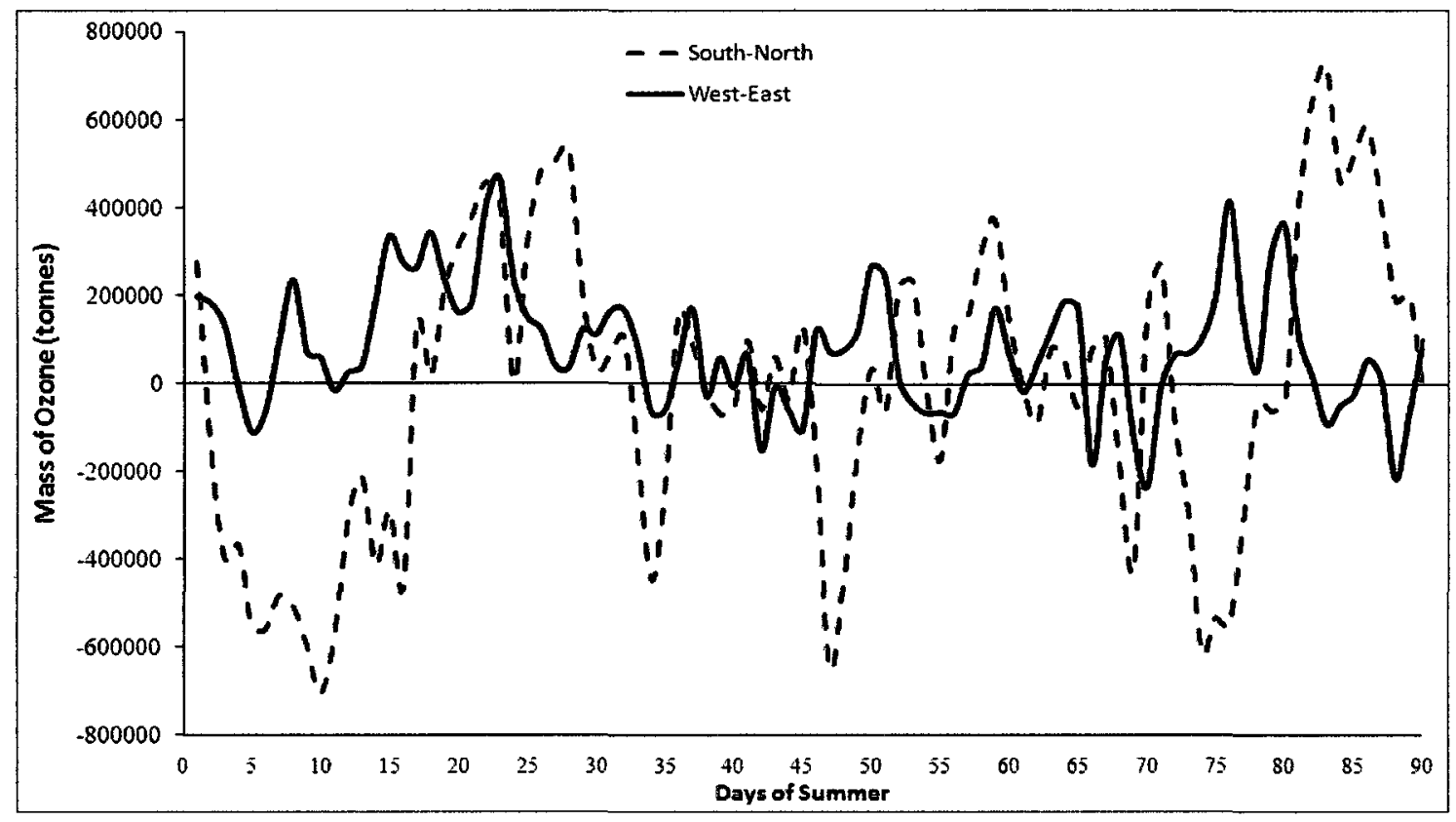

b)

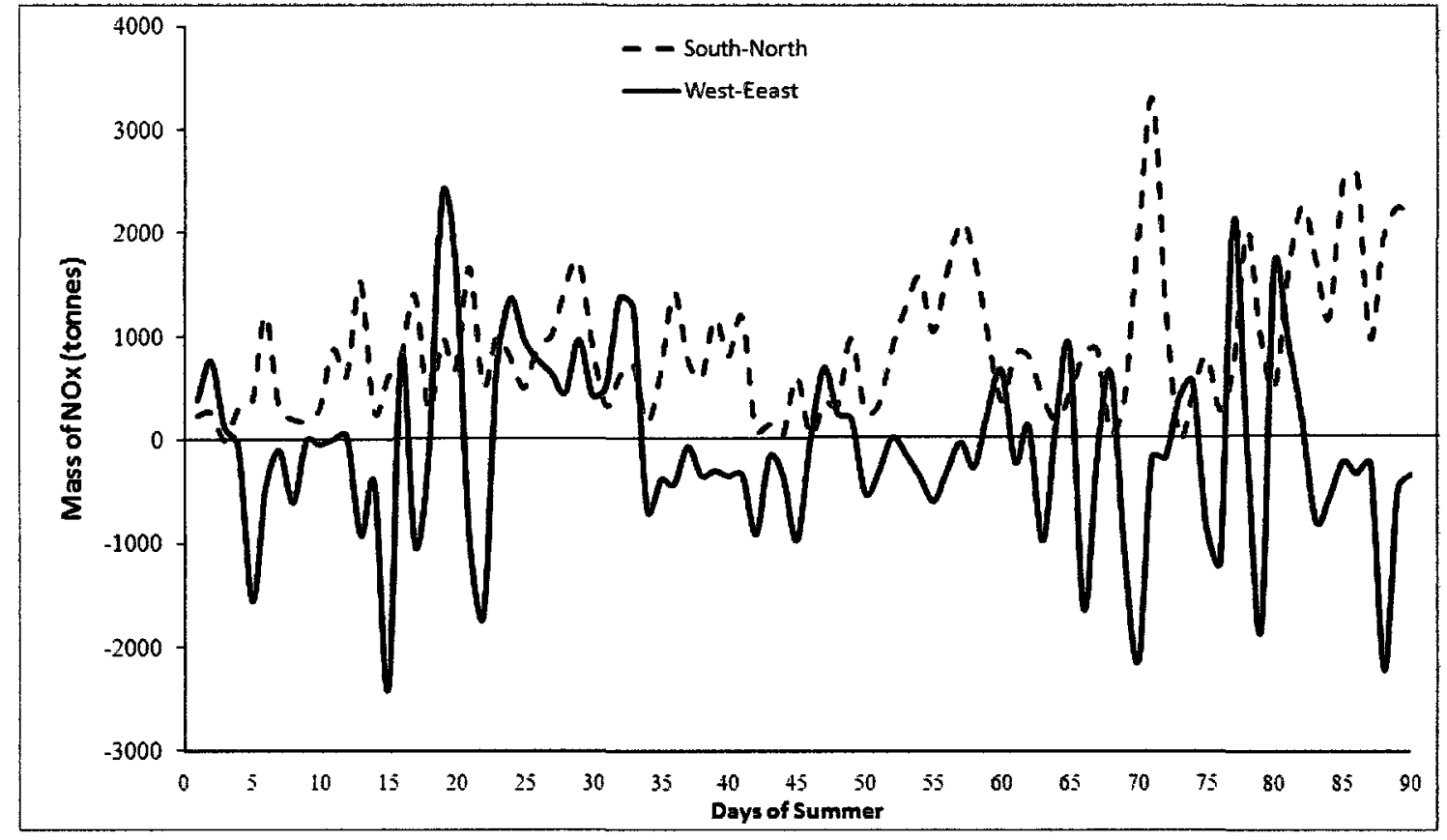


c)

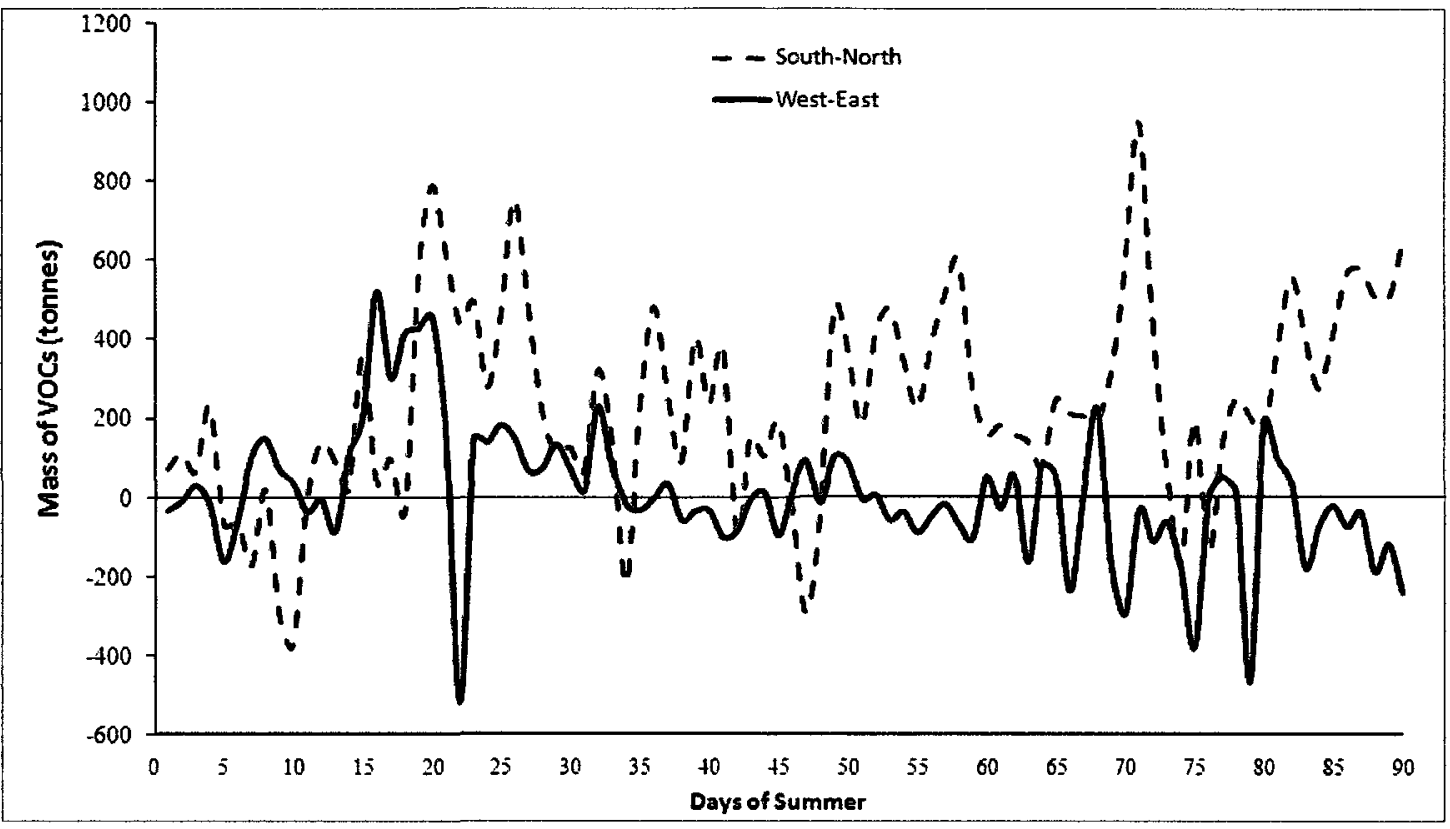

Figure 5.27 Summer time series of masses (tonnes) of a) Ozone, b) $\mathrm{NO}_{\mathrm{x}}$, and c)VOCs exported from the US to Canada (positive) and from Canada to the US (negative) in longitudinal (solid line) and latitudinal (dash line) directions during the Summer of 2007.

$\mathrm{NO}_{\mathrm{x}}$ and VOC concentrations are typically higher in the boundary layer, and as such, transport of $\mathrm{NO}_{\mathrm{x}}$ happens mainly in the boundary layer. Due to their relatively short lifetime these compounds have higher concentrations closer to their sources and in the boundary layer. Similarly, shorter lifetime for $\mathrm{NO}_{\mathrm{x}}$ and VOCs leads to a vertically heterogeneous distribution at various heights. This is the underlying reason for differences in spatio-temporal variability of import/export across the border. The cross border transport of ozone, $\mathrm{NO}_{\mathrm{x}}$, and VOCs in the boundary layer (here taken as the first $2 \mathrm{~km}$ above the surface), and free troposphere (tropospheric layers above the boundary layer) were calculated. The latitudinal (south to north) mass export of pollutants in the border area in the boundary layer and in the free troposphere are compared in Figure 5.28. 


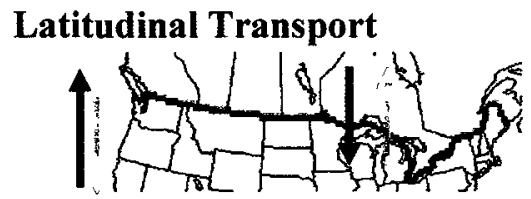

a) Ozone in the Boundary Layer

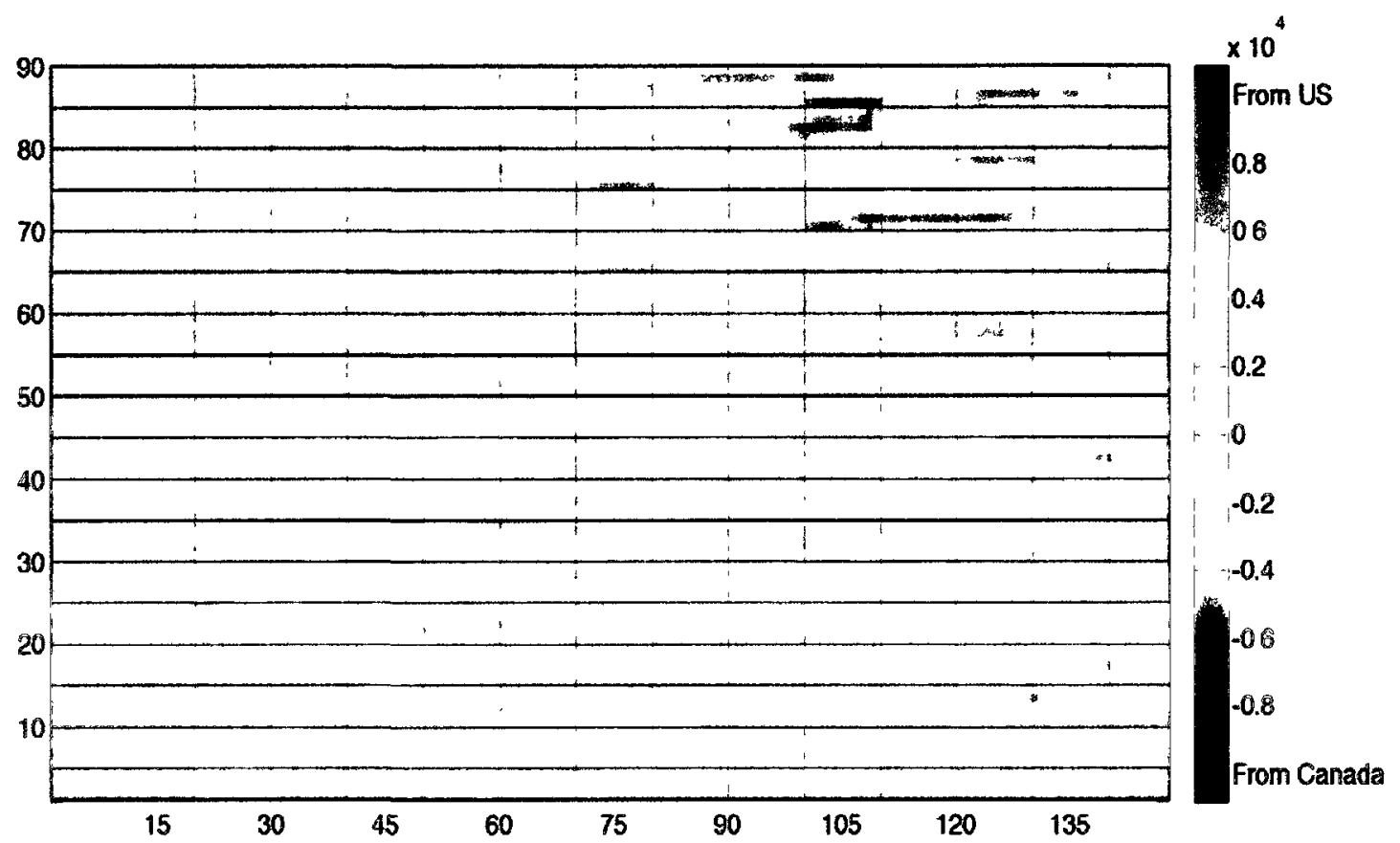

b)Ozone in the Free Troposphere

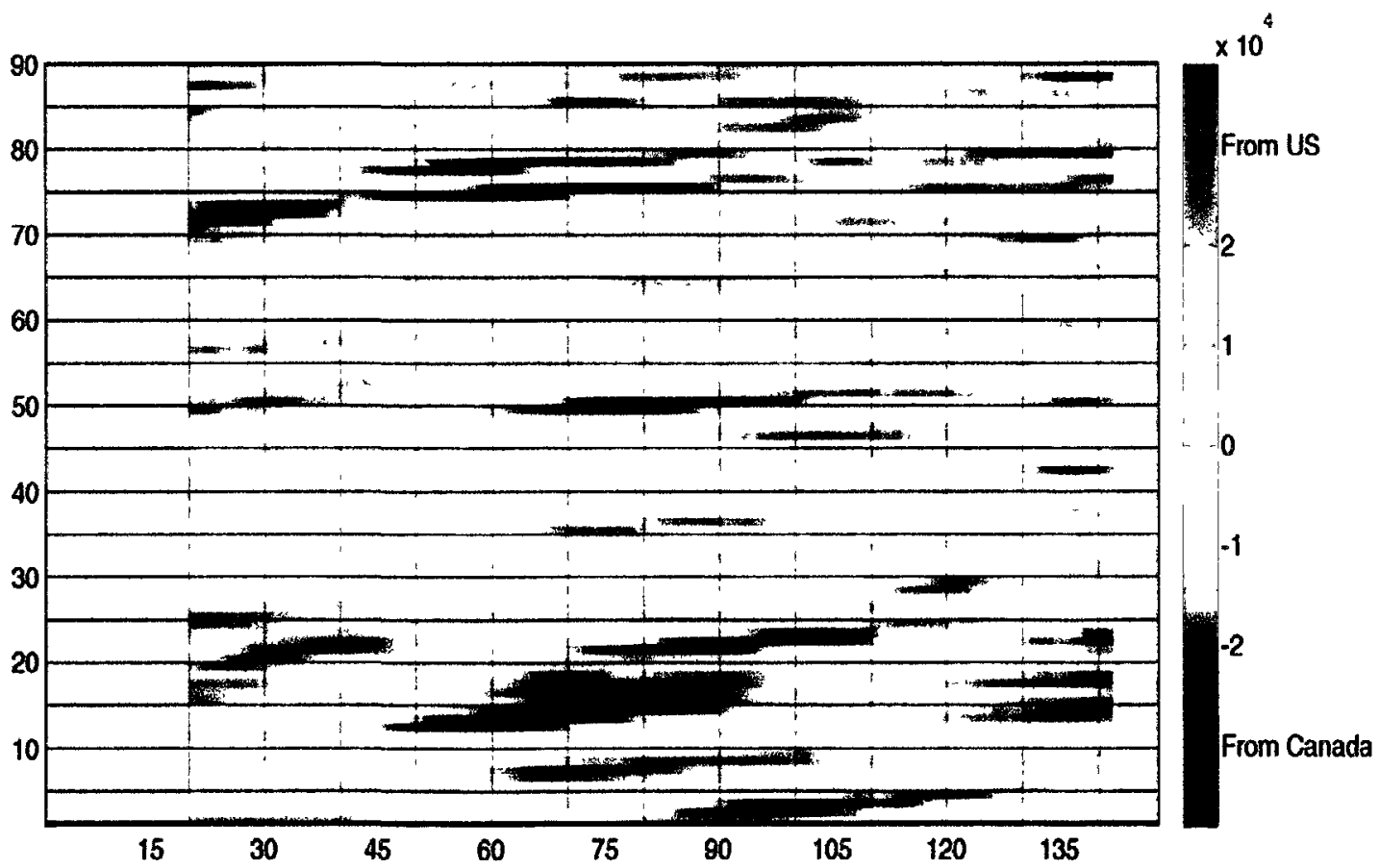


c) $\mathrm{NO}_{\mathbf{x}}$ in the Boundary Layer

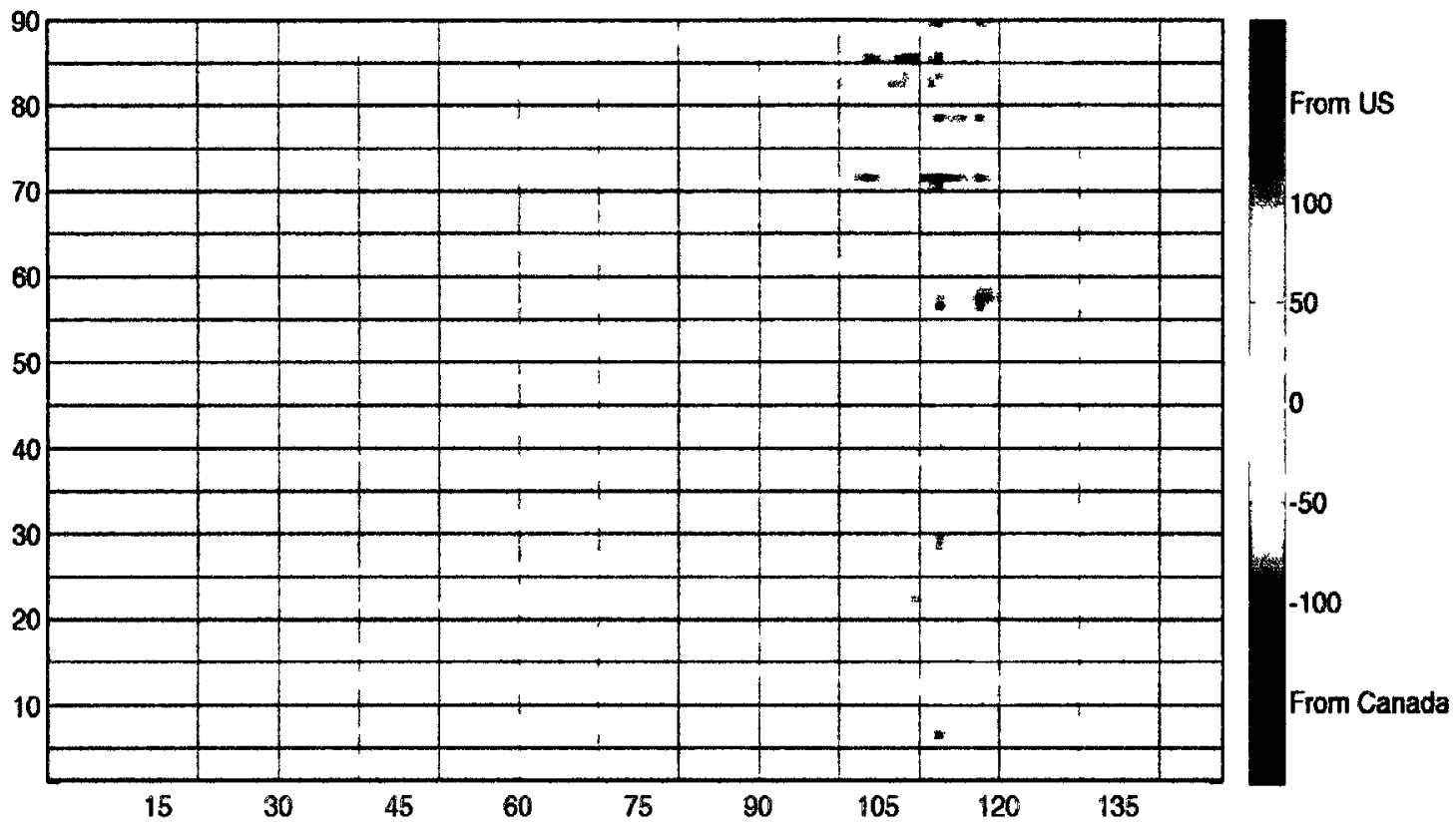

d) $\mathrm{NO}_{\mathrm{x}}$ in the Free Troposphere

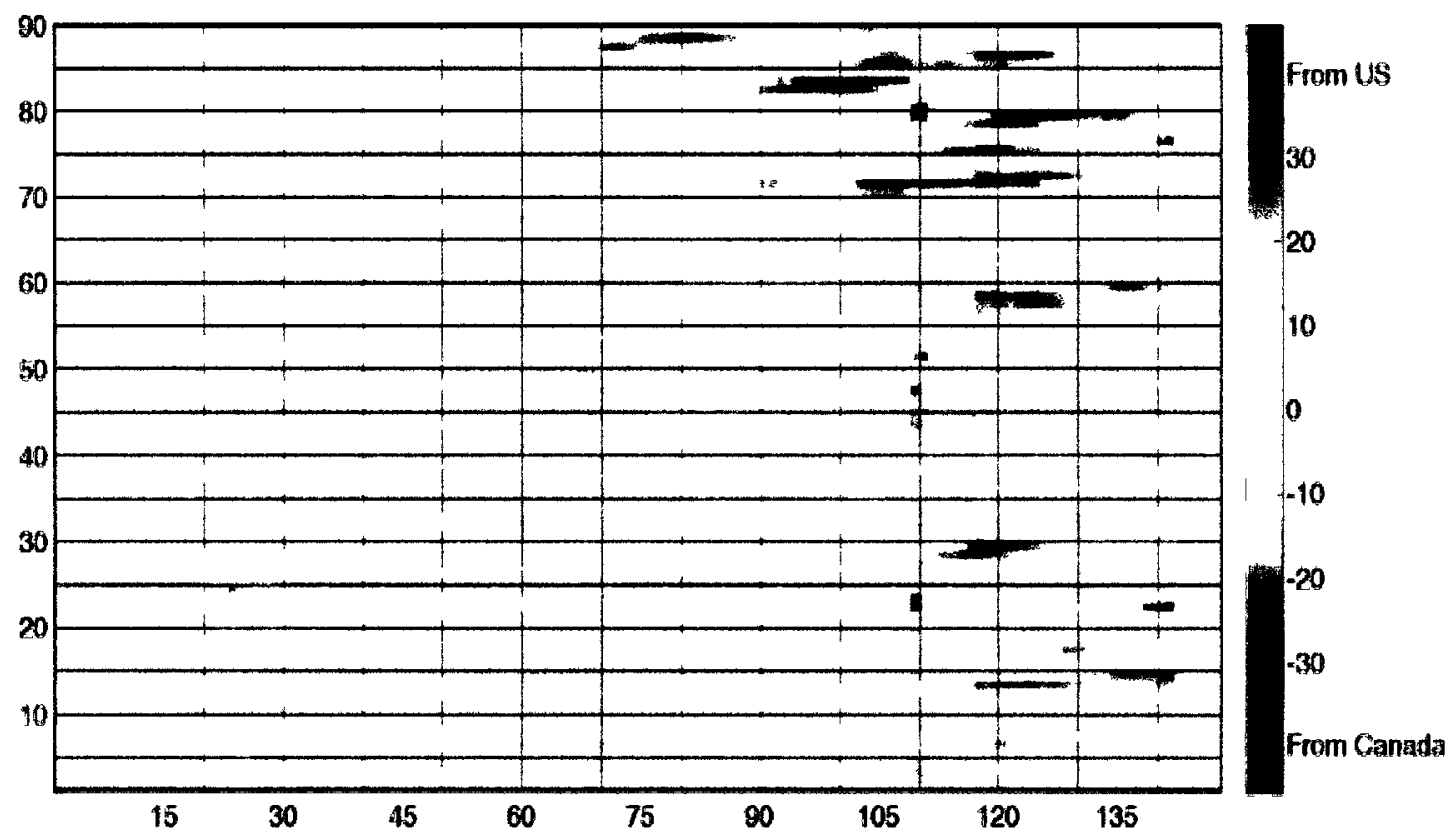


e) Ethylene (VOCs) in the Boundary Layer

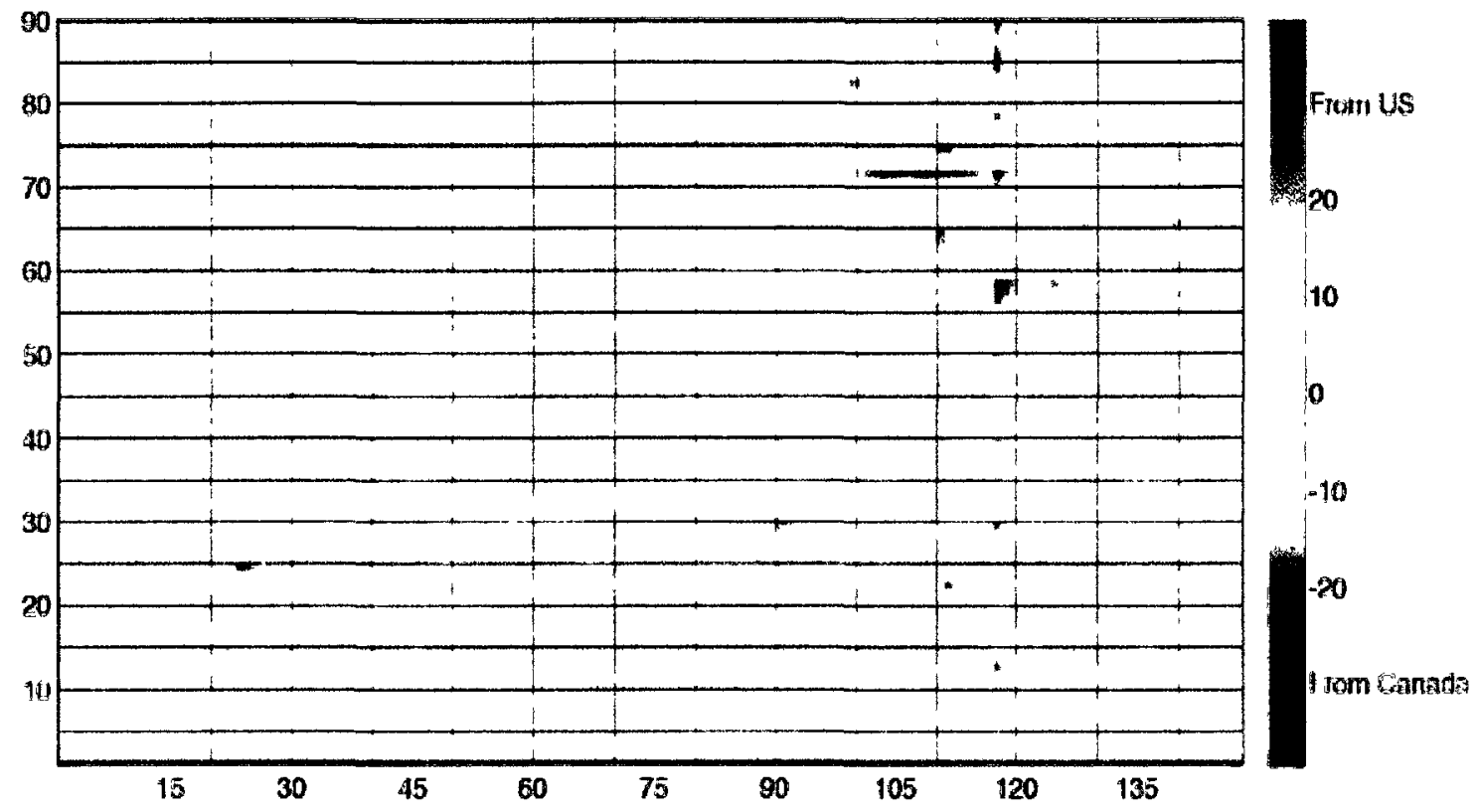

f) Ethylene (VOC) in the Free Troposphere

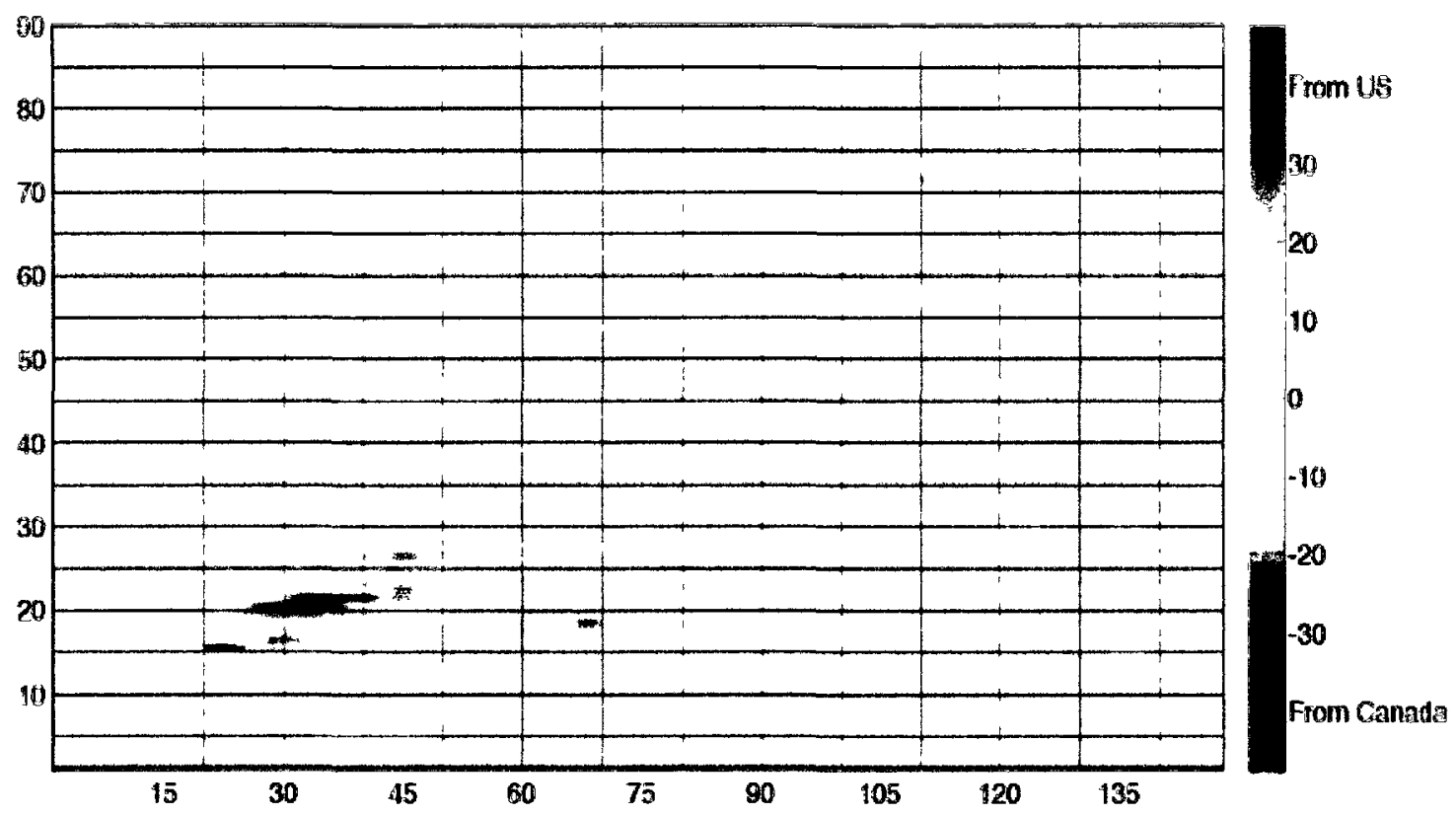

Figure 5.28 Latitudinal (south-to-north) export of different pollutants in the boundary layer and in the free troposphere during the summer of 2007 . The $y$-axis shows the 90 days of simulation and the $x$-axis shows the 148 columns included in the domain. The red color is for export of mass (tonnes) from US to Canada and the blue color shows export of mass from Canada to US. Figure (a) and (b) show ozone (c) and (d) show NO and (e) and (f) show Ethylene. 
The mass export of ozone in the boundary layer and in the free troposphere is compared in plots (a) and (b). As expected, the transport of ozone happens more significantly in the free-troposphere; the numbers in plot (b) are an order of magnitude greater than plot (a). The stronger wind fields and generally higher ozone concentrations in the upper layers cause long-lived species (e.g., ozone) to be transported rapidly and more severely. However, species with shorter lifetime like $\mathrm{NO}_{\mathrm{x}}$ are more concentrated in the boundary layer. Accordingly, $\mathrm{NO}_{\mathrm{x}}$ export occurs somewhat more significantly in the boundary layer; the magnitude of mass transport in plot (c) is greater than in plot (d) (legends are numbered differently). Similarly, VOCs (ethylene) is also exported more considerably in the boundary layer rather than the free troposphere. However, the difference is not as significant as the one seen in $\mathrm{NO}_{\mathrm{x}}$ export pattern reflecting its longer lifetime. Similar to ozone, the export of air in the free troposphere is more significant (an order of magnitude larger) than the one in the boundary layer due to the strong wind field in the free-troposphere, but it is not shown.

The differences between free tropospheric and near-surface $\mathrm{NO}_{\mathrm{x}}$ and VOCs border crossings are also explored for the case of longitudinal transport (Figure 5.29). Similarly, the longitudinal transport of ozone in free-troposphere (plot (b)) happens more significantly (10 times greater) than in the boundary layer (plot (a)). The difference is more substantial in this direction, as the wind has a stronger (i.e. geostrophic) component in the free-troposphere. Similar to the latitudinal direction, the longitudinal transports of ozone precursors also occur more significantly in the boundary layer than in the free troposphere. Again, a similar pattern is seen between the transport of air and ozone in longitudinal direction in different vertical layers. 


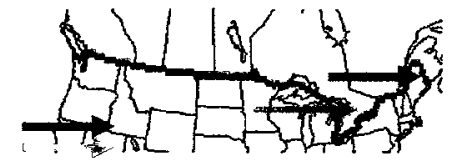

a) Ozone in the Boundary Layer

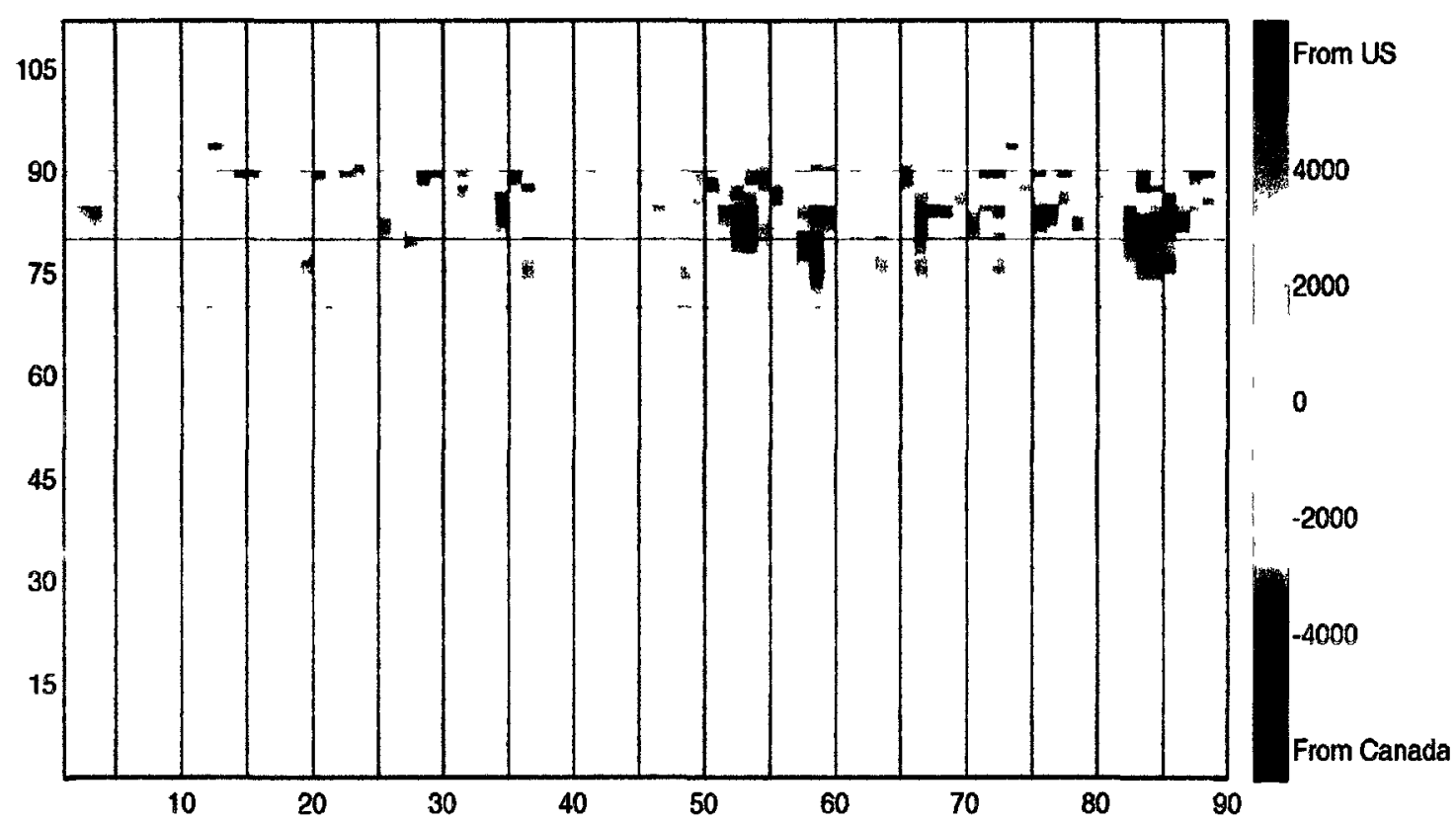

b) Ozone in the Free troposphere

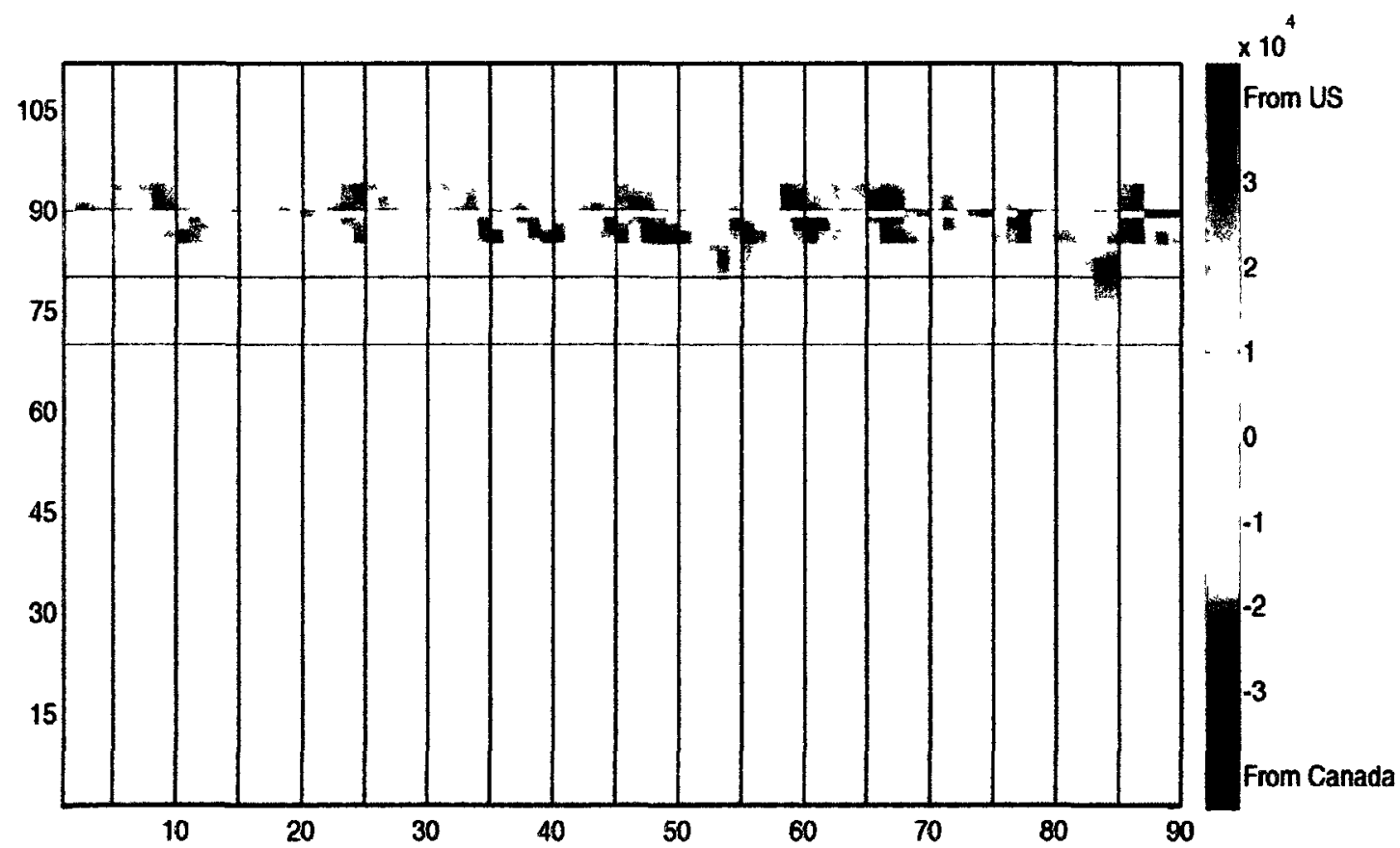


c) $\mathrm{NO}_{x}$ in the Boundary Layer

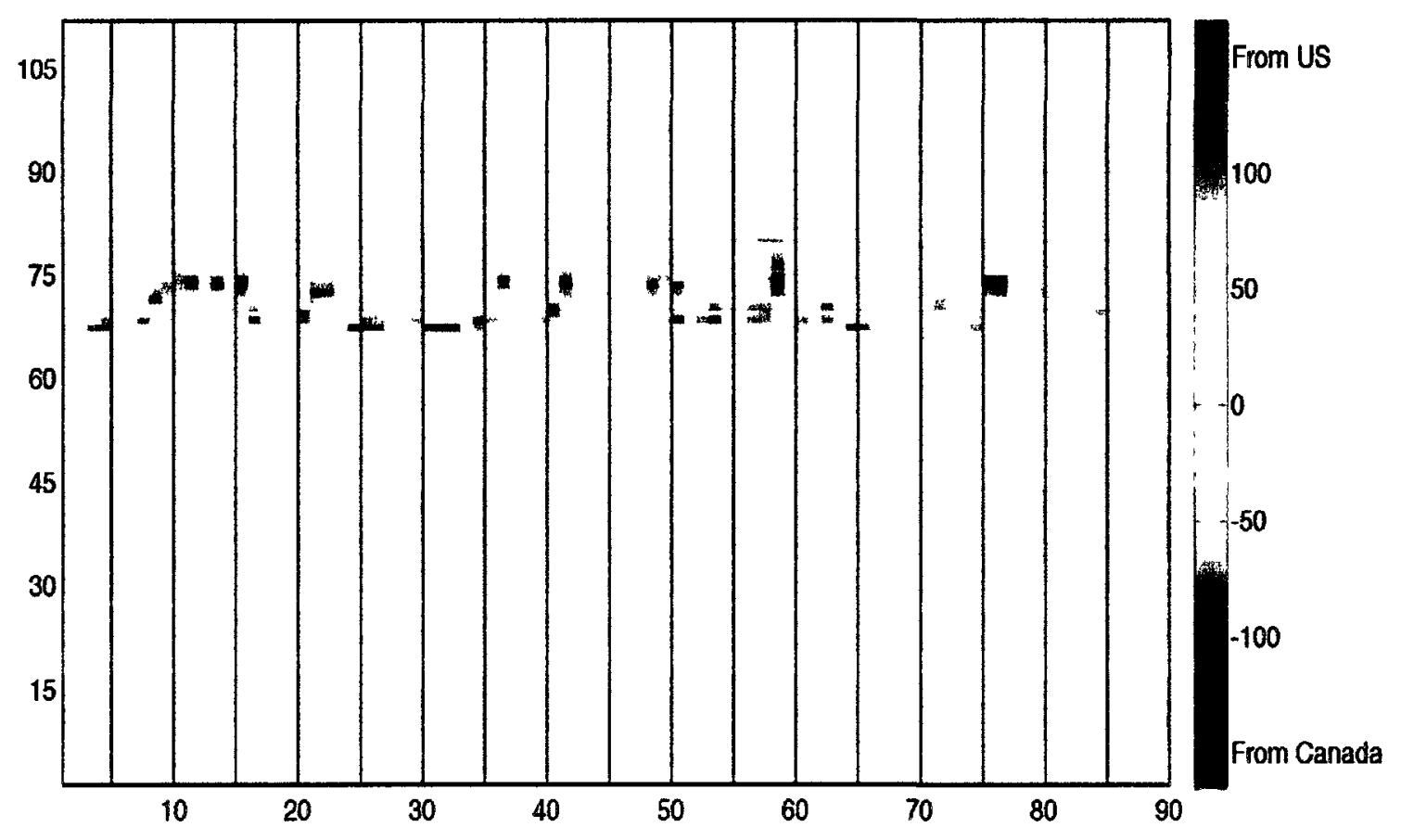

d) $\mathrm{NO}_{x}$ in the Free Troposphere

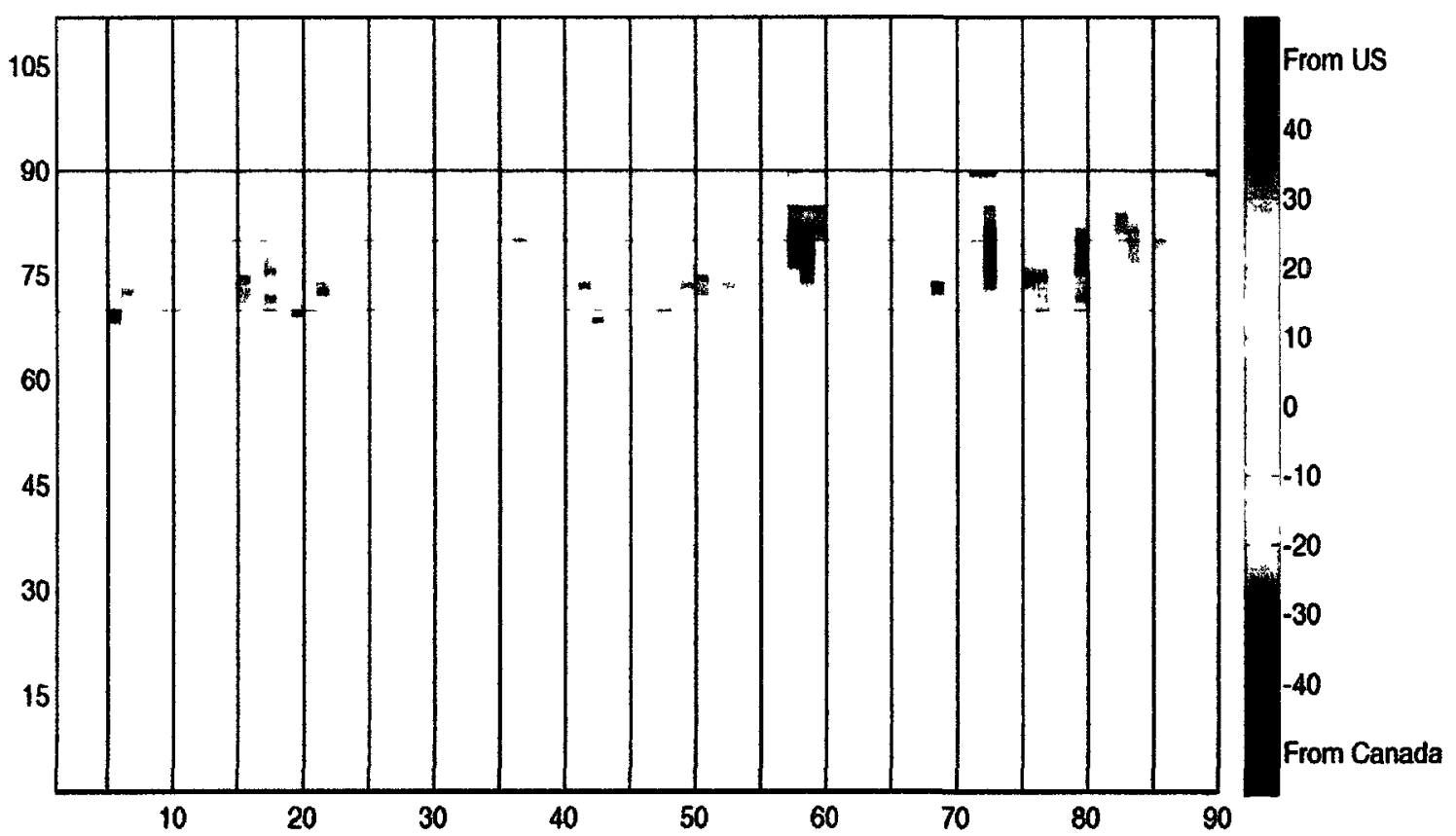


e) Ethylene (VOCs) in the Boundary layer

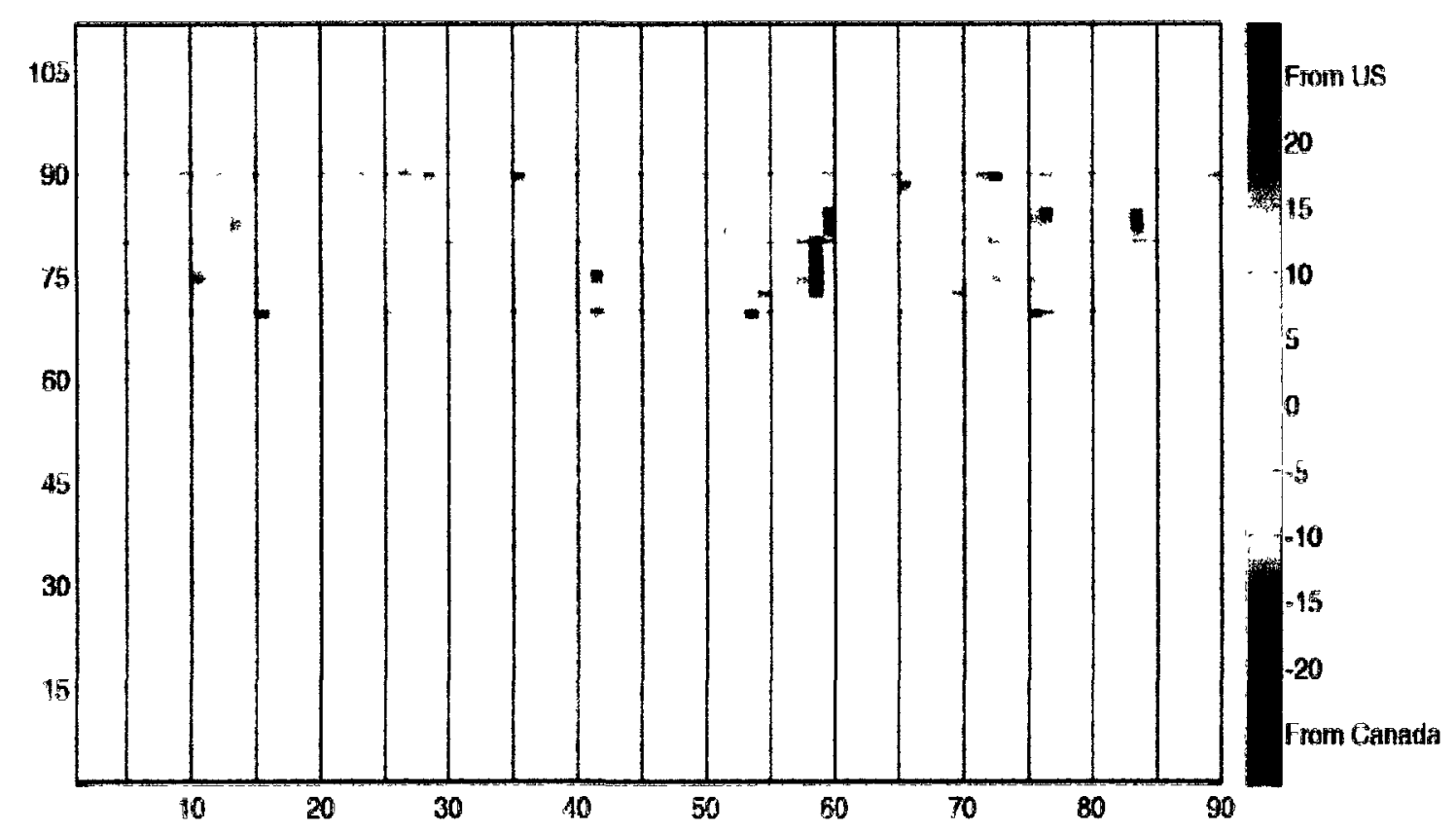

f) Ethylene (VOCs) in the Free Troposphere

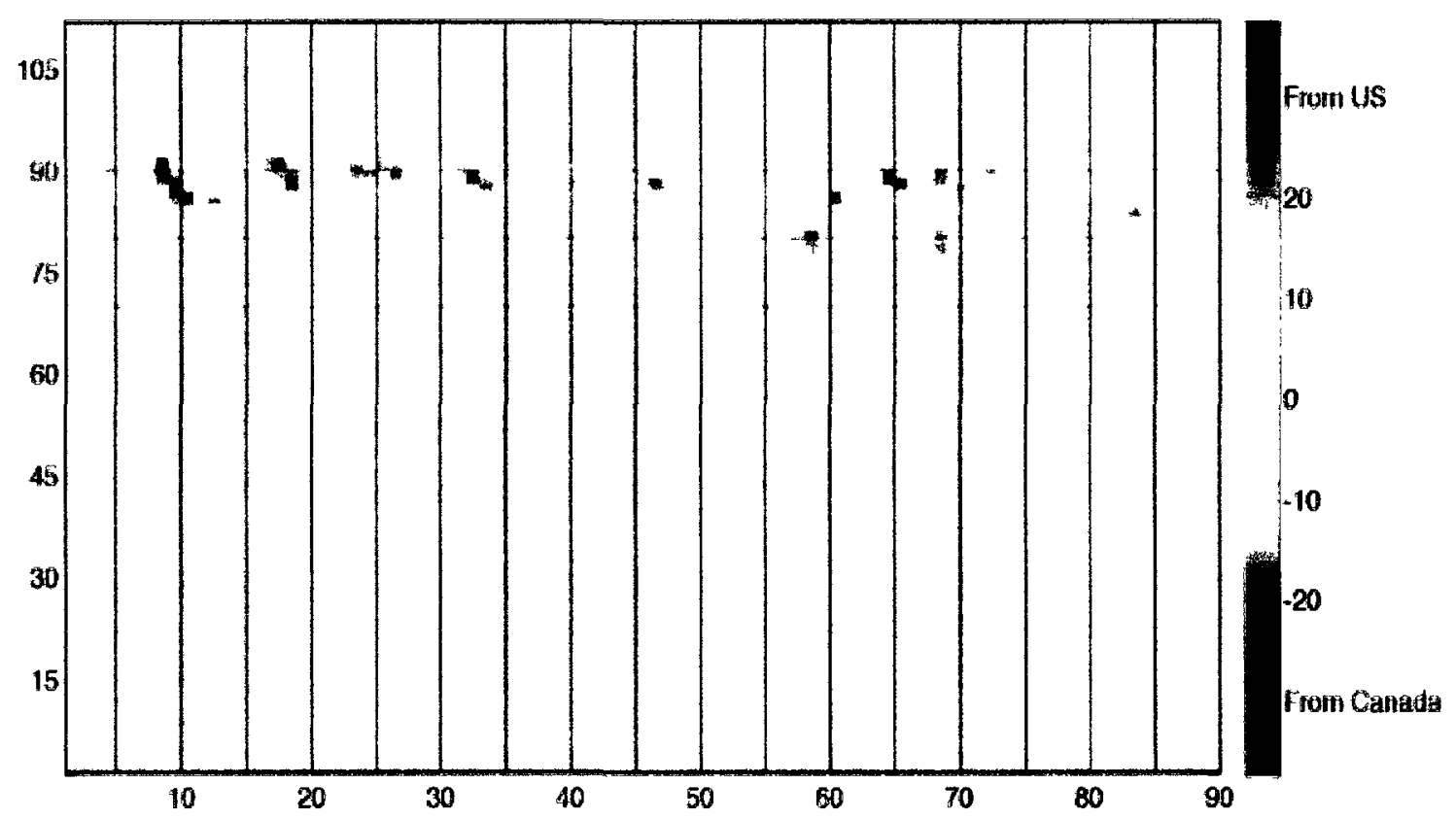

Figure 5.29 Longitudinal (west-to-east) export of different pollutants in boundary layer and in the free troposphere during the summer of 2007. The $\mathbf{x}$-axis shows the 90 days of the simulation and the $y$-axis shows the 112 rows included in the domain. The red color shows export of mass (tonnes) from US to Canada and the blue color shows export of mass from Canada to US. Figures (a) and (b) show ozone (c) and (d) show NO $\mathrm{O}_{\mathrm{x}}(\mathrm{e})$ and (f) show Ethylene. 


\section{Chapter 6: Conclusions and Future Work}

Long-range transport of ozone and its precursors across the US-Canada border during the Summer of 2007 is quantified using a number of approaches. Selected metrics were defined and calculated as daily average ozone and maximum $8 \mathrm{~h}$-average ozone across the receptor areas of each country. While maximum 8 h-average ozone reflects the impact on daytime high concentration areas, the daily average ozone metric also takes into account the impact of emissions zero-out scenarios on nighttime concentrations of ozone. Different methods applied in this work enabled the quantification of source-receptor relationships in this region. Although each method quantified the long-range transport of ozone across Canada-US border from different perspective they all resulted in more or less similar findings that are outlined below.

First and foremost, it was consistently found that during the summer of 2007 American emissions had a significantly larger contribution to the surface ozone air quality in Canadian border area than Canadian emissions to the US border area. This point could be inferred from various approaches. Not only was the impact of American emissions very substantial on the domestic ozone air quality, but they also 
had as large an impact as domestic Canadian emissions in Canada. More interestingly, American emissions rather than domestic emissions had a more considerable contribution to the ozone exceedances above CWS in the border area of Canada. Conversely, emissions from Canada had a mostly insignificant impact on ozone metrics in the US-Canada border areas during the episode with the exception of some northeast regions. Southern Ontario and northeast US were areas the most affected by cross-border transport in Canada and the US during the Summer 2007, respectively. It is noteworthy to mention that the level of reduction in US ozone concentrations seen in our study (peaking at $42 \mathrm{ppb}$ in northeast US) is in good agreement with previous studies [Wang et al., 2009]. However, we concluded that for certain areas of Canada contributions from American emissions were as high as (peaking at $72 \mathrm{ppb}$ ) those from domestic sources. Comparison of ozone air quality improvement in two selected metrics in this study shed light on the fact that the effects of the zero-out scenarios are larger during the day and when ozone concentrations are high. This emphasizes the fact that diurnal high ozone concentrations in Canada are effectively reduced by lowering foreign emissions especially for Canada. This is of particular policy importance as these points are typically those that drive the regulatory process. Also, these points are generally located in some of the most populated areas in Canada, i.e. southern and southeastern Ontario. Given the level of impact of American emissions on ozone concentrations in US-Canada border areas, it can be stated that ozone nonattainment events in this area can be reduced and controlled under tighter American emission reduction policies. This highlights the need for policies with more focused attention on cross-border emissions, particularly from the US sources, to achieve ozone standards in the US-Canada border area. 
Second, nonlinearity of ozone response with respect to magnitude of emissions reduction was examined by comparison of marginal (10\%) and zero-out sensitivities. For the majority of the locations in the receptor area of Canada, particularly in southern Ontario, zero-out reductions result in generally larger sensitivities than marginal perturbations. The larger response of maximum 8h-average ozone in southern Ontario to the zero-out rather than marginal reductions indicates a daytime concave response of ozone with respect to $\mathrm{NO}_{\mathrm{x}}$ in this area. However, in the US particularly in northeast, the marginal sensitivities are equal and to some extent larger than the zero-out sensitivities. Furthermore, for Canada, a largely nonlinear behavior is observed while for the US deviations from linearity ( 1 on 1 line) are much smaller. It was concluded that the impact of American emissions on the chemical regime in Canada is substantial enough to trigger a regime change and the consequent nonlinear behavior. By contrast, the impact of Canadian emissions on the overall composition and making of the US atmosphere is much smaller, and in general (with the exception of northeast US) not large enough to cause large degree of nonlinearity.

Third, we found that ozone response to reduction of anthropogenic emissions was similar in spatial distribution and magnitude to that of $\mathrm{NO}_{\mathrm{x}}$, which underlines the importance of current $\mathrm{NO}_{\mathbf{x}}$ reduction policies. By employing backward sensitivity analysis, the major $\mathrm{NO}_{\mathrm{x}}$ emission sources whose emissions result in high ozone concentrations in US-Canada border areas were identified. Daily average ozone over the surface of Canada showed great sensitivities to urban centers in the US as far as southern California. Among those centers New York, Detroit, and Los Angeles were easily distinguished. Large sensitivity of average ozone over Canada to $\mathrm{NO}_{\mathbf{x}}$ emissions in southern California (Los Angeles) will require further studies before 
conclusive judgment can be made. Similarly, Canadian centers such as Montreal, Ottawa, Toronto, Calgary and Vancouver seem to be the main contributing sources to surface ozone pollution of the US border area. The relatively high emissions of $\mathrm{NO}_{\mathbf{x}}$ in these cities influence the local surface ozone concentrations as well. Elimination of domestic emissions causes increase in daily average ozone concentrations in these cities. Even marginal reduction in domestic emissions (10\%) causes an increase in average ozone concentrations in some of the western centers including Calgary and Vancouver. These findings suggest that there is a need for a more detailed investigation of the impact of long-range transport in metropolitan areas. Furthermore, the temporal variations seen in sensitivities of ozone with respect to the $\mathrm{NO}_{\mathrm{x}}$ sources, particularly in July is difficult to be assessed and depends on a myriad of factors including transport and chemistry.

Finally, budgeting of transport of ozone and its precursors across the border reveals the impact of wind field strength, direction and its temporal variation on cross-border export of pollutions in this region. It was concluded that net export of ozone in westto-east direction occurs mainly from the US to Canada in southern Ontario and from Canada into the US in northern New York. Both phenomena cause sizeable ozone air quality impairment in respective regions, particularly in Ontario. The export of ozone from the US in south-to-north direction occurs mainly in the east and west coasts and from Canada across midwestern provinces/states. As expected, the transport of ozone happens more significantly in the free-troposphere with a similar distribution as air. In contrast, transport of ozone precursors occur primarily in the boundary layer and mainly from the US in south-to-north direction. 
Although the current study somewhat overestimated ozone concentrations across the US and Canada, satisfactory agreement was seen between model predicted maximum $8 \mathrm{~h}$-average ozone and observation data in monitoring sites close to the border where highest cross-border impacts are expected. It is also important to note that our primary goal was to provide methodologies for comprehensive assessment of cross-border transport. We did not intend to draw policy conclusions or locate the blame. Drawing policy conclusions require simulations over longer periods (multi-year episodes), use of higher resolution, and improved inventories.

Furthermore, current version of the adjoint model for CMAQ only includes the gasphase processes, and as a result, our analysis remains limited to the transport of ozone. However, the methodology developed will be readily applicable to multipollutant analysis of long-range transport once the adjoint model is extended to aerosol processes (under development). Additionally, employing adjoint sensitivity analysis for investigation of other functional targets of ozone, e.g., population exposure and mortality, in Canada and the US will also provide interesting results about contribution of individual foreign sources to various air quality end-metrics.

There are a number of future directions where this study can be improved upon. Some of these directions are already mentioned above. A summary of suggested future work is given below: 
- Reliable emission inventories are essential for applicability of cross-border studies. In addition to efforts for improving the quality of inventories and emission modeling, one can use top-down approaches for refinement of available inventories. This is accomplished through inverse modeling of emissions such that models are pushed to be more consistent with observations.

- In our study CMAQ was driven by time invariant boundary conditions that are based on climatology. This blurs the true impact of intercontinental transport on North American concentrations. One can attempt to drive CMAQ with boundary conditions that are provided by a global model such as GEOSChem. GEOS-Chem and CMAQ are coupled in the forward mode. If that coupling is extended to backward (adjoint) simulations (under development), then the same analysis carried out in this study can be performed on a truly regional-to-global scale.

- Given the temporal variability in cross-border transport, it is important to repeat this study over considerably longer periods of time. It should also be investigated whether there is a seasonal pattern to cross-border transport.

- Considering ozone in isolation from other pollutants is another limitation of this study that can be overcome in future work. Multi-pollutant cross-border analysis provides a more comprehensive perspective on the dynamics of pollution transport in North America. Multi-pollutant backward analysis of 
cross-border transport requires an adjoint of aerosol processes in CMAQ (under development).

- While the focus of this work was on US-Canada border, the same approach can be applied to inter-provincial transport of ozone or other pollutants. Similarly, the suite of approaches used in this study can also improve our understanding of intercontinental transport. 


\section{REFERENCES}

Auvray, M. \& Bey, I. 2005, "Long-range transport to Europe: Seasonal variations and implications for the European ozone budget", Journal of Geophysical Research, 110.

Bell, M. L., McDermott, A., Zeger, S. L., Samet, J. M., Dominici, F, 2004. "Ozone and short-term mortality in 95USurban communities". Journal of American Medical Association, 292, pp. 2372-2378.

Bergin, M.S., Shih, J.S., Krupnick, A.J., Boylan, J.W., Wilkinson, J.G., Odman, M.T. \& Russell, A.G. 2007, "Regional air quality: local and interstate impacts of $\mathrm{NO}_{\mathrm{x}}$ and SO2 emissions on ozone and fine particulate matter in the eastern United States", Environmental Science and Technology, 41, 13, pp. 4677-4689.

Byun, D. W., Ching, J. K. S, 1999, "Science algorithms of the EPA Models 3Community Multiscale. Air Quality (CMAQ) modeling system". http://www.epa.gov/asmdnerl/CMAQ/CMAQscienceDoc.html (August 2010).

Byun, D.W., Pleim, J., Tang, R. \& Bourgeois, A. 1999a, "Meteorology-chemistry interface processor (MCIP) for Models-3 Community Multiscale Air Quality (CMAQ) modeling system", Washington, DC, US Environmental Protection Agency, Office of Research and Development.

Byun, D.W., Young, J., Pleim, J., Odman, M.T. \& Alapaty, K. 1999b, "Numerical transport algorithms for the Community Multiscale Air Quality (CMAQ) chemical transport model in generalized coordinates", Science Algorithms of the EPA Models-3 Community Multiscale Air Quality (CMAQ) Modeling System, EPA/600/R-99, 30, pp. 7-1.

Carter, W. P. L., 2000. "Documentation of the SAPRC99 chemical mechanism for VOC reactivity assessment". Air Pollution Research Center and College of Engineering, Center for Environmental Research and Technology, University of California, Riverside, CA.

CEP Sparse Matrix Operator Kernel Emissions "Modeling System (SMOKE) User Manual"; Carolina Environmental Program: 2006. http://www.smokemodel.org/version2.6/SMOKE_v26_manual.pdf

Chen, J., Ying, Q. \& Kleeman, M.J. 2009, "Source apportionment of visual impairment during the California regional PM10/PM2. 5 air quality study", Atmospheric Environment, 43, 39, pp. 6136-6144.

Cohan, D.S., Hakami, A., Hu, Y. \& Russell, A.G. 2005, "Nonlinear response of ozone to emissions: source apportionment and sensitivity analysis", Environmental science \& technology, 39, 17, pp. 6739-6748. 
Colella, P., and P. L. Woodward, 1984, "The piecewise parabolic method (PPM) for gasdynamical simulations". Journal of Computer Physics, 54, pp. 174-201.

CRS 2010, McCarthy. J. E., 2010, “Ozone Air Quality Standards: EPA's Proposed": January 2010 Revisions, Congressional Research Service, 7-5700, R41062, www.crs.gov

Dodge, M.C. 1977. "Combined use of modeling techniques and smog chamber data to derive ozone-precursor relationships".International Conference on Photochemical Oxidant Pollution and its Control: Proceedings, Vol. II., B. Pp. 881-889, Dimitriades, ed. EPA/600/3-77-001b. U.S. Environmental Protection Agency, Environmental Sciences Research Laboratory, Research Triangle Park, N.C

Damian, V., Sandu, A., Damian, M., Potra, F. \& Carmichael, G.R. 2002, "The kinetic preprocessor KPP-a software environment for solving chemical kinetics", Computers \& Chemical Engineering, 26, 11, pp. 1567-1579.

Duncan, B. \& Bey, I. 2004, "A modeling study of the export pathways of pollution from Europe: Seasonal and interannual variations (1987-1997)", Journal of Geophysical Research, 109, pp. D08301.

Elbern, H., \& Schmidt, H., and Ebel, A.1997, "Variational data assimilation for tropospheric chemistry modeling", Journal of Geophysical Research, 102 pp.15967-15985.

Elbern, H., \& Schmidt, H. 1999, "A four-dimensional variational chemistrydata assimilations scheme for Eulerian chemistry transport modeling", Journal of Geophysical Research. 104, pp.18583-18598.

Elbern, H., Schmidt, H., Talagrand, O., Ebel, A. 2000, “4D-variational data assimilation with an adjoint air quality model for emission analysis". Environ Model Software, 15, 539-548.

Environment Canada, 2000, "Canada-wide standards for particulate matter and ozone", Canadian Council of Ministers of the Environment (CCME), June 5-6, 2000, Quebec City, http://www.ccme.ca/assets/pdf/pmozone_standard_e.pdf

Environment Canada, 2003,National Air Pollution Surveillance (NAPS) data, (http://www.etc-cte.ec.gc.ca/napsdata/Default.aspx)

Environment Canada, 2010, "Canada United States Air Quality Agreement progress report 2010”, http://www.ec.gc.ca/publications/4B98B185-7523-4CFF-90F25688EBA89E4A/CanadaUnitedStatesAirQualityAgreementProgressReport2010. pdf

Gropp, W. \& Lusk, E. 1996, "User's Guide for mpich, a Portable Implementation of MPI". http://parallel.ru/docs/Parallel/mpich/userguide/paper.html 
Fiore, A.M., Jacob, D.J., Bey, I., Yantosca, R.M., Field, B.D., Fusco, A.C. \& Wilkinson, J.G. 2002, "Background ozone over the United States in summer: Origin, trend, and contribution to pollution episodes", Journal of Geophysical Research, 107, 10.pp. 1029.

Fiore, A., Dentener, F., Wild, O., Cuvelier, C., Schultz, M., Hess, P., Textor, C., Schulz, M., Doherty, R. \& Horowitz, L. 2009, "Multi-model Estimates of Intercontinental Source-Receptor Relationships for Ozone 1 Pollution 2", Science, 54, pp. 55.

Fisher, M. \& Lary, D. J. 1995," Lagrangian four-dimensional variational data assimilation of chemical species", Quarterly Journal of the Royal Meteorological Society 121, 1681-1704, 1995.

Gou, T., Singh, K. \& Sandu, A. 2009, "Chemical Data Assimilation with CMAQ: Continuous vs. Discrete Advection Adjoints", Computational Science-ICCS 2009, pp. 312-321.

Hakami, A.; Odman, M. T.; Russell, A. G. 2003, "High-order, direct sensitivity analysis of multidimensional air quality models". Environmental Science and Technology, 37, pp. 2442-2452.

Hakami, A., Bergin, M.S. \& Russell, A.G. 2004, "Ozone formation potential of organic compounds in the eastern United States: a comparison of episodes, inventories, and domains", Environmental Science and Technology, 38, 24, pp. 6748-6759.

Hakami, A., Henze, D., Seinfeld, J., Chai, T., Tang, Y., Carmichael, G. \& Sandu, A. 2005, "Adjoint inverse modeling of black carbon during the Asian Pacific Regional Aerosol Characterization Experiment, Journal of Geophysical Research, vol. 110, D14301, doi:10.1029/2004JD005671, 2005.

Hakami, A., Seinfeld, J.H., Chai, T., Tang, Y., Carmichael, G.R. \& Sandu, D. 2006, "Adjoint Sensitivity Analysis of Ozone Nonattainment over the Continental United States", Environmental Science and Technology, 40, no. 12, pp. 38553864.

Hakami, A., Henze, D.K., Seinfeld, J.H., Singh, K., Sandu, A., Kim, S., Byun, D. \& Li, Q. 2007, "The Adjoint of CMAQ", Environmental science \& technology, 41, no. 22 , pp. $7807-7817$.

Henze, D., Hakami, A. \& Seinfeld, J. 2007, "Development of the adjoint of GEOSChem", Atmospheric Chemistry and Physics, 7, 9, pp. 2413-2433.

Henze, D. K., J. H. Seinfeld and D. T. Shindell, 2009, "Inverse modeling and mapping U.S. air quality influences of inorganic PM2.5 precursor emissions with the adjoint of GEOS-Chem", Atomspheric Chemistry and Physics 9, pp. 58775903. 
Hopke, P.K. 2003, "Recent developments in receptor modeling", Journal of Chemometrics, 17, no. 5, pp. 255-265.

Hudman, R., Jacob, D., Cooper, O., Evans, M., Heald, C., Park, R., Fehsenfeld, F., Flocke, F., Holloway, J. \& Hubler, G. 2004, "Ozone production in transpacific Asian pollution plumes and implications for ozone air quality in California", , Journal of Geophysical Research, 109, 23, pp. 1-14.

Hudman, R., Murray, L.T., Jacob, D.J., Turquety, S., Wu, S., Millet, D., Avery, M., Goldstein, A., Holloway, J. \& Ryerson, T. 2009, "North American influence on tropospheric ozone and the effects of recent emission reductions: Constraints from ICARTT observations", Journal of Geophysical Research, 114.

Jacob, D.J., Logan, J.A. \& Murti, P.P. 1999, "Effect of rising Asian emissions on surface ozone in the United States", Geophysical Research Letters, 26, 14, pp. 2175-2178.

Jin, L., Tonse, S., Cohan, D.S., Mao, X., Harley, R.A. \& Brown, N.J. 2008, "Sensitivity analysis of ozone formation and transport for a Central California air pollution episode", Environmental Science and Technology, 42, 10, pp. 36833689 .

Kim, S., Byun, D.W. \& Cohan, D. 2009, "Contributions of inter-and intra-state emissions to ozone over Dallas-Fort Worth, Texas", Civil Engineering and Environmental Systems, 26, no. 1, pp. 103-116.

Lee, S., Liu, W., Wang, Y., Russell, A.G. \& Edgerton, E.S. 2008, "Source apportionment of PM2. 5: Comparing PMF and CMB results for four ambient monitoring sites in the southeastern United States", Atmospheric Environment, 42,18 , pp. 4126-4137.

Levy, J. I., Chemerynski, S. M., Sarnat, J. A. 2005, "Ozone Exposure and Mortality: An Empiric Bayes Meta-regression Analysis". Epidemiology, 16, 458-468.

Li, Q., Jacob, D.J., Bey, I., Palmer, P.I., Duncan, B.N., Field, B.D., Martin, R.V., Fiore, A.M., Yantosca, R.M. \& Parrish, D.D. 2002, "Transatlantic transport of pollution and its effects on surface ozone in Europe and North America", Journal of Geophysical Research, 107, D13, pp. 4166.

Liang, J., Horowitz, L.W., Jacob, D.J., Wang, Y., Fiore, A.M., Logan, J.A., Gardner, G.M. \& Munger, J.W. 1998, "Seasonal budgets of reactive nitrogen species and ozone over the United States, and export fluxes to the global atmosphere", Journal of Geophysical Research, 103, pp. 13.

Menut, L., Vautard, R., Beekmann, M., and Honore, C. 2000," Sensitivity of photochemical pollution using the adjoint of a simplified chemistry-transport model", Journal of Geophysical Research, 105, pp. 379-15

NCAR, 2010, Wang, W., Bruyère, C., Duda, M., Dudhia, J., Gill, D., Lin, H. C., Michalakes, J., Rizvi, S., \& Zhang, X., 2010, "Weather Research and 
Forecasting, ARW Version 3 Modelling System User Guide", Mesoscale Microscale Meteorology Division, National Center for Atmospheric Research (NCAR), http://www.mmm.ucar.edu/wrf/users/

National Center for Environmental Predictions (NCEP), 2005, "GRIB data”, http://www.nco.ncep.noaa.gov/pmb/docs/grib2/grib2_doc.shtml

Nester, K. \& Panitz, H.J. 2006, "Sensitivity analysis by the adjoint chemistry transport model DRAISfor an episode in the Berlin Ozone (BERLIOZ) experiment", Atmospheric Chemistry and Physics, 6, no. 8, pp. 2091-2106.

National Research Council (NRC), 1991, "Rethinking the Ozone Problem in Urban and Regional Air Pollution, Committee on Tropospheric Ozone Formation and Measurement", National Academy Press, Washington, D.C. 1991, p.163-168

Pochanart, P., Akimoto, H., Kajii, Y., Potemkin, V. \& Khodzher, T. 2003, "Regional background ozone and carbon monoxide variations in remote Siberia", East Asia, Journal of Geophysical Research, 4028.

Russell, A. \& Dennis, R. 2000, "NARSTO critical review of photochemical models and modeling", Atmospheric Environment, 34, 12-14, pp. 2283-2324.

Sandu, A., Daescu, D.N., Carmichael, G.R. \& Chai, T. 2005, "Adjoint sensitivity analysis of regional air quality models", Journal of Computational Physics, 204, pp. 222-252.

Seaman, N.L. 2000, "Meteorological modeling for air-quality assessments", Atmospheric Environment, 34, 12-14, pp. 2231-2259.

Seinfeld, J.H. \& Pandis, S.N. 1998, "From air pollution to climate change", Atmospheric Chemistry and Physics, John Wiley \& Sons, New York, 1326.

Schmidt, H., \& Martin, D. 2003, "Adjoint sensitivity of episodic ozone in the Paris area to emissions on the continental scale". Journal of Geophysical Research, 108, pp. 8561

Singh. K., Sandu. A., Hakami., A., Seinfeld., J, , 2007,"CMAQ adjoint user's manual"

Stohl, A. \& Trickl, T. 1999, "A textbook example of long-range transportSimultaneous observation of ozone maxima of stratospheric and North American origin in the free troposphere over Europe", Journal of Geophysical Research, 104,30 , pp. 445-462.

Stohl, A., Forster, C., Eckhardt, S., Spichtinger, N., Huntrieser, H., Heland, J., Schlager, H., Wilhelm, S., Arnold, F. \& Cooper, O. 2003, "A backward modeling study of intercontinental pollution transport using aircraft measurements", Journal of Geophysical Research, 108, pp. 4370.

Tesche, T. 1983, "Photochemical dispersion modeling: Review of model concepts and applications studies", Environment International, 9, 6, pp. 465-489. 
TF HTAP, 2007, "Hemispheric Transport of Air Pollution: Interim Report Prepared by the Task Force on Hemispheric Transport of Air Pollution Acting Within the Framework of the Convention on Long-range Trans-boundary Air Pollution", United Nations Publications.

Tong, D.Q. \& Mauzerall, D.L. 2008, "Summertime State-Level Source-Receptor Relationships between Nitrogen Oxides Emissions and Surface Ozone Concentrations over the Continental United States", Environment Science and Technology, 42, 21, pp. 7976-7984.

UNECE 2006, "Strategies and policies for air pollution abatement", 2006 review prepared under the Convention on Long-Range Trans-boundary Air Pollution (CLRTAP), New York and Geneva, http://www.unece.org/env/lrtap/welcome.html.

US Environmental Protection Agency, 1991, Guideline for Regulatory Application of the Urban Airshed Model. Office of Air and Radiation, Office of Air Quality Planning and Standards, USEPA Report No. EPA-450/4-91-013. U.S. EPA, O\$ce of Air Quality Planning and Standards, Research Triangle Park, North Carolina.

US Environmental Protection Agency, 1999, Emission Projections, the PechanAvanti Group, presented to Projections Committee, in Emission Inventory Improvement Program http://www.epa.gov/ttn/chief/eiip/techreport/volume10/x01.pdf

US Environmental Protection Agency, 2003, “Ozone Transport Commission (OTC) $\mathrm{NO}_{\mathrm{x}}$ budget program 1999-2002 progress report”. US EPA Clean Air Markets Programs and Regulations.

US Environmental Protection Agency, 2005, “Clean Air Interstate Rule - Basic Information", 2005. http://www.epa.gov/cair/basic.html (accessed January 16, 2007)

US Environmental Protection Agency, 2006, "Air Quality Criteria for Ozone and Related Photochemical Oxidants (Final)”, Vols. I, II, and III. EPA 600/R$05004 \mathrm{aF}-\mathrm{cF}$

US Environmental Protection Agency, 2007," Guidance on the Use of Models and Other Analysis for Demonstrating Attainment of Air Quality Goals for Ozone PM2.5 and Regional Haze", EPA -454/B-07-002,April 2007, Air Quality Analysis Division

US Environmental Protection Agency, 2008, 40 CFR Part 50 and 40 CFR Part 58 [EPAHQ-OAR-2005-0172; FRL-RIN 2060-AN24], "National Ambient Air Quality Standards for Ozone".

US Environmental Protection Agency, 2009," National Emissions Inventory (NEI) Air Pollutant Emissions Trends Data", http://www.epa.gov/ttnchie1/trends/ 
US Environmental Protection Agency, 2010, "Technology Transfer Network, Air Quality System", http://www.epa.gov/ttn/airs/airsaqs/index.htm

Vautard, R.; Beekmann, M.; Menut, L. 2000, "Applications of adjoint modelling in atmospheric chemistry: Sensitivity and inverse modeling", Environment Modeling Software, 15, pp. 703-709.

Vukicevic, T., \& Hess, P, 2000, "Analysis of tropospheric transport in the Pacific Basin using the adjoint technique". Journal of Geophysical Research, $105 \mathrm{pp}$. 7213-7230.

Wang, K.Y., Lary, D., Shallcross, D., Hall, S. \& Pyle, J. 2001, "A review on the use of the adjoint method in four - dimensional atmospheric - chemistry data assimilation", Quarterly Journal of the Royal Meteorological Society, 127, 576, pp. 2181-2204.

Wang, Y., Jacob, D.J. \& Logan, J.A. 1998, "Global simulation of tropospheric O 3$\mathrm{NO} \sim \mathrm{x}$-hydrocarbon chemistry 3 . Origin of tropospheric ozone and effects of nonmethane hydrocarbons", Journal of Geophysical Research, 103, pp. 10-10.

Wang, H., Jacob, D.J., Le Sager, P., Streets, D.G., Park, R.J., Gilliland, A.B. \& van Donkelaar, A. 2009, "Surface ozone background in the United States: Canadian and Mexican pollution influences", Atmospheric Environment, 43, pp. 13101319.

West, J., Naik, V., Horowitz, L. \& Fiore, A. 2009, "Effect of regional precursor emission controls on long-range ozone transport- Part 1: Short-term changes in ozone air quality", Atmospheric Chemistry and Physics, 9, 16, pp. 6077-6093.

World Health Organization (WHO), 2008, Amann, M., Derwent, D., Forsberg, B., Hanninen, O., Hurley, F., Krzyzanowski. M., Leeuw, F.D., Liu, S.J., Mandin, C., Schneider, J. Schwarze, P., Simpson, D., "Health risks of ozone from long-range trans-boundary air pollution", World Health Organization, Regional Office for Europe. www.euro.who.int/_data/assets/pdf_file/0005/78647/E91843.pdf

Wu, S., Duncan, B.N., Jacob, D.J., Fiore, A.M. \& Wild, O. 2009, "Chemical nonlinearities in relating intercontinental ozone pollution to anthropogenic emissions", Geophys.Res.Lett, 36.

Yang, Y.J., Wilkinson, J.G. \& Russell, A.G. 1997, "Fast, direct sensitivity analysis of multidimensional photochemical models", Environ Science and Technology, 31, 10 , pp. 2859-2868.

Yarwood, G., S. Rao, M. Yocke, and G. Whitten, 2005: "Updates to the Carbon Bond chemical mechanism: CB05", Final Report to the U.S. EPA, RT-0400675, Available online at www.camx.com

Yarwood, G., Morris, R.E. \& Wilson, G.M. 2007, "Particulate matter source apportionment technology (PSAT) in the CAMx photochemical grid model", Air Pollution Modeling and Its Application XVII, pp. 478-492. 
Zhang, L., Jacob, D.J., Kopacz, M., Henze, D.K., Singh, K. \& Jaffe, D.A. 2009, "Intercontinental source attribution of ozone pollution at western US sites using an adjoint method", Geophysical Research Letters, 36, pp. L11810.

Zhang, L., Jacob, D., Boersma, K., Jaffe, D., Olson, J., Bowman, K., Worden, J., Thompson, A., Avery, M. \& Cohen, R. 2008, "Transpacific transport of ozone pollution and the effect of recent Asian emission increases on air quality in North America: an integrated analysis using satellite, aircraft, ozonesonde, and surface observations", Atmospheric Chemistry and Physics, 8, 20, pp. 6117-6136. 


\section{APPENDIX A}

\section{A SIMPIFIED EXAMPLE OF APPLYING ADJOINT METHOD}

In this example, application of adjoint method for sensitivity analysis of concentrations (or any metric) of the species involving in a simple chemical reaction cycle is presented [Wang et al, 2001]. Considering the following chemical cycle:

$$
\begin{aligned}
& A+B \stackrel{K_{1}}{\longrightarrow} C+D+E \\
& D+F \stackrel{K_{2}}{\longrightarrow} A+E \\
& C+F \stackrel{K_{3}}{\longrightarrow} B+E \\
& \text { net }=2 F \stackrel{k}{\longrightarrow} 3 E
\end{aligned}
$$

where $k 1, k 2, k 3$ are reaction rate coefficients. The gas-phase rate equations are written in matrix shown in Eq (A-2) [Wang et al, 2001]:

$$
\frac{d l}{d t}=F(I)
$$

where $I$ is the input vector, and $I$ and $F(I)$ are defined as :

$$
I=\left\{\begin{array}{l}
F \\
A \\
B \\
D \\
C
\end{array}\right\}, \quad F(I)=\left\{\begin{array}{l}
-k_{2}[D][F]-k_{3}[C][F] \\
-k_{1}[A][B]+k_{2}[D][F] \\
-k_{1}[A][B]+k_{3}[C][F] \\
k_{1}[A][B]-k_{2}[D][F] \\
k_{1}[A][B]-k_{3}[C][F]
\end{array}\right\}
$$

Now, if inputs $I$ results in the outputs $O$ during the time interval $\Delta t$ by $\mathrm{G}, O=G(I)$, then the $G$ is [Wang et al, 2001]:

$$
G=\left\{\begin{array}{l}
F^{n}+\Delta t\left(-k_{2}\left[D^{n} \llbracket F^{n}\right]-k_{3}\left[C^{n} \llbracket F^{n}\right]\right) \\
A^{n}+\Delta t\left(-k_{1}\left[A^{n} \llbracket B^{n}\right]+k_{2}[D]^{n}\left[F^{n}\right]\right. \\
B^{n}+\Delta t\left(-k_{1}\left[A^{n} \llbracket B^{n}\right]+k_{3}\left[B^{n}\left[E^{n}\right]\right.\right. \\
D^{n}+\Delta t\left(k_{1}\left[A^{n} \llbracket B^{n}\right]-k_{2}\left[D \llbracket F^{n}\right]\right. \\
C^{n}+\Delta t\left(k_{1}\left[A^{n} \llbracket B^{n}\right]-k_{3}\left[B^{n}\left[E^{n}\right]\right.\right.
\end{array}\right\}=\left\{\begin{array}{l}
G_{1} \\
G_{2} \\
G_{3} \\
G_{4} \\
G_{5}
\end{array}\right\}
$$


As seen, $G$ is nonlinear function with respect to $I$, where $I$ is the concentration vector in time step $\mathrm{n}$ and $O$ is concentration vector in time step $n+1$ :

$$
I=\left\{\begin{array}{l}
F^{n} \\
A^{n} \\
B^{n} \\
D^{n} \\
C^{n}
\end{array}\right\} \text {, and } O=\left\{\begin{array}{l}
F^{n+1} \\
A^{n+1} \\
B^{n+1} \\
D^{n+1} \\
C^{n+1}
\end{array}\right\}
$$

The tangent linear equation corresponding to the $\mathrm{Eq}(\mathrm{A}-2)$ is [Wang et al , 2001]:

$$
\frac{\delta d I}{d t}=F^{\prime} I
$$

and, knowing that $I$ results in the outputs $O$ during the time interval $\Delta t$ by $G$, will results in:

$$
\delta O=G^{\prime} \delta I
$$

where $G^{\prime}$ is the Jacodian or tangent linear matrix and is defined as:

$$
G^{\prime}=\frac{\partial G}{\partial I}=\left\{\begin{array}{llccc}
\frac{\partial G_{1}}{\partial F^{n}} & \frac{\partial G_{1}}{\partial A^{n}} & \frac{\partial G_{1}}{\partial B^{n}} & \frac{\partial G_{1}}{\partial D^{n}} & \frac{\partial G_{1}}{\partial C^{n}} \\
\frac{\partial G_{2}^{n}}{\partial F^{n}} & \ldots & \ldots & \ldots & \ldots \\
\frac{\partial G_{3}}{\partial F^{n}} & \ldots & \ldots & \ldots & \ldots \\
\frac{\partial G_{4}}{\partial F^{n}} & \ldots & \ldots & \ldots & \ldots \\
\frac{\partial G_{5}}{\partial F^{n}} & \frac{\partial G_{5}}{\partial A^{n}} & \frac{\partial G_{5}}{\partial B^{n}} & \frac{\partial G_{5}}{\partial D^{n}} & \frac{\partial G_{5}}{\partial C^{n}}
\end{array}\right\}
$$

If we define a $J$ as a scalar-valued function of the output (cost function), then the sensitivity of the cost function with respect to the model input (e.g. concentration of species $F$ at time step $n$ ) is [Wang et al , 2001]:

$$
\frac{\partial J}{\partial F^{n}}=\frac{\partial G(I)}{\partial F^{n}} \times \frac{\partial J}{\partial G(I)}=\frac{\partial G(I)}{\partial F^{n}} \times \frac{\partial J}{\partial O}=
$$




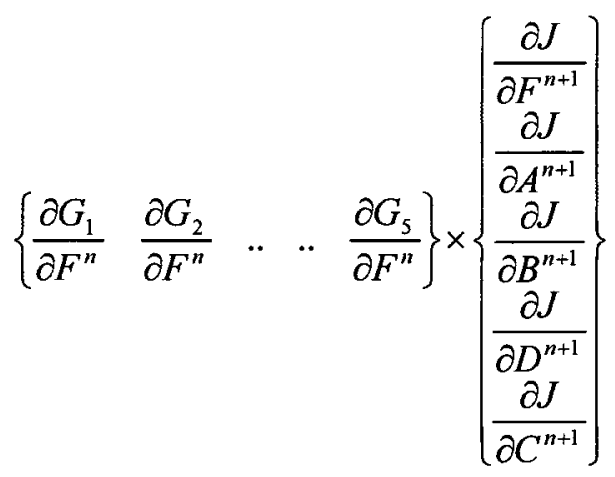

The gradient of cost function can be derived with respect to the other species in a similar way. Eventually, the gradient of the cost function with respect to all indices in the input vector, $I$, will be [Wang et al, 2001]:

$$
\nabla_{I} J=\left\{\begin{array}{ccccc}
\frac{\partial G_{1}}{\partial F^{n}} & \frac{\partial G_{2}}{\partial F^{n}} & . . & . . & \frac{\partial G_{5}}{\partial F^{n}} \\
\frac{\partial G_{1}}{\partial A^{n}} & & & & \frac{\partial G_{5}}{\partial A^{n}} \\
\cdots & & & & \cdots \\
\cdots & & & & \ldots . \\
\frac{\partial G_{1}}{\partial C^{n}} & \frac{\partial G_{2}}{\partial C^{n}} & \ldots & \ldots & \frac{\partial G_{1}}{\partial C^{n}}
\end{array}\right\} \times\left\{\begin{array}{c}
\frac{\partial J}{\partial F^{n+1}} \\
\frac{\partial J}{\partial A^{n+1}} \\
\frac{\partial J}{\partial B^{n+1}} \\
\frac{\partial J}{\partial D^{n+1}} \\
\frac{\partial J}{\partial C^{n+1}}
\end{array}\right\}=G^{\prime *} \times \nabla_{O} J
$$

where the $G^{\prime *}$ is transpose of Jacobian matrix $G^{\prime}$ (i.e., called the adjoint matrix); an efficient way of calculating the gradient of cost function $J$ to the $u$. The tangent linear matrix $\left(G^{\prime}\right)$ directly calculates the corresponding perturbation on output $(\delta O)$ as a result of perturbation on input $(\delta I)$ as it is shown in Eq (A-7). However, the adjoint matrix $\left(\mathrm{G}^{\prime *}\right)$ converts the gradient of a cost function $(J)$ with respect to the output $\left(\nabla_{o} J\right)$ into the gradient of the function $J$ with respect to the input vector $\left(\nabla_{I} J\right)$. 


\section{APPENDIX B}

\section{TERRAIN FOLLOWING HYDROSTATIC-PRESSURE VERTIVCAL- COORDINATE IN METEOROLOGICAL MODEL}

The terrain-following hydrostatic-pressure vertical coordinate denoted by $\eta$ and defined as $\eta=\left(p_{h}-p_{h t}\right) / \mu$ where $\mu=p_{h s}-p_{h t} p_{h}$ is the hydrostatic component of the pressure, and $p_{h s}$ and $p_{h t}$ refer to values along the surface and top boundaries, respectively. The coordinate definition is the traditional $\sigma$ coordinate used in many hydrostatic atmospheric models. $\sigma$ varies from a value of 1 at the surface to 0 at the upper boundary of the model domain (Figure $\mathrm{B} 1$ ). This coordinate is also called a mass vertical coordinate. In CMAQ the $20 \mathrm{~m}$ is a typical height of the first layer (varying in different locations), and the height will increase by altitude, up to $4-5 \mathrm{~km}$ for the highest layers.
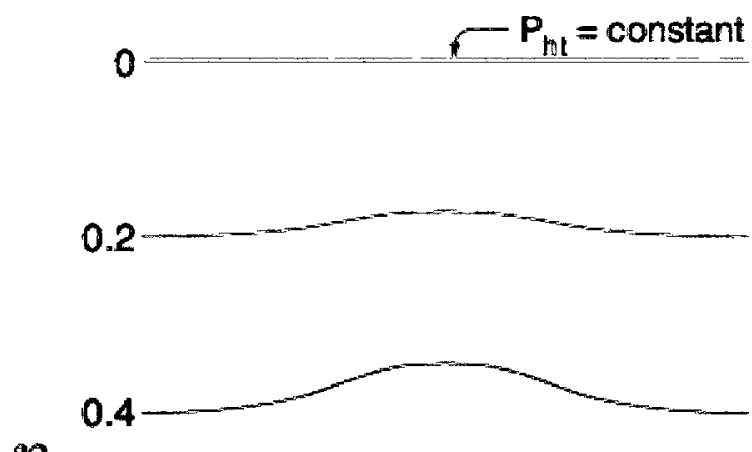

$\eta$
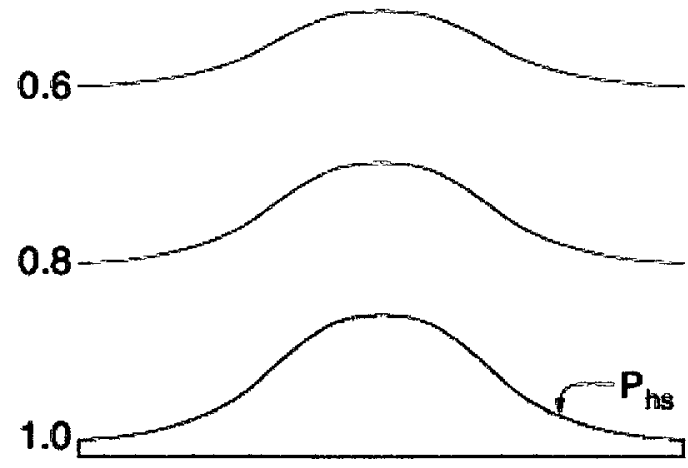

Figure B.1Terrain following ( $\eta$-coordinate) vertical layers in the meteorological model [NCAR, 2010] 